\title{
Advanced Compressor Engine Controls to Enhance Operation, Reliability and Integrity
}

\author{
Final Report \\ Reporting Period Start Date: 09/22/03 \\ Reporting Period End Date: 12/31/04
}

\author{
Principal Authors: \\ Gary D. Bourn \\ Jess W. Gingrich \\ Jack A. Smith
}

March 2004

DOE Award No. DE-FC26-03NT41859

SwRI Project No. 03.10198

Submitting Organization:

Southwest Research Institute ${ }^{\circledR}$

6220 Culebra Road

San Antonio, TX 78238-5166 


\section{DISCLAIMER}

"This report was prepared as an account of work sponsored by an agency of the United States Government. Neither the United States Government nor any agency thereof, nor any of their employees, makes a warranty, express or implied, or assumes any legal liability or responsibility for the accuracy, completeness, or usefulness of any information, apparatus, product, or process disclosed, or represents that its use would not infringe privately owned rights. Reference herein to any specific commercial product, process, or service by trade name, trademark, manufacturer, or otherwise does not necessarily constitute or imply its endorsement, recommendation, or favoring by the United States Government or any agency thereof. The views and opinions of authors expressed herein do not necessarily state or reflect those of the United States Government or any agency thereof." 


\section{ABSTRACT}

This document is the final report for the "Advanced Compressor Engine Controls to Enhance Operation, Reliability, and Integrity" project. SwRI conducted this project for DOE in conjunction with Cooper Compression, under DOE contract number DE-FC26-03NT41859. This report addresses an investigation of engine controls for integral compressor engines and the development of control strategies that implement closed-loop $\mathrm{NO}_{\mathrm{X}}$ emissions feedback. 


\section{EXECUTIVE SUMMARY}

This document is the final report for the "Advanced Compressor Engine Controls to Enhance Operation, Reliability, and Integrity" project. SwRI conducted this project for DOE in conjunction with Cooper Compression, under DOE contract number DE-FC26-03NT41859. The objective of this project was to develop, evaluate, and demonstrate advanced engine control technologies and hardware, specifically, closed-loop $\mathrm{NO}_{\mathrm{X}}$ emissions control on a two-stroke integral reciprocating engine/compressor used for pipeline gas transmission service. This work used a Cooper-Bessemer GMVH-6 laboratory engine owned by Cooper Compression and installed in a test facility at Southwest Research Institute (SwRI).

The gas transmission industry operates approximately 4,000 integral engine compressors, the majority being two-stroke, with a median age of 45 years and a median size of 2000 horsepower. These engines have historically exhibited poor performance and high emissions, due in part to poor engine control. The end results are misfires and partial burns that lead to increased fuel usage and exhaust emissions. Many of the slow-speed integral engines in the gas compression industry utilize control systems that have simplistic air/fuel control strategies that do not have a capability to compensate for changing conditions or provide feedback for efficient diagnostics. However, research into more advanced control systems for integral compressor engines has increased tremendously in recent years.

Recent advancements in control logic were reviewed and analyzed in this program to understand the effectiveness of each. A hierarchy of control strategies was outlined for various applications of the $\mathrm{NO}_{\mathrm{X}}$ sensor feedback. This hierarchy ranged from the simplest and least expensive application to advanced system utilizing closed-loop control with adaptive learn. In addition, two specific closed-loop control strategies were developed in this program utilizing the real-time $\mathrm{NO}_{\mathrm{X}}$ sensor feedback.

The first strategy developed in this program was called the Modified Fuel-Air Curve. The Modified Fuel-Air Curve system was programmed into a PC-based control system and the laboratory engine was used for demonstration testing. The test results showed that the closedloop $\mathrm{NO}_{\mathrm{X}}$ system allowed the error from target $\mathrm{NO}_{\mathrm{X}}$ to be reduced from approximately 30 percent in normal open-loop control to approximately 10 percent under closed-loop. Analysis of the $\mathrm{NO}_{\mathrm{X}}$-efficiency trade-off for the GMVH-6 engine showed that reducing the $\mathrm{NO}_{\mathrm{X}}$ margin from 30 to 10 percent would give a 4 percent improvement in specific fuel consumption. This fuel consumption improvement equates to an approximate annual savings of $\$ 1.8 \mathrm{M}$ for 100 sixcylinder engines (assumed equivalent to the laboratory engine) operating at an 80 percent utilization if fuel cost is $\$ 7.32$ per Mcf. For larger engines, which are realistic for the current fleet of integral engines, the dollar amount would be higher.

The second strategy developed involves using a trapped equivalence ratio strategy. This system utilizes model-based calculations of scavenging and trapping efficiencies. Both the $\mathrm{NO}_{\mathrm{X}}$ and $\mathrm{O}_{2}$ channels from the sensor provide closed-loop feedback to trim the model coefficients and output command. Demonstration testing of this system was not conducted due to unavailability of the laboratory engine. 


\section{TABLE OF CONTENTS}

Page

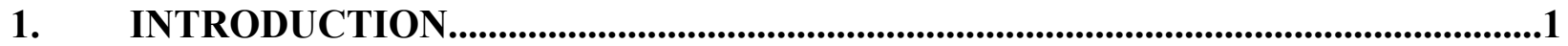

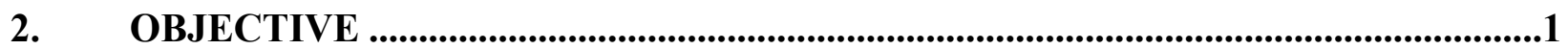

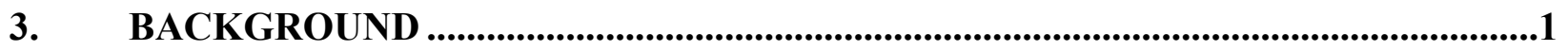

4. TWO-STROKE INTEGRAL COMPRESSOR ENGINES .............................................2

5. ENGINE CONTROL BACKGROUND ..........................................................................

5.1 CONTROL CATEGORIES .................................................................................

5.2 Basic Automotive Engine Control Strategies ..............................................6

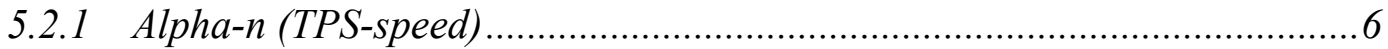

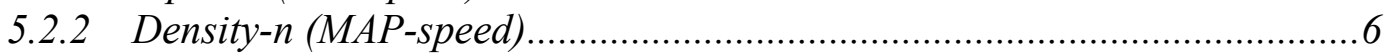

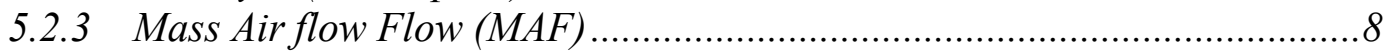

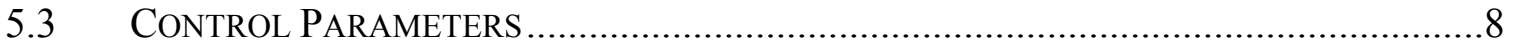

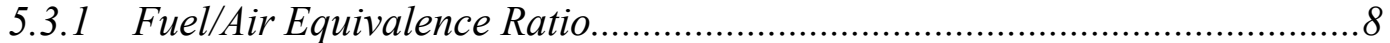

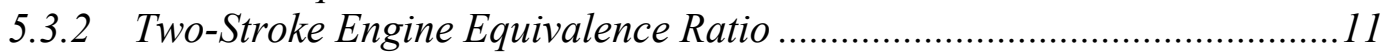

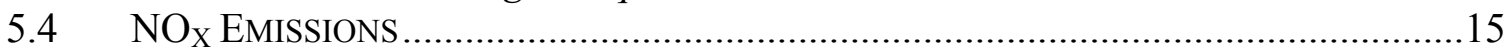

5.5 BASIC COMPRESSOR ENGINE CONTROL STRATEGIES.............................................17

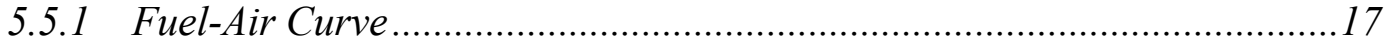

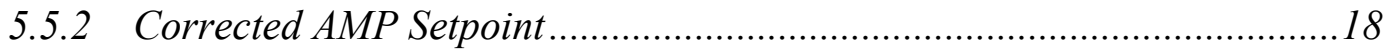

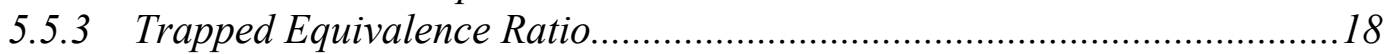

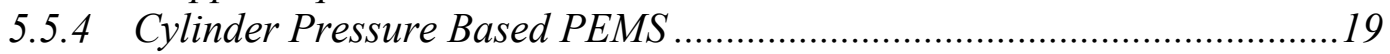

5.5.5 Integrated Engine-Compressor Controls.................................................19

5.5.6 Enabling Technology ........................................................................... 19

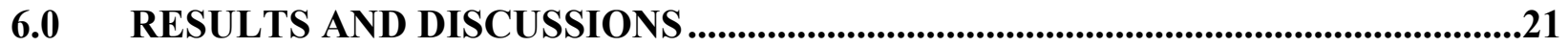

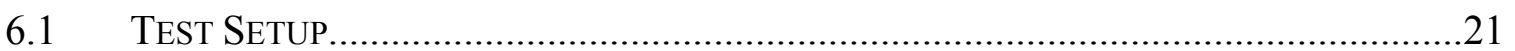

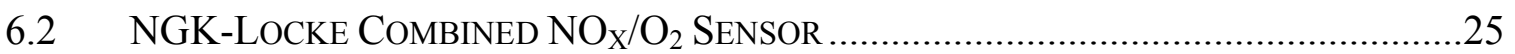

6.3 HiERARCHY OF ClOSED-LoOP CONTROL STRATEGIES ………..............................29

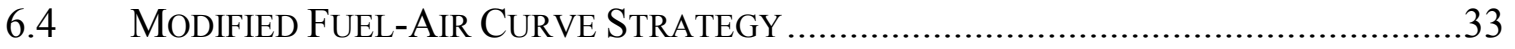

6.5 TRAPPED EquiVALENCE RATIO StRATEGY ......................................................

7.0 CONCLUSIONS ..................................................................................................................43 


\section{LIST OF TABLES}

Page

Table 5.1. Example Natural Gas Composition and Stoichiometric A/F Ratio ...............................9

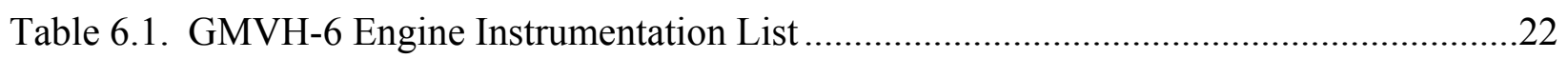

Table B.1. Rate Coefficients for the Thermal No Mechanism ......................................................

\section{LIST OF FIGURES}

Page

Figure 4.1. Cross Section of a Cooper-Bessemer GMVH Integral Compressor Engine .................2

Figure 4.2. Typical Integral Compressor Engine Control System Layout.......................................4

Figure 5.1. Terminology and Basic Structure of a Feedback Control System [1] ...........................5

Figure 5.2. Typical Spark-Ignited Lean-Burn Operating Limit for Steady Speed \& Load ...........10

Figure 5.3. Exhaust Emissions Versus Equivalence Ratio [2] .....................................................15

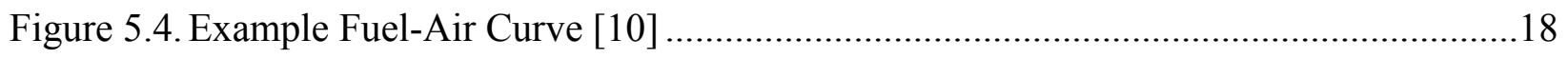

Figure 6.1. Photograph of GMVH-6 Laboratory Research Engine ...........................................21

Figure 6.2. Photograph of RPECS and Data Acquisition System...............................................23

Figure 6.3. Photograph of Interior Controls Junction Box.........................................................24

Figure 6.4. Photograph of Engine-Side Control Junction Box.........................................................24

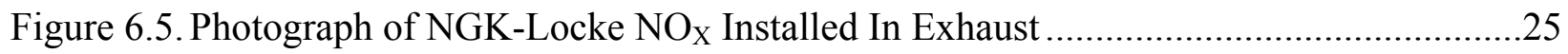

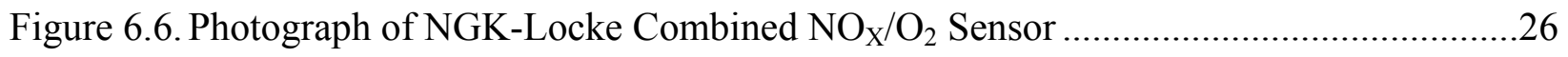

Figure 6.7. $\mathrm{NO}_{\mathrm{X}}$ Calibration Data for 0-1000 and 0-2000ppm NGK Sensors ................................27

Figure 6.8. Global Equivalence Ratio Calibration of 0-1000 \& 0-2000ppm NGK Sensors ..........27

Figure 6.9. $\mathrm{NO}_{\mathrm{X}}$ Calibration Data for 0-2000ppm NGK Sensor Over 1 Year Span.......................28

Figure 6.10. Comparison of $\mathrm{NGK} \mathrm{NO}_{\mathrm{X}}$ and Emissions Bench Analyzer Over Transient

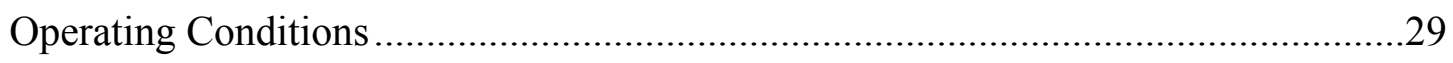

Figure 6.11. Flowcharts of Simple Strategies with $\mathrm{NO}_{\mathrm{X}}$ Sensor Feedback ................................30

Figure 6.12. Flowchart of Basic Closed-Loop $\mathrm{NO}_{\mathrm{X}}$ or Equivalence Ratio Control ...................31

Figure 6.13. Flowchart of Basic $\mathrm{NO}_{\mathrm{X}}$ or Equivalence Ratio Trim of Model-Based Control.....32 
Figure 6.14. Multiple Fuel-Air Curves for Constant $\mathrm{NO}_{\mathrm{X}}$ and Different Speeds

Figure 6.15. Surface Plot of Initial Modified Fuel-Air Curve RPECS Calibration ...................35

Figure 6.16. Schematic of Modified Fuel-Air Curve Algorithm ...........................................36

Figure 6.17. Engine Test Data Without Closed-Loop $\mathrm{NO}_{\mathrm{X}}$ Control........................................37

Figure 6.18. Engine Test Data With Closed-Loop $\mathrm{NO}_{\mathrm{X}}$ Control ............................................38

Figure 6.19. GMVH Engine Brake Specific $\mathrm{NO}_{\mathrm{X}}$ versus Brake Specific Fuel Consumption ...39

Figure 6.20. Comparison of Flow Coefficient Derived from Measured Air flow and Predicted

from Regression Model..................................................................................4 41

Figure 6.21. Comparison of Dry Total Mass Air flow and Modeled Total Mass Air flow .......42

Figure 6.22. Calculated Trapped Equivalence Ratio versus Engine Speed ...........................42

Figure 6.23. Schematic of Trapped Equivalence Ratio Algorithm .......................................43 


\section{INTRODUCTION}

This document provides the final report for the "Advanced Compressor Engine Controls to Enhance Operation, Reliability, and Integrity" project. SwRI has conducted this project for DOE in conjunction with Cooper Compression, under DOE contract number DE-FC26-03NT41859. This report addresses an investigation of engine controls for integral compressor engines and the development of control strategies that implement closed-loop $\mathrm{NO}_{\mathrm{X}}$ emissions feedback.

\section{OBJECTIVE}

The objective of this project was to develop, evaluate, and demonstrate advanced engine control technologies and hardware, specifically, closed-loop $\mathrm{NO}_{\mathrm{X}}$ emissions control on a two-stroke integral reciprocating engine/compressor used for pipeline gas transmission service. As part of the development, a review of past and current control technology was conducted. This work utilized a Cooper-Bessemer GMVH-6 laboratory engine owned by Cooper Compression and installed in a test facility at SwRI. The approach involved three research activities including engine/test cell configuration, engine testing, and data analysis.

\section{BACKGROUND}

The gas transmission industry operates approximately 4,000 integral engine compressors, the majority being two-stroke, with a median age of 45 years and a median size of 2000 horsepower. These engines pump at least half of the $23 \mathrm{TCF}$ of natural gas presently consumed in the United States. These engines are no longer produced, and with the projections for increased demand of natural gas and the expense of replacement, it would be advantageous to modernize the existing fleet to allow for continued operation with increased efficiency and emissions compliance.

Integral gas compression engines have historically exhibited poor performance and high emissions, due in part to poor engine control. The end results are misfires and partial burns that lead to increased fuel usage and exhaust emissions. Many of the slow-speed integral engines in the gas compression industry utilize control systems that have simplistic air/fuel control strategies that do not have a capability to compensate for changing conditions or provide feedback for efficient diagnostics. The automotive and heavy-duty truck industries have advanced the state of electronics, sensors, diagnostics, and control algorithms for maximum efficiency, minimum emissions, and broadest operating envelope. Communications between the various power train components have also been developed for optimized operation and interaction between auxiliary systems.

To comply with future emissions legislation, and to increase industry wide competitiveness, existing engines need modern control systems and modern electronic sensors to maximize fuel economy while remaining emissions compliant. In addition, engine health monitoring and safety requirements mandate that additional sensors be installed to prevent inefficient operation, to be emission compliant, be pro-active in maintenance scheduling, expand the operating envelope, and allow for efficient operation at conditions that do not affect the structural integrity of the unit. The work reported in this document is a step toward bringing integral gas compression 
engine control and health-monitoring up to par with modern engine control technology, with new concepts that address the specific nature of integral compressor engine operation.

\section{TWO-STROKE INTEGRAL COMPRESSOR ENGINES}

These engines are unique in that the compressor is integrated into the engine design, and is therefore not a separate component. A cross-sectional view of a typical integral compressor engine is provided in Figure 4.1. The compressors are reciprocating units, double acting, with pockets to change the individual clearance volumes and, in-turn, the throughput of the individual compressors. The reciprocating design of the compressors creates an uneven loading on the engine within each revolution, and the sequence in which the pockets are opened or closed (load steps) creates an additional variance in the dynamic loading. Since the compressors are connected directly to the crankshaft, and a variable dynamic load is induced, the instantaneous rotational velocity (IRV) of the crankshaft is affected. Add in the fact that combustion is never completely stable, the IRV is further exacerbated.

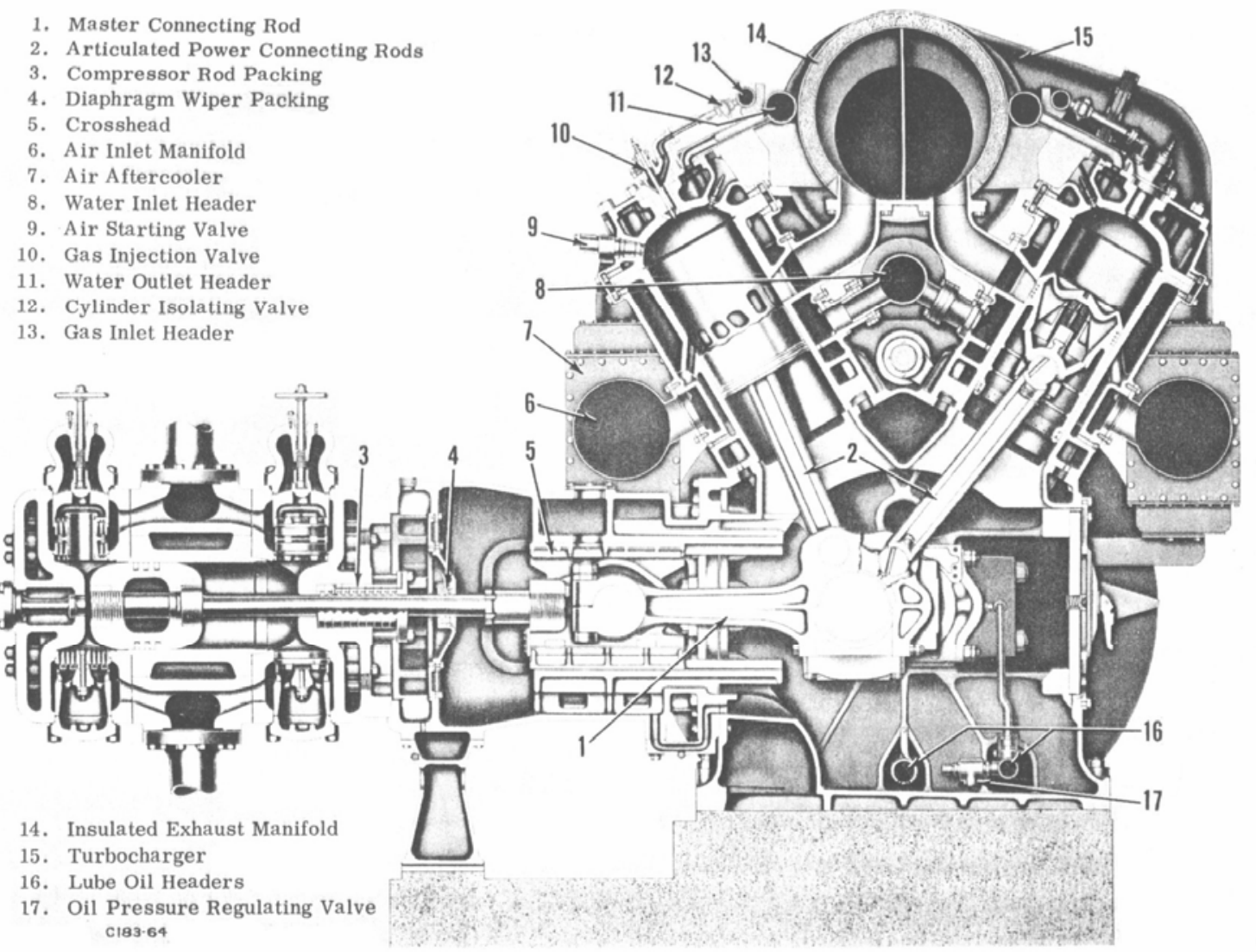

Figure 4.1. Cross Section of a Cooper-Bessemer GMVH Integral Compressor Engine

The two-stroke integral engines are mostly loop scavenged with inlet and exhaust ports fixed in the cylinder liner. Port opening and closing is governed by piston motion. A few of the two- 
stroke engines are uniflow scavenged, which have inlet ports and exhaust valves. In both designs, the dynamic port timing is a function of the dynamic piston motion, or crankshaft IRV. During port/valve opening, the flow through the cylinder is governed by fluid dynamics, specifically the ratio of exhaust pressure to inlet pressure. Pulsations in the manifolds, due to design and/or unsteady combustion, affect the dynamic pressures during scavenging and create deviations in flow between cycles and cylinders. All the factors that affect air flow and cylinder scavenging, in turn affect the trapped air/fuel ratio and combustion.

An additional aspect of integral compressors engines, especially the two-stroke designs, is that they feature direct in-cylinder fuel admission to prevent scavenging of raw fuel into the exhaust. This direct fuel admission is performed with a cam-actuated poppet valve that has a fixed duration tied to crankshaft speed. The control variables with this design are the main fuel header pressure and individual balance valves to each cylinder that are manually adjustable. A governor typically modulates the main fuel header pressure to maintain the engine speed setpoint. The pinch valves are manually adjusted to provide some compensation to individual cylinders to balance combustion across the engine.

Many of the two-stroke integral engines are turbocharged, or have been retro-fitted with turbochargers. The turbocharger comprises an exhaust turbine coupled to an inlet compressor. Typically, a wastegate is installed upstream of the exhaust turbine to bypass exhaust gas when less inlet air flow is required for the operating condition. Since fuel flow is utilized to govern engine speed, the wastegate can be used for global control of the air/fuel ratio. The most common control strategy is to control the inlet air manifold pressure (via wastegate) as a function of fuel header pressure. Present-day systems utilize programmable logic controllers (PLC) to perform this task, along with functions such as start-up, shut-down, and safety alarming. The control strategies often emulate the manual-pneumatic control systems they are replacing, and operate in an open-loop mode. There are, however, several engines still operating with the manual-pneumatic systems.

Ignition systems are becoming more sophisticated for these engines, progressing from a magneto style to systems with microprocessors. The newer systems offer the ability to program ignition timing as a function of engine speed and/or inlet manifold pressure. These systems, however, are typically setup independently from the air/fuel controller with little or no communication. A schematic of a typical control system layout is provided in Figure 4.2. 


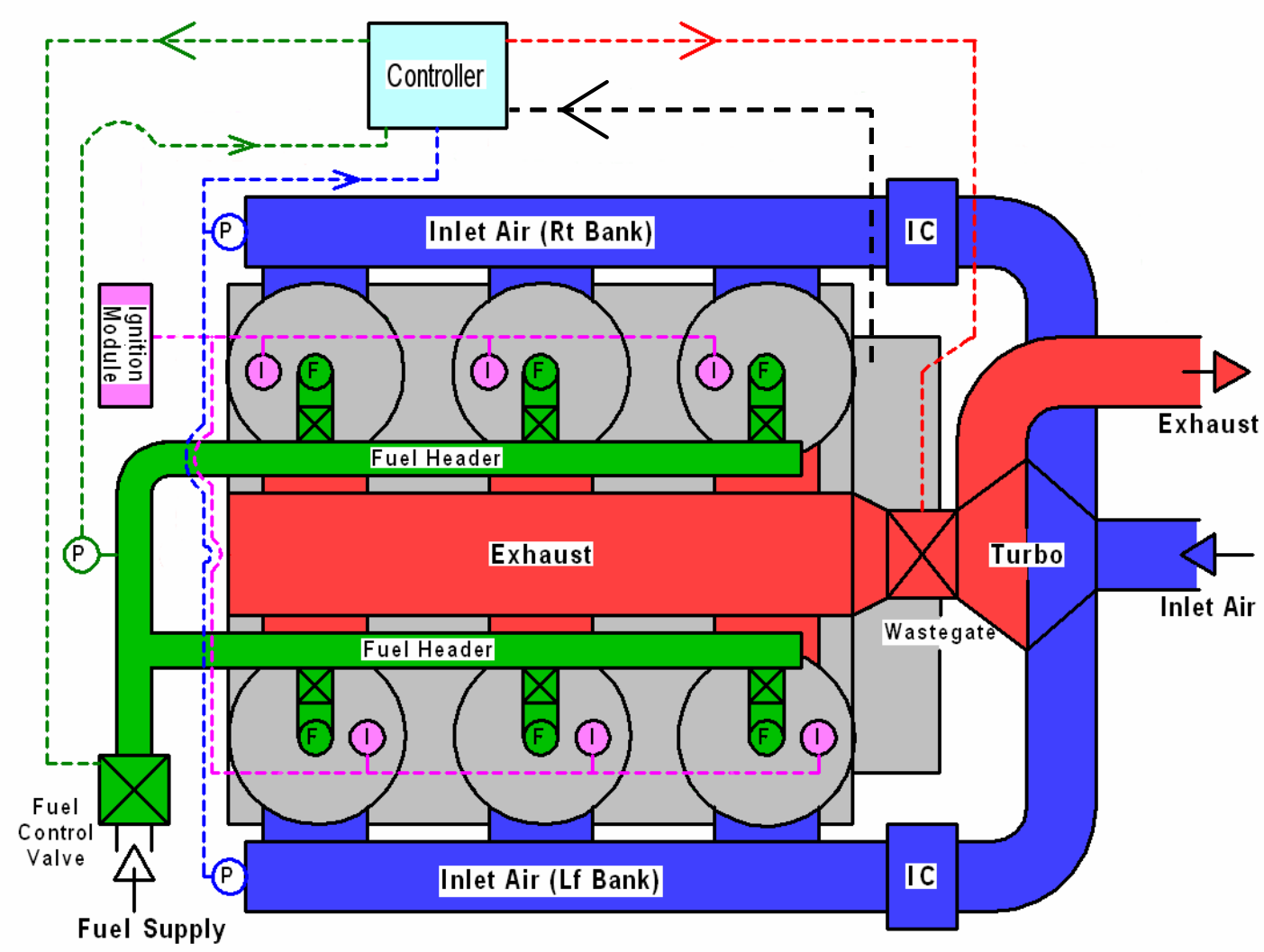

Figure 4.2. Typical Integral Compressor Engine Control System Layout

\section{ENGINE CONTROL BACKGROUND}

As part of the development of closed-loop $\mathrm{NO}_{\mathrm{X}}$ control technology, a review of control technology from a variety of engine applications was conducted. This review covered past and current integral compressor engine control strategies, as well as a brief review of closed-loop automotive systems. Potential control parameters such as equivalence ratio and $\mathrm{NO}_{\mathrm{X}}$ were also reviewed in detail for their application to integral engine control strategies. Brief descriptions are provided in the following sections as a prelude to the closed-loop $\mathrm{NO}_{\mathrm{X}}$ developments discussed in Section 6.0.

\subsection{Control Categories}

The purpose of a control system is to maintain a desired process condition or output by regulating or adjusting parameters which the process is dependant. There are three main categories of control systems, though each category is comprised of an ever-evolving population of stratagems. The categories include manual control, open-loop control, and closed loop control.

- A manually controlled system is self-explanatory, wherein continuous operator involvement is necessary to maintain control. 
- With open-loop control, the process inputs, A(s), have no dependence on the process outputs, $\mathrm{C}(\mathrm{s})$. Open-loop control schemes are often augmented with predictive algorithms based on a variety of measured or modeled parameters, $\mathrm{G}_{\mathrm{a}}(\mathrm{s})$. This often enable a more precise approximation of the output parameter, but the resulting "state" of the process output is not measured and/or not fed back to the control system.

- Closed-loop control requires feedback. The feedback is used to adjust or trim the open-loop scheme and command to the process, F(s). The variety and complexity of closed-loop control systems stem from the algorithms implemented to determine the command, $\mathrm{G}_{\mathrm{m}}(\mathrm{s})$.

There are many techniques used to characterize the process under control, which helps to expedite controller design and meet the desired performance specification (i.e. stability, accuracy, and speed of response). Figure 5.1 depicts a generic closed-loop control format including system elements and signals [1].

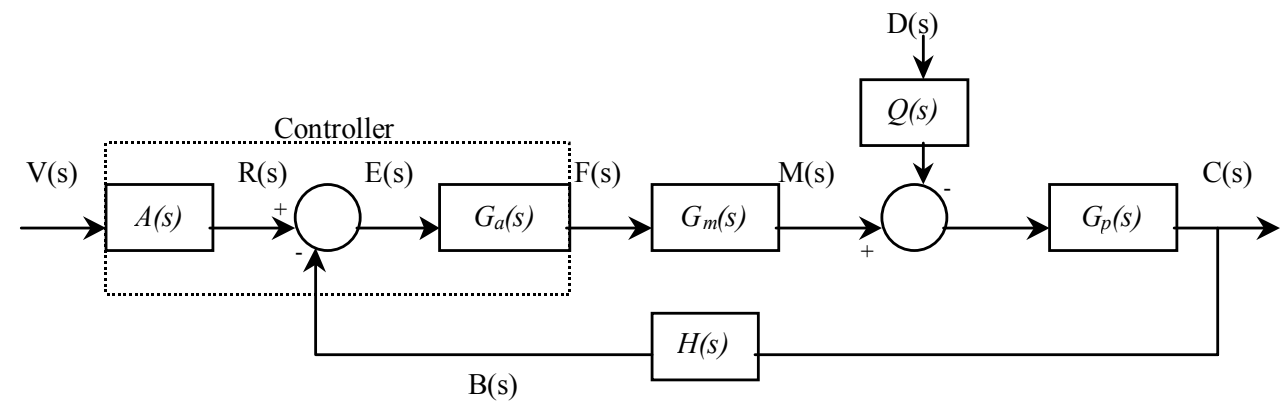

\section{ELEMENTS}

$\mathrm{A}(\mathrm{s}) \quad$ Input Elements

$\mathrm{G}_{\mathrm{a}}(\mathrm{s}) \quad$ Control Logic Elements

$\mathrm{G}_{\mathrm{m}}(\mathrm{s}) \quad$ Final Control Elements

$\mathrm{G}_{\mathrm{p}}(\mathrm{s}) \quad$ Plant Elements

$\mathrm{H}(\mathrm{s}) \quad$ Feedback Elements

Q(s) Disturbance Elements

\section{SIGNALS}

B(s) Feedback Signal

C(s) Controlled Variable or Output

D(s) Disturbance Input

E(s) Error or Actuating Signal

F(s) Control Signal

M(s) Manipulated Variable

R(s) Reference Input

V(s) Command Input

\section{Figure 5.1. Terminology and Basic Structure of a Feedback Control System [1]}

Controls for internal combustion engines vary widely depending on the type and application of the engine. The most advanced systems are used in automotive gasoline engines, which are the greatest in number and therefore have the greatest impact on the environment - air pollution and energy consumption. As concern increases for the environmental impact of other engine types, electronic control systems for these engines will increase in complexity. Many of the current control systems for compressor engines are of the open-loop style, so there is much to be gained with closed loop control.

Closed-loop control for internal combustion engines has primarily focused on the use of air/fuel ratio feedback due to this parameter's significant impact on engine exhaust emissions and fuel consumption. Air/fuel ratio feedback is often in terms of fuel/air equivalence ratio, which is discussed in detail in the next section. Other closed-loop feedback signals can be utilized, such as $\mathrm{NO}_{\mathrm{X}}$ emissions, depending on the control scheme and available sensors. 


\subsection{Basic Automotive Engine Control Strategies}

As part of this project, basic automotive control strategies were reviewed. The most basic principle behind automotive fuel injection is to estimate the mass of air trapped in the cylinder and inject the appropriate mass of fuel. Several different methods exist to perform the calculation. The most widely used examples are detailed below.

\subsubsection{Alpha-n (TPS-speed)}

The most basic control strategy for port injected engines is alpha-n. The "alpha" stands for throttle angle and the " $\mathrm{n}$ " stands for engine speed. Open loop fueling is calculated from a table (or function), based on engine speed and throttle angle. Since this is the most basic form of electronic fuel injection, it is used primarily in applications where strict absolute emissions targets are not a concern (i.e. motorcycles and racing engines).

The major downside to alpha-n is that the injection system is not robust enough to account for hardware changes or sensor failure. If a TPS sensor is adjusted or installed differently from when the engine was mapped, the fuel maps will have to be recalibrated.

Alpha-n injection systems must correct, or trim, the fuel tables to account for changes in the ambient conditions relative to conditions when the engine was mapped. Barometric pressure and ambient temperature, or inlet air temperature, are usually used to trim the fuel.

\subsubsection{Density-n (MAP-speed)}

Most of the first fully electronic fuel injection systems used a density-n (or speed-density) fuel calculation. Density-n injection systems use the measured intake manifold pressure and speed to calculate fueling. Open loop fueling can be calculated in two ways: using the pressure measurement as an input to a table, or using a model to calculate air mass based on a table of volumetric efficiency. Either method produces the same results, but both will be covered separately below.

Some engine control units (ECU) use a table with intake manifold pressure on one axis and engine speed on another to calculate open loop fueling. The output from the table may be either a fuel injector pulse width, or a desired injected mass of fuel which then goes through a fuel mass to injector pulse width transfer function.

The other option to determine fuel mass is to calculate the mass of air going into the cylinder, usually using a table of volumetric efficiency, and mathematically calculate the required fueling. The equation to calculate the mass air flow is:

$$
\dot{m}_{\text {air }}=D \cdot \rho \cdot V E \cdot N
$$

where:

$$
D=\text { displacement }
$$




$$
\begin{array}{ll}
\rho & =\text { density } \\
V E & =\text { volumetric efficiency } \\
N & =\text { engine speed }
\end{array}
$$

The density may be calculated by:

$$
\rho=\frac{P}{R T}
$$

where:

$$
\begin{array}{ll}
P & =\text { MAP (manifold absolute pressure) -sensor } \\
R & =\text { gas constant for air } \\
T & =\text { MAT (manifold absolute temperature) -sensor }
\end{array}
$$

Once the mass of air is known, the mass of fuel may be calculated. The simplest way is to use a table of desired air/fuel ratios. Through most of the engine operating range, the targeted air/fuel ratio will be stoichiometric (approximately 14.7 for gasoline). At higher engine loads where power is the main concern, the targeted air/fuel ratio may be richer (between 12 and 10).

Density-n injection systems of the second variety generally do not need to trim the open loop fueling because the density is being directly measured with the pressure and temperature measurements. Density-n injection systems of the first variety need to be corrected for inlet temperature but do not need barometric compensation since the manifold pressure is still being measured (still used as in input to the table).

For best emissions performance the fuel injection system must maintain a narrow band of air/fuel ratio near stoichiometry where catalyst efficiency is maximum. The open loop command will get the system close, but many variables may cause deviations from the target. Some of these variables reduce the engine volumetric efficiency like increased engine backpressure, worn or out-of-adjustment valve train, or buildup on the engine valves. Other variables act to change the amount of fuel delivered for a given pulse width like a faulty fuel pressure regulator, under performing fuel pump, or dirty injectors. Still others will affect the needed mass of fuel to maintain the target air/fuel ratio like fuels with a different stoichiometric air to fuel ratios. It is the job of the closed loop controller to account for the differences.

Closed loop controllers use feedback devices to calculate the error of the system and correct the system output targeting zero error. In the case of the fuel injection system, the feedback device is an exhaust gas oxygen sensor (EGO). A switching EGO sensor, as used in most passenger cars, provides an essentially digital output of whether the engine is rich or lean. This type of EGO sensor is often called a lambda sensor. The latest passenger car systems have begun to use wide band sensors that provide linear response as a function of fuel/air equivalence ratio. They measure how rich or how lean the engine is operating at that instant.

Proper catalyst (catalytic converter) efficiency occurs when the engine is operated cyclically about stoichiometry varying between slightly rich and slightly lean. If the target is slightly rich, the ECU uses the open loop fueling to try and reach slightly rich. The EGO is used to verify that 
the target is met. If the engine is still lean, the ECU will continue to richen the mixture until it sees the switch. The same process occurs when trying to run lean. The ECU will remember how much trimming had to occur to switch correctly, and store that value as the short term trim so that it can more quickly reach the operating rich/lean points again as the engine continues to run at the set point. When a pattern of continual short term trim at an operating point is recognized, the ECU will store this as a long term trim so that the fueling will be more precise when returning to this operating point from another. The actual delivered fuel is a combination of the open loop fueling, short term trim, and long term trim.

\subsubsection{Mass Air flow Flow (MAF)}

Most new passenger cars use mass air flow sensors to measure the mass of air entering the engine. Unlike alpha-n and density-n systems that infer the mass of air from previous experience, mass air flow sensors actually measure the mass flow rate of air entering the engine. With a known mass flow rate, engine speed, and number of cylinders, the mass of air in each cylinder is easily calculated. A desired air/fuel ratio can then be met by commanding the required fuel quantity.

The mass air flow sensor type is typically a hot-wire anemometer. In this type of sensor, a heated element at a controlled temperature, either wire or film, loses energy to the passing air. The power dissipated is therefore proportional to the air flow.

Closed loop control and short and long term trims occur similarly to the density-n systems. Unlike density-n systems, the trims are generally there to account for degradation in the mass air flow sensor performance or changes in the mass air flow sensor transfer function.

\subsection{Control Parameters}

\subsubsection{Fuel/Air Equivalence Ratio}

Engine power, efficiency, and emissions are largely a function of the fuel-air mixture introduced into the engine. The air/fuel ratio is an important control parameter for spark-ignited engines to optimize performance and emissions. For each fuel composition, there is a specific mixture ratio where a hydrocarbon fuel can be completely oxidized called the stoichiometric air/fuel ratio. Complete oxidation at the stoichiometric ratio will cause the fuel carbon to be converted to carbon dioxide $\left(\mathrm{CO}_{2}\right)$ and the fuel hydrogen to be converted to water $\left(\mathrm{H}_{2} \mathrm{O}\right)$. The chemical equation for complete oxidation of a hydrocarbon fuel is provided below:

$$
\mathrm{C}_{n} \mathrm{H}_{m}+\left(n+\frac{m}{4}\right)\left(\mathrm{O}_{2}+3.773 \mathrm{~N}_{2}\right) \Rightarrow n \mathrm{CO}_{2}+\frac{m}{2} \mathrm{H}_{2} \mathrm{O}+3.773\left(n+\frac{m}{4}\right) N_{2}
$$

Note the $n$ and $m$ terms in the hydrocarbon fuel symbol represent the atoms of each element in the fuel molecule. Since there are many different hydrocarbon fuels, with different atomic proportions, it is common practice to utilize the hydrogen/carbon ratio of the fuel in the symbol as follows: 


$$
\mathrm{CH}_{x} \quad \text { where: } x=m / n
$$

The equation for determining the stoichiometric air/fuel ratio on a mass basis for a hydrocarbon fuel then becomes [2]:

$$
\left(\frac{M_{\text {air }}}{M_{\text {fuel }}}\right)_{s}=\frac{(1+x / 4)(32+3.773 \times 28.16)}{12.011+1.008 x}
$$

Some fuels, such as natural gas, also contain oxygen (in the form of $\mathrm{CO}_{2}$ ) and nitrogen. The oxygen/carbon $(y)$ and nitrogen/carbon $(z)$ molar ratios are therefore required in addition to the hydrogen/carbon ratio $(x)$ for determining the stoichiometric air/fuel ratio as follows [3]:

$$
\left(\frac{M_{\text {air }}}{M_{\text {fuel }}}\right)_{s}=\frac{4.3211[15.999(2+0.5 x-y+z)]}{12.011+1.008 x+15.999 y+14.007 z}
$$

Natural gas is a mixture of several constituents, and the molar percentages of each constituent must be known to calculate the stoichiometric air/fuel ratio accurately. The molar percentages of each constituent are also required to determine the overall fuel heating value. A gas chromatograph is typically employed to perform this measurement. An example measurement of natural gas composition, and the resulting calculations of stoichiometric air/fuel ratio, is provided

\begin{tabular}{|c|c|c|c|c|c|}
\hline $\begin{array}{c}\text { GC Mole } \\
\text { Percent } \\
\end{array}$ & Name & Formula & $\begin{array}{c}\text { Molecular } \\
\text { Weight }\end{array}$ & $\begin{array}{c}\text { Lower HV } \\
\text { BTU/lb } \\
\end{array}$ & $\begin{array}{c}\text { Mass } \\
\text { Fraction } \\
\end{array}$ \\
\hline 0.620 & NITROGEN & $\overline{\mathrm{N}_{2}}$ & 28.013 & 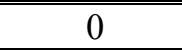 & "0.010 \\
\hline 95.119 & METHANE & $\mathrm{CH}_{4}$ & 16.043 & 21495 & 0.893 \\
\hline 1.439 & CARBON DIOXIDE & $\mathrm{CO}_{2}$ & 44.010 & 0 & 0.037 \\
\hline 0.000 & ETHYLENE & $\mathrm{C}_{2} \mathrm{H}_{4}$ & 28.054 & 20275 & 0.000 \\
\hline 2.095 & ETHANE & $\mathrm{C}_{2} \mathrm{H}_{6}$ & 30.070 & 20418 & 0.037 \\
\hline 0.000 & HYDROGEN SULFIDE & $\mathrm{H}_{2} \mathrm{~S}$ & 34.082 & 6537 & 0.000 \\
\hline 0.418 & PROPANE & $\mathrm{C}_{3} \mathrm{H}_{8}$ & 44.097 & 19937 & 0.011 \\
\hline 0.079 & ISO-BUTANE & & 58.123 & 19628 & 0.003 \\
\hline 0.088 & BUTANE & $\mathrm{C}_{4} \mathrm{H}_{10}$ & 58.123 & 19678 & 0.003 \\
\hline 0.041 & ISO-PENTANE & & 72.150 & 19459 & 0.002 \\
\hline 0.027 & PENTANE & $\mathrm{C}_{5} \mathrm{H}_{12}$ & 72.150 & 19507 & 0.001 \\
\hline 0.042 & HEXANE & $\mathrm{C}_{6} \mathrm{H}_{14}$ & 86.177 & 19415 & 0.002 \\
\hline 0.028 & HEPTANE & $\mathrm{C}_{7} \mathrm{H}_{16}$ & 100.204 & 19329 & 0.002 \\
\hline 0.004 & OCTANE & $\mathrm{C}_{8} \mathrm{H}_{18}$ & 114.231 & 19291 & 0.000 \\
\hline 0.000 & OXYGEN & $\mathrm{O}_{2}$ & 31.999 & 0 & 0.000 \\
\hline 0.000 & HYDROGEN & $\mathrm{H}_{2}$ & 2.016 & 51623 & 0.000 \\
\hline 0.000 & PROPYLENE & $\mathrm{C}_{3} \mathrm{H}_{6}$ & 42.081 & 19687 & 0.000 \\
\hline 0.000 & CARBON MONOXIDE & $\mathrm{CO}$ & 28.010 & 4347 & 0.000 \\
\hline $\begin{array}{c}\mathbf{A} / \mathbf{F} \\
\text { Stoich }\end{array}$ & & $\begin{array}{c}\mathbf{H} / \mathbf{C} \\
\text { Ratio } \\
\end{array}$ & $\begin{array}{c}\mathbf{O} / \mathbf{C} \\
\text { Ratio } \\
\end{array}$ & $\begin{array}{c}\mathrm{N} / \mathrm{C} \\
\text { Ratio } \\
\end{array}$ & $\begin{array}{c}\text { Lower HV } \\
\text { BTU/lb }\end{array}$ \\
\hline 16.34 & & 3.86 & 0.03 & 0.01 & 20399 \\
\hline
\end{tabular}
in Table 5.1.

Table 5.1. Example Natural Gas Composition and Stoichiometric A/F Ratio 
Many spark-ignited engines, especially large-bore stationary engines, do not operate at stoichiometric air/fuel ratios. These engines often operate with excess air in a lean-burn configuration with actual air/fuel ratios much greater than stoichiometry. The many different fuel types, having different stoichiometric air/fuel ratios, and the different operating air/fuel ratios introduce complexity in control and comparison of performance among different engines. A more informative air-fuel parameter that normalizes these differences is the fuel/air equivalence ratio $(\Phi)$. The equivalence ratio is the ratio of the stoichiometric air/fuel ratio to the actual air/fuel ratio, as shown in the equation below. A value of unity for the equivalence ratio means stoichiometry, and values less than unity indicate lean operation. The inverse of the equivalence ratio, lambda $(\lambda)$, is also sometimes used as a normalized air-fuel parameter.

$$
\Phi=\lambda^{-1}=\frac{(A / F) \text { stoich }}{(A / F) \text { actual }}
$$

As mentioned previously, the fuel-air equivalence ratio has a significant impact on engine exhaust emissions and fuel consumption. For lean-burn stationary engines operating at steady speed and load, there is an operating envelope bound by knock, misfire, and mechanical design limits of peak cylinder pressure and pre-turbine temperature. This operating envelope is illustrated in Figure 5.2. The envelope as shown depicts the ignition timing versus fuel/air equivalence ratio. Within the bounds of the envelope, there is region of peak fuel efficiency for lines of constant $\mathrm{NO}_{\mathrm{X}}$ emissions. Thus, the optimum operating point is a given spark timing and fuel/air equivalence ratio that resides on the target $\mathrm{NO}_{\mathrm{X}}$ emissions line and is located as close to the peak efficiency region as possible, with acceptable margins for misfire, knock, and mechanical limits.

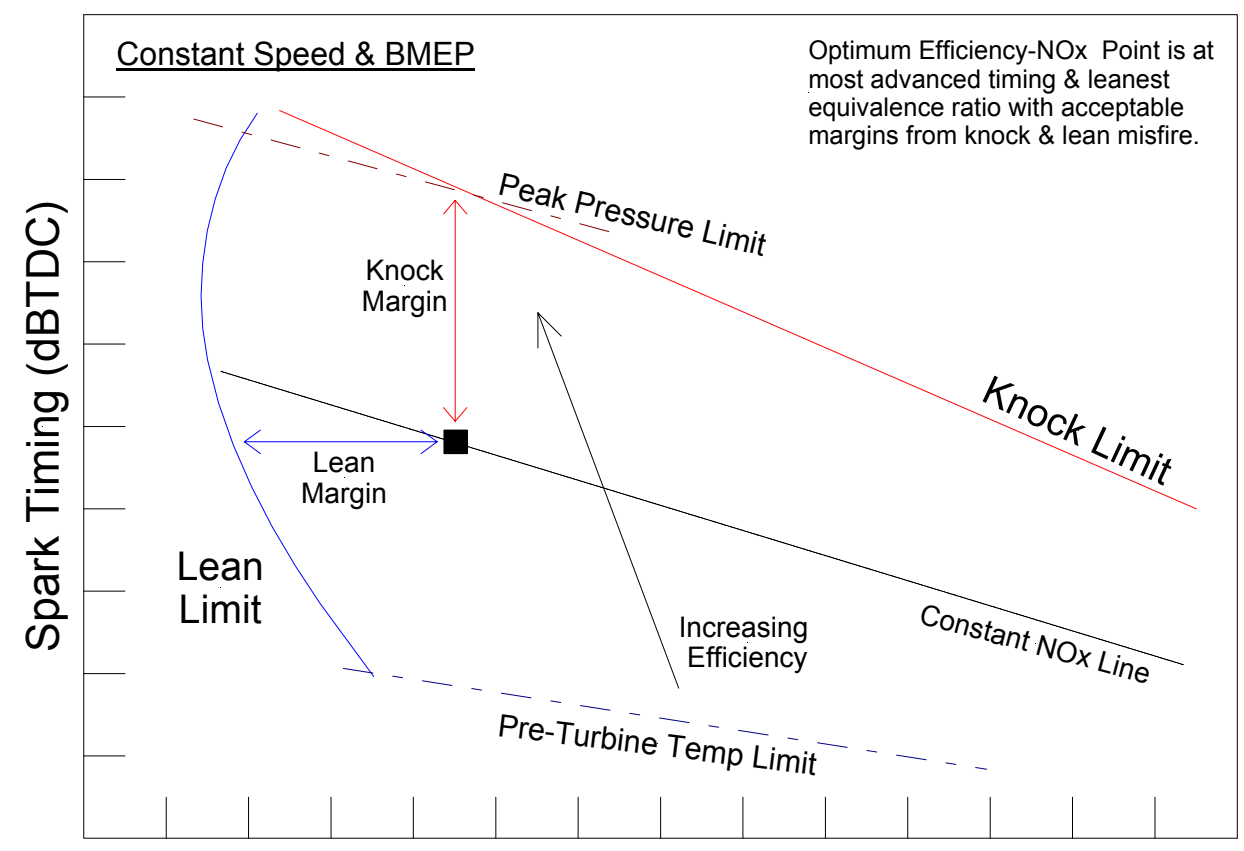

Fuel-Air Equivalence Ratio

Figure 5.2. Typical Spark-Ignited Lean-Burn Operating Envelope for Steady Speed \& Load 
Determining the actual air/fuel ratio requires that the air and fuel mass flows both be accurately measured during operation. In many instances with large-bore engines, one or both of these measurements is not readily available, specifically the mass air flow. Fuel flow is sometimes measured, but often the measuring device does not possess the accuracy or response required for real-time control. Many large-bore engines also do not utilize electronic fuel injection, so fuel flow cannot be determined from an injector calibration. Fluid dynamic models may be used for fuel and air flows in large bore stationary engines, which operate primarily at steady-state conditions, with acceptable results if the inputs and coefficients are available and accurate.

An alternative approach is to measure the equivalence ratio directly with an exhaust gas sensor. For lean-burn engines, a wide-range universal exhaust gas oxygen (UEGO) sensor can be utilized to control to a specific equivalence ratio. The UEGO sensor signal is calibrated for a specific fuel type, and gives an output directly proportional to equivalence ratio. Calibration typically involves deriving equivalence ratio from exhaust emissions, as discussed in Appendix $A$, and then correlating to UEGO sensor voltage. The NGK-Locke $\mathrm{NO}_{\mathrm{X}}$ sensor, described in Section 6.2, has the UEGO function as well as output for exhaust $\mathrm{NO}_{\mathrm{X}}$ concentration.

\subsubsection{Two-Stroke Engine Equivalence Ratio}

If the subject engine is a two-stroke spark-ignited engine, the equivalence ratio calculated from overall mass flows, UEGO sensor output, or exhaust measurements is the exhaust or global equivalence ratio. The value derived will be significantly leaner than the actual equivalence ratio for combustion, due to dilution of the exhaust gas with excess air that passes through the cylinder during scavenging. The actual equivalence ratio for combustion includes only the air mass trapped in the cylinder after the scavenging process is complete. This is therefore termed the trapped equivalence ratio, and the equation is as follows:

$$
\Phi_{\text {trapped }}=\frac{(A / F) \text { stoich }}{\left(A_{\text {trapped }} / F\right) \text { actual }}
$$

The equation above assumes that all the fuel admitted into the cylinder is trapped, which for direct in-cylinder admission/injection this is a valid assumption. Trapped air mass is almost impossible to measure due to varying amounts of residual gas from the previous cycle, except in tightly controlled laboratory environments with specialized instrumentation. Therefore, various techniques are utilized to estimate the trapped air mass for determining the trapped equivalence ratio.

\section{Trapping Efficiency Technique}

One technique for determining the trapped air mass is to utilize a technique outlined by Taylor [4]. With this technique, the total mass air flow through the engine must be known (measured or modeled). A scavenging ratio is first determined as the ratio of the actual to the ideal mass air, typically in terms of a flow rate. The ideal air mass is that which would fill the cylinder at bottom dead center, or the maximum total cylinder volume. The equations for scavenging ratio are as follows [4]: 


$$
R_{s}=\frac{\left(\dot{M}_{\text {air }}\right)_{\text {actual }}}{\left(\dot{M}_{\text {air }}\right)_{\text {ideal }}}=\frac{\left(\dot{M}_{\text {air }}\right)_{\text {actual }}}{N \cdot V_{c y l} \cdot \rho_{s}}
$$

where:

$$
\begin{aligned}
\dot{M}_{\text {air }} & =\text { dry mass air flow } \\
N & =\text { engine speed } \\
V_{c y l} & =\text { total cylinder volume at bottom dead center } \\
\rho_{s} & =\text { density of dry inlet air } \\
& =\frac{P_{\text {exh }}}{R_{\text {air }} \cdot T_{\text {inlet }}} \times\left(\frac{1}{1+1.6 h}\right) \\
P_{\text {exh }} & =\text { pressure of trapped air, typically at exhaust pressure } \\
T_{\text {inlet }} \quad= & \text { temperature of trapped air, typically assumed to be inlet temperature } \\
R_{\text {air }} \quad= & \text { gas constant for air, assuming fuel admitted directly in-cylinder } \\
h & =\text { mass fraction of water vapor in inlet air }
\end{aligned}
$$

With the scavenging ratio derived, the scavenging efficiency can be calculated. The scavenging efficiency is the ratio of the air mass retained to the ideal mass retained. For the ideal case, the scavenging efficiency would equal the scavenging ratio, and is termed perfect scavenging. The opposite extreme case is termed complete short-circuiting, which is a process where the cylinder contents from the previous cycle are not scavenged and the fresh air flows straight through the cylinder from inlet to exhaust. In reality, two-stroke scavenging will be somewhere in between these cases with some air scavenging the residual, some air short-circuiting, and some of the fresh air charge mixing with the residual gas.

The most commonly assumed case for real operation is termed complete mixing, and assumes the fresh charge mixes completely with the residual gas. The scavenging and trapping efficiency equations for the complete mixing case are as follows [4]:

$$
\begin{array}{ll}
e_{s}=1-\exp ^{-R_{s}} & \text { scavenging efficiency } \\
\Gamma=\frac{e_{s}}{R_{s}}=\frac{1-\exp ^{R_{s}}}{R_{s}} & \text { trapping efficiency }
\end{array}
$$

The accuracy of the complete mixing case depends on several factors, including the scavenging arrangement (loop, cross, uniflow, etc.), the mean piston speed (or engine speed), and inlet to 
exhaust port/valve geometry differences. Published data from detailed laboratory experiments of scavenging in two-stroke engines of various sizes and types have shown a deviation from the complete mixing case with changing mean piston speed $[2,4]$. Therefore, a possible correction procedure can be determined to account for speed dependencies, provided data for a given engine exists to properly derive the magnitude and function. The correction could be an offset for the scavenging type (engine specific) and a multiplier for operating condition effects (i.e. engine speed). The resulting equation could be in the following form:

$$
\left(e_{s}\right)_{c o r r}=\left(\left(1-\exp ^{R_{s}}\right)+A\right) \times B
$$

Once the trapping efficiency has been estimated, the trapped mass air flow can be computed and used to calculate the trapped equivalence ratio. The trapped mass air flow is simply the total mass air flow times the trapping efficiency. The resulting equation for trapped equivalence ratio using trapping efficiency is as follows:

$$
\Phi_{\text {trapped }}=\frac{(A / F) \text { stoich }}{\frac{\Gamma\left(\dot{M}_{\text {air }}\right)_{\text {total }}}{\dot{M}_{\text {fuel }}}}
$$

The total mass air flow through the engine can be measured, or predicted from either empirical based models or with fluid flow based models. One technique for predicting the mass air flow is to utilize equations outlined by Taylor for gas flow through two orifices in series. The inlet and exhaust ports/valves act as orifices, with the cylinder as the volume separating the orifices. The equation yields a continuous mass flow, representative of the total mass air flow, which can be used directly in the equivalence ratio equation. The mass air flow equation is as follows [4]:

$$
\dot{M}_{\text {air }}=A C a \rho \phi_{1}
$$

where:

$$
\begin{aligned}
& A=\quad \text { orifice area, or reference area (piston bore area is a convenient reference) } \\
& C=\text { orifice flow coefficient (ratio of actual mass flow to ideal flow through } \\
& a=\quad \text { speed of sound in gas in upstream reservoir } \\
& \rho=\quad \text { density (typically derived at inlet temperature and exhaust pressure) } \\
& \phi_{1}=\sqrt{\frac{2}{\gamma-1}\left[\left(\frac{P_{e x h}}{P_{\text {int }}}\right)^{\frac{2}{\gamma}}-\left(\frac{P_{e x h}}{P_{\text {int }}}\right)^{\frac{\gamma+1}{\gamma}}\right]} \\
& \text { non-choked flow-for air, when } \gamma=1.4,\left(\frac{P_{e x h}}{P_{\text {int }}}\right)>0.528
\end{aligned}
$$




$$
\begin{aligned}
\phi_{1}= & \sqrt{\left(\frac{2}{\gamma+1}\right)^{\frac{\gamma+1}{\gamma-1}}} \\
& \text { choked flow - for air, when } \gamma=1.4,\left(\frac{P_{\text {exh }}}{P_{\mathrm{int}}}\right) \leq 0.528\left(\phi_{1}=0.578\right)
\end{aligned}
$$

The key to accurate estimation of mass air flow with this technique is the proper determination of the flow coefficient value. For most two-stroke engines under firing conditions and pressure ratios of 0.65 to 0.95 , the flow coefficient will range from 0.02 to 0.035 . While the flow coefficient is primarily a function of the pressure ratio across the cylinder, the engine speed and combustion profile will affect it slightly.

The scavenging process occurs over only a portion of the cycle, and the air flow is therefore unsteady. Engine speed affects the time duration of the scavenging process, which in turn affects the instantaneous air flow, but is offset somewhat by the change in number of events per unit time. The combustion process can affect the cylinder pressure at the time of port/valve opening, and therefore instantaneous air flow, depending on the firing pressure and phasing of combustion (early or late). Parameters such as ignition timing and the trapped equivalence ratio affect the combustion profile.

\section{Ideal Gas Law Technique}

A technique to estimate the trapped air mass directly is to utilize the ideal gas law. The ideal gas law equation is rearranged to solve for mass with pressure, volume, temperature, and gas properties as inputs. This method is somewhat similar to the calculation of the ideal total mass flow for the denominator in the scavenging ratio calculation above, except that this method is for the ideal trapped mass air flow. The pressure is assumed to be the exhaust pressure near port/valve closure, due to the fact exhaust ports/valves typically close after the inlet. It is assumed that the cylinder pressure is very near exhaust pressure at the beginning of compression. The volume is assumed to be the total cylinder volume at the period of exhaust port closing where inflow/outflow has ceased. The temperature is often assumed to be similar to the inlet air temperature, but in actuality is likely higher due to heat transfer from the combustion chamber walls during scavenging. A simple method to partially account for this phenomenon is to calculate a weighted average of the inlet air and jacket wall temperatures [5]. Finally, the gas properties are assumed to be for air. This technique also assumes that displacement of air mass in the cylinder by fuel mass is negligible. Equations for ideal gas based trapped mass air flow are as follows:

$$
\begin{aligned}
& \left(m_{\text {air }}\right)_{\text {trap }}=\frac{P_{\text {exh }} V_{\text {trap }}}{R_{\text {air }} T_{\text {inlet }}} \\
& \left(\dot{M}_{\text {air }}\right)_{\text {trap }}=\left(m_{\text {air }}\right)_{\text {trap }} \times N
\end{aligned}
$$


This method may be slightly more susceptible to engine speed and combustion profile affects than the flow coefficient based fluid dynamic model. Fletcher et al. outlined the correlation of $\mathrm{NO}_{\mathrm{X}}$ emissions with trapped equivalence ratio for an approach similar to this technique, and showed a greater engine speed correction is required than with the trapping efficiency based technique [5].

\subsection{NO Emissions}

The formation of $\mathrm{NO}_{\mathrm{X}}$ is complex and strongly dependent on flame temperature. Flame temperature is highest just rich of stoichiometric, but since formation of $\mathrm{NO}_{\mathrm{X}}$ also requires oxygen, the peak production will be slightly lean of stoichiometry. This is illustrated in Figure 5.3, published by Heywood [2]. The time period at critical flame temperature also influences $\mathrm{NO}_{\mathrm{X}}$ formation. Therefore, low flame speeds with lean mixtures, or reduced engine speed, provide a longer period of time for $\mathrm{NO}_{\mathrm{X}}$ to form.

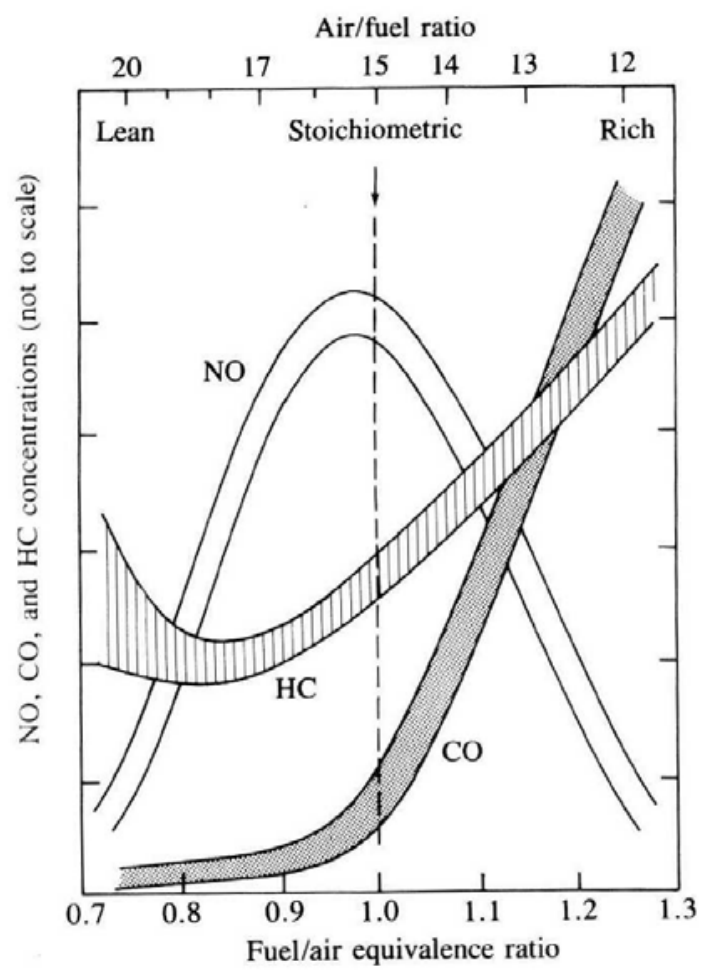

Figure 5.3. Exhaust Emissions Versus Equivalence Ratio [2]

NO is formed during combustion by three mechanisms: thermal, prompt, and nitrous oxide [6]. The extended Zeldovich mechanism provides the basis for the thermal mechanism, and this is typically what $\mathrm{NO}\left(\right.$ or $\mathrm{NO}_{\mathrm{X}}$ ) predictions are usually based upon. Details regarding the three mechanisms and the NO rate of formation equation are provided in Appendix B. Simplification of the rate equation for purposes of data trending during engine development or for simple model-based controls have often been performed $[7,8,9]$. These simplifications typically ignore factors such as concentrations of $\mathrm{N}_{2}$ and $\mathrm{O}_{2}$, and time constants. One such simplified routine 
published by Wood is for predicting the relative change in $\mathrm{NO}_{\mathrm{X}}$, and requires a baseline or reference data for coefficient derivation [7]. This simple equation is as follows:

$$
N O_{x}=B \times \exp \left(-\frac{A}{T}\right)
$$

where:

$$
\begin{aligned}
& A=\quad \text { constant (activation energy) } \\
& B=\quad \text { constant (specific to application) } \\
& T=\quad \text { peak combustion temperature }
\end{aligned}
$$

Modified for relative change from a reference condition:

$$
\frac{N O_{X}}{\left(N O_{X}\right)_{\text {ref }}}=\exp \left[A \times\left\{\left(\frac{1}{T}\right)_{\text {ref }}-\left(\frac{1}{T}\right)\right\}\right]
$$

The peak combustion temperature can be calculated from thermodynamic analysis of measured cylinder pressure, and trapped masses of fuel, air, and residual. The peak combustion temperature can be substituted by the bulk gas temperature from ideal gas analysis, or the estimated temperature from ideal cycle equations. As long as the method is consistent, the coefficients can be fit for a given reference condition. The temperature equation presented by Wood is as follows [7]:

$$
T=T_{1} \times r^{(k-1)}+\frac{\left(H V \times m_{f u e l}\right)}{\left(C_{V} \times m_{\text {total }}\right)}
$$

where:

$$
\begin{aligned}
& T_{1}=\quad \text { temperature at start of compression } \\
& r=\quad \text { effective compression ratio } \\
& k=\quad \text { ratio of specific heats (typically } 1.4 \text { used) } \\
& H V=\text { fuel heating value by mass } \\
& m_{\text {fuel }}=\text { trapped mass of fuel } \\
& m_{\text {total }}=\text { trapped mass of fuel, air, and residual } \\
& C_{V}=\text { specific heat of cylinder gasses }
\end{aligned}
$$

Another use for a simplified $\mathrm{NO}_{\mathrm{X}}$ rate equation is for parametric emissions monitoring (PEMS) and engine control. Beshouri published a PEMS approach utilizing an equation similar to 5.20 where coefficients are tuned via empirical data [9]. Once the equation is tuned for a specific engine or engine model, and an acceptable error margin selected, the system can provide a continuous prediction of $\mathrm{NO}_{\mathrm{X}}$ emissions for determining whether or not the engine is maintaining compliance. The temperature calculation used by Beshouri is an effective bulk temperature $\left(\mathrm{T}_{\mathrm{eb}}\right)$, which requires measurement of cylinder pressure, and is determined as follows [9]:

$$
T_{e b}=\frac{P_{P} \cdot V_{e f f}}{P_{\text {fill }} \cdot V_{\text {fill }}} \times T_{\text {fill }}
$$


where:

$$
\begin{aligned}
& T_{\text {fill }}=\text { cylinder filling temperature (air manifold temperature) } \\
& P_{\text {fill }}=\text { cylinder filling pressure (air or exhaust manifold pressure) } \\
& V_{\text {fill }}=\text { trapped cylinder volume (at port/valve closure) } \\
& V_{\text {eff }}=\text { empirical effective volume } \\
& P_{P}=\text { peak cylinder firing pressure }
\end{aligned}
$$

\subsection{Basic Compressor Engine Control Strategies}

Integral gas compression engines have historically exhibited poor performance and high emissions due in part to poor engine control. The end results are misfires and partial burns that lead to increased fuel consumption and exhaust emissions. Most installed control systems lack the technology, sensors, and algorithms to detect and correct for out-of-range sensors or malperformance. Modern electronic controls are being developed and implemented that focus specifically on compliance to a specified emissions level. These modern control systems typically include empirically derived and model based relationships to predict $\mathrm{NO}_{\mathrm{X}}$ emissions as a function of either estimated trapped equivalence ratio or as a direct result of engine operating parameters.

\subsubsection{Fuel-Air Curve}

The traditional approach for air/fuel control is to utilize a fuel-air curve. This curve is a linear relationship between the fuel header pressure (mechanical fuel admission valves) and air manifold pressure (inlet or boost pressure). This curve accounts for engine speed and load changes, where the air manifold pressure (AMP) is adjusted to maintain the relationship with fuel header pressure (FHP). The FHP is a result of governor response to maintain the engine speed setpoint. Therefore, air follows fuel in this approach. Adjustments to account for effects of air manifold temperature (AMT) are provided by developing offsetting curves or biases. Derivation of this curve is empirically based from calibrating the engine in the operating envelope. This is an open-loop strategy that does not ensure a specific air/fuel ratio setpoint is always maintained, nor does it ensure that a $\mathrm{NO}_{\mathrm{X}}$ emissions level is always maintained. An example of a fuel-air curve was provided by Cooper Compression, and is depicted in Figure 5.4 below [10]. 


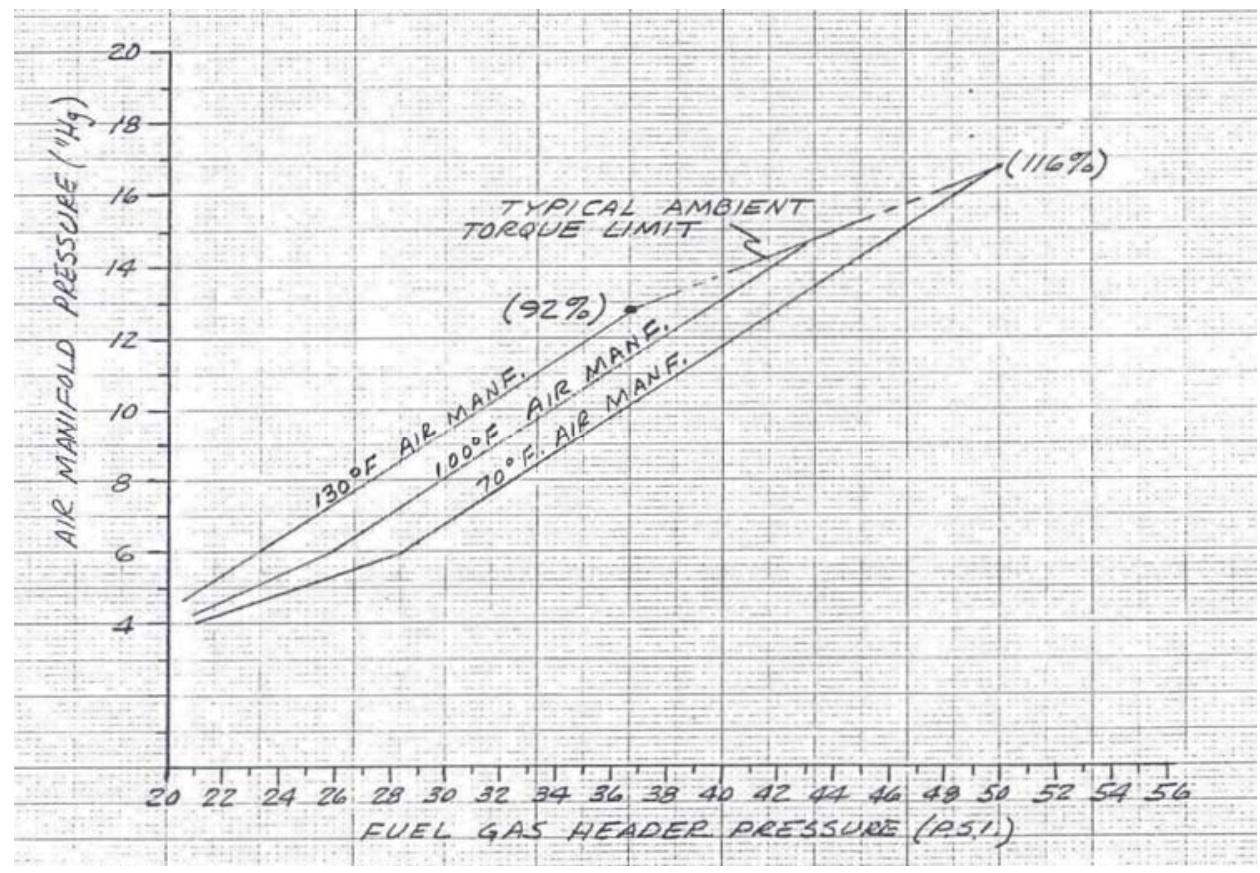

Figure 5.4. Example Fuel-Air Curve [10]

\subsubsection{Corrected AMP Setpoint}

A control strategy published by Matthews et al. utilizes an AMP setpoint similar to the fuel-air curve above, except the AMP setpoint is a function of the desired equivalence ratio rather than FHP [11]. As can be seen in the equations in Section 5.3.2, there are several measured parameters required for the various derivations. Several of these parameters are not typically measured on compressor engines (e.g. exhaust pressure). Therefore, this method seeks to minimize required measurements and to derive a setpoint that would be familiar to station personnel with experience using the fuel-air curve.

The AMP setpoint method involves combining and re-arranging equations 5.14, 5.18, and 5.19 to solve for the AMP (inlet guage pressure) for a specific trapped equivalence ratio. The desire for a specified trapped equivalence ratio stems from the well documented relationship of $\mathrm{NO}_{\mathrm{X}}$ emissions as a function of trapped equivalence ratio. Methods to compensate for engine speed dependency are addressed with a correction in the form of a polynomial equation. This method provides increased accuracy over the fuel-air curve in that trapped equivalence ratio, and therefore $\mathrm{NO}_{\mathrm{X}}$ emissions, are addressed and controlled.

\subsubsection{Trapped Equivalence Ratio}

The fuel/air equivalence ratio is becoming more utilized as a control parameter for integral gas compression engines [5,12,13]. Regulations for $\mathrm{NO}_{\mathrm{X}}$ emissions have driven the need to develop control strategies that can maintain or limit the $\mathrm{NO}_{\mathrm{X}}$ level emitted. Since $\mathrm{NO}_{\mathrm{X}}$ emissions are strongly a function of the fuel-air equivalence ratio, controlling the engine to operate at a specified equivalence ratio largely affects the engine-out $\mathrm{NO}_{\mathrm{X}}$ emissions. 
The implementation on two-stroke integral engines typically involves calculation of trapped equivalence ratio with equations 5.14, 5.18, and 5.19, and developing an empirically based relationship for $\mathrm{NO}_{\mathrm{X}}$ emissions. Adjustment parameters such as engine speed, ignition timing, inlet temperature, and even engine type are implemented as correction factors to the calculated trapped equivalence ratio $[5,12]$. The objective is to reduce the multi-parameter regression to one relationship of $\mathrm{NO}_{\mathrm{X}}$ versus corrected trapped equivalence ratio for all operating conditions and for all similar engines. With a large base of historical data behind the development of the regression model, minimum calibration data points should be required when commissioning this approach on a new unit.

\subsubsection{Cylinder Pressure Based PEMS}

Another advanced control strategy being developed for integral compressor engines is the use of models derived for PEMS systems. As described in Section 5.4, $\mathrm{NO}_{\mathrm{X}}$ emissions can be predicted reasonably well with a simple equation based on the peak combustion temperature, or effective bulk gas temperature. For controls purposes, the model can be rearranged where instead of predicting $\mathrm{NO}_{\mathrm{X}}$ for a given operating condition, the operating parameters can be determined for a given $\mathrm{NO}_{\mathrm{X}}$ setpoint $[9,12]$. This method requires use of continuous cylinder pressure monitoring for the derivation of temperature with equation 5.23 .

Development of low cost and durable continuous cylinder pressure transducers remains challenging, however progress is being made. Kistler has developed a piezo-electric transducer with integrated charge amplifier. IMES has developed a strain-gauge based transducer. There is also interest in even lower cost sensors, such as load washers, that provide indicating values of peak pressure and location of peak pressure.

\subsubsection{Integrated Engine-Compressor Controls}

SwRI conducted a program for GMRC and PRCI to investigate the coupling of engine and compressor controls [14]. The premise for this research was that the compressor control and engine control should be coupled for optimal control of both. It was theorized that cyclical loading of the compressors could impart sufficient variations in crankshaft IRV where cylinder scavenging and combustion in various power cylinders could be affected, especially when loading between compressors was uneven. Data acquired during this project showed that $\mathrm{NO}_{\mathrm{X}}$ emissions were affected by the compressor load step for a given engine speed and compressor horsepower. Additional research into this phenomenon was conducted to determine the factors contributing to consistent step changes in $\mathrm{NO}_{\mathrm{X}}$ with load step [15]. This research however, showed mean engine load (horsepower) to dominate the trend of $\mathrm{NO}_{\mathrm{X}}$ versus load-step.

\subsubsection{Enabling Technology}

Other low-emissions technology for integral compressor engines is being developed. The interest in these technologies in terms of engine control is the potential for enabling more advanced strategies and algorithms. The technologies of interest are as follows: 
- Electronic Fuel Injection (EFI) - EFI for integral compressor engines is currently available from Enginuity, Hoerbiger, and DigiCon [16,17,18]. These systems involve elevated injection pressures from the standard mechanical poppet valve system. The higher pressures and nozzle designs are primarily for improved in-cylinder mixing consistency to achieve more repeatable combustion. The advantage for electronic controls is the ability to control injection duration (speed governing), injection timing, and individual cylinder biasing as a function of engine operating conditions. An accurate calibration to enable real-time fuel flow per cylinder and per cycle could offer many benefits for optimizing the engine performance, providing better diagnostics, and enabling more sophisticated model-based control algorithms for individual cylinder control.

- Pre-Combustion Chambers (PCC) - PCC has been available for many years from Cooper Compression and several engines feature these as part of low-emissions retrofits [19,20]. Dressor-Rand, CECO, and Diesel Supply, among others, also manufacture PCC's for compressor engines. The PCC offers tremendously increased ignition energy, that overcomes poor in-cylinder mixing and greatly improves combustion stability. With a PCC, combustion occurs in the small chamber, and the hot combustion gasses exiting the prechamber penetrate the main chamber. This process enables significantly leaner operation and, in turn, lowers $\mathrm{NO}_{\mathrm{X}}$ emissions. The benefit is more repeatable combustion over a wider operating range for less stringent requirements on monitoring/calculating limits of operation. Additionally, measurements for control logic calculations will be more stable with the reduced combustion instability, providing potentially more accurate real-time control.

- Ionization Current Feedback - Ionization current results from the application of a positive DC voltage to the spark plug electrodes. The current signal profile provides indication of misfire, knock, and air/fuel ratio. The current signal is low, in the milliamp range, and becomes lower with leaner equivalence ratios. These systems are becoming more prevalent in automotive applications. Woodward is developing a system for large-bore stationary engines $[21,22]$. The benefits of such a system for engine control are many. The signal can be used as a closed-loop control feedback for misfire detection, knock detection, and diagnostics. This system can potentially enable a more aggressive calibration, with reduced knock and misfire margins, for increased efficiency.

- Knock Detection - Knock detection is very common in automotive engines and control systems. Knock detection systems for large-bore spark-ignited engines are becoming available. Combustion knock, or detonation, results in a high frequency sound wave through the mechanical structure of the engine. This high-frequency ringing can be detected with accelerometer based sensors tuned to the knock frequency of a particular engine. A knock detection system enables a more advanced ignition timing, to be used for improved efficiency while offering the ability to protect the engine from damage. When knock is detected, the control system can either retard timing or lean the air/fuel mixture. A sensor from Metrix has been evaluated in a separate DOE project by SwRI on several integral compressor engines with promising results [23]. 


\subsection{RESULTS AND DISCUSSIONS}

Given the information derived from the review of control technology, the development of new strategies for integral compressor engine control was performed in this project. These developments focused on the addition of closed-loop feedback from a sensor manufactured by NGK-Locke. A discussion on the NGK-Locke sensor and its performance is provided in this section. The closed-loop $\mathrm{NO}_{\mathrm{X}}$ strategies developed ranged from simple application to existing systems to complete control strategies with closed-loop feedback an integral feature. The laboratory setup for controls development and demonstration is also outlined in this section.

\subsection{Test Setup}

The test bed for this work is a Cooper-Bessemer GMVH six cylinder turbocharged engine. This engine belongs to Cooper Compression and was installed at the laboratories of Southwest Research Institute (SwRI) for research and development of products to support the gas transmission industry. The GMVH-6 has the compressors removed and a dynamometer connect to the flywheel to apply load. The engine setup, including the foundation, was designed to resemble typical station installation as close as possible. A photograph of the test engine is provided in Figure 6.1.

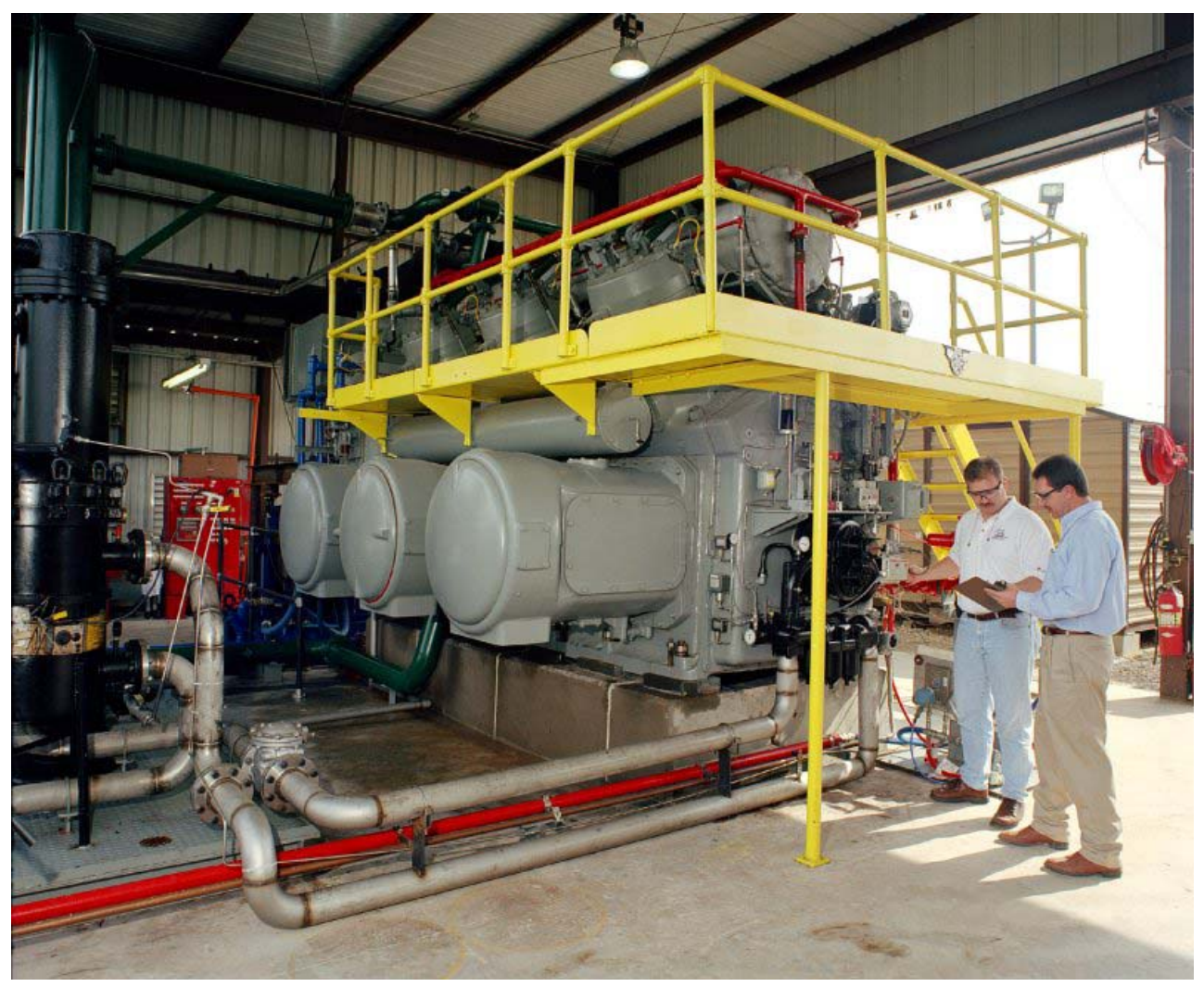

Figure 6.1. Photograph of GMVH-6 Laboratory Research Engine 
The GMVH-6 research engine has the standard mechanical fuel valves and pneumatically controlled fuel control regulator. The governor has been removed, and the dynamometer controller is set to maintain engine speed. Load is then set by adjusting the fuel header pressure with a PID controller. The engine was configured by Cooper Compression prior to installation in a standard Cleanburn TM configuration with Jet-Cell igniters. Testing in open-chamber configuration can be accomplished by replacing the Jet-Cells with spark plug adapters. A CPU2000 is installed for ignition control, and software is installed on the data acquisition controller to command spark timing.

The engine is heavily instrumented with a variety of pressure, temperature, frequency, flow, and position sensors. Each cylinder is instrumented with flush-mounted piezo-electric transducers, and each cylinder's exhaust runner is instrumented with dynamic pressure transducers. Dynamic pressure transducers are installed in each intake manifold. An emissions bench featuring compliance grade analyzers for $\mathrm{HC}, \mathrm{CO}, \mathrm{NO}_{\mathrm{X}}, \mathrm{CO}_{2}$, and $\mathrm{O}_{2}$ is utilized for all emissions measurements. A Horiba FTIR is also available for hydrocarbon speciation. A complete list of the instrumentation package is given in Table 6.1 .

Table 6.1. GMVH-6 Engine Instrumentation List

\begin{tabular}{|l|l|}
\hline Time-Averaged Measurements & Oil Pressure \\
\hline Engine Speed & Turbocharger Oil Pressure \\
\hline Turbocharger Shaft Speed & Coolant Inlet \& Outlet Pressure \\
\hline Turbocharger Wastegate Position & Pre-Turbine Pressure \\
\hline Engine Torque & Stack Pressure \\
\hline Total Fuel Flow & Compressor Inlet Temperature \\
\hline Pre-Chamber Fuel Flow & Compressor Left \& Right Outlet Temperatures \\
\hline Fuel Gas Composition & Inlet Manifold Left \& Right Temperatures \\
\hline Fuel Gas Heating Value & Fuel Header Temperature \\
\hline Total Air Flow & Pre-Chamber Header Temperature \\
\hline Barometric Pressure & Individual Cyl. Exhaust Runner Temperatures \\
\hline Ambient Temperature & Pre-Turbine Temperature \\
\hline Ambient Humidity & Post-Turbine Temperature \\
\hline Exhaust NOx Concentration & I/C Inlet Left \& Right Water Temperatures \\
\hline Exhaust CO Concentration & I/C Outlet Left \& Right Water Temperatures \\
\hline Exhaust HC Concentration & Oil Sump Temperature \\
\hline Exhaust CO2 Concentration & Oil Inlet Temperature \\
\hline Exhaust O2 Concentration & Turbocharger Oil Inlet Temperature \\
\hline Exhaust Equivalence Ratio & Coolant Inlet \& Outlet Temperatures \\
\hline Inlet Manifold Left \& Right Pressures & Individual Cyl. Head Temperatures \\
\hline Fuel Header Pressure & Dynomometer Inlet \& Outlet Temperatures \\
\hline Pre-Chamber Header Pressure & Cylinder 1L Exhaust Runner Pressure \\
\hline Crank-Angle Resolved (Dynamic) Measurements \\
\hline Cylinder 1L Firing Pressure & Cylinder 2L Exhaust Runner Pressure \\
\hline Cylinder 2L Firing Pressure & Cylinder 3L Exhaust Runner Pressure \\
\hline Cylinder 3L Firing Pressure & Cylinder 1R Exhaust Runner Pressure \\
\hline Cylinder 1R Firing Pressure & Cylinder 2R Exhaust Runner Pressure \\
\hline Cylinder 2R Firing Pressure & Cylinder 3R Exhaust Runner Pressure \\
\hline Cylinder 3R Firing Pressure & Right Inlet Manifold Plenum Pressure \\
\hline Left Inlet Manifold Plenum Pressure & Exhaust Manifold Plenum Pressure \\
\hline Cylinder 1L Pre-Chamber Firing Pressure & \\
\hline
\end{tabular}

For development and demonstration, a PC-based control system was installed in the test cell. SwRI developed this system for flexible engine control developments on a variety of engines for various applications. This system is called the Rapid Prototyping Engine Control Systems (RPECS), and features both off-the-shelf and custom designed hardware for data acquisition and 
synchronous tasks such as ignition timing and fuel injection commands. The RPECS also possesses data logging and plotting capabilities as well. The RPECS software is written in high level $\mathrm{C}$ and visual $\mathrm{C}++$ languages for rapid code modifications, which can be easily ported to many popular dedicated microprocessors. Photographs of the RPECS and sensor installations are provided in Figures 6.2 to 6.5 .

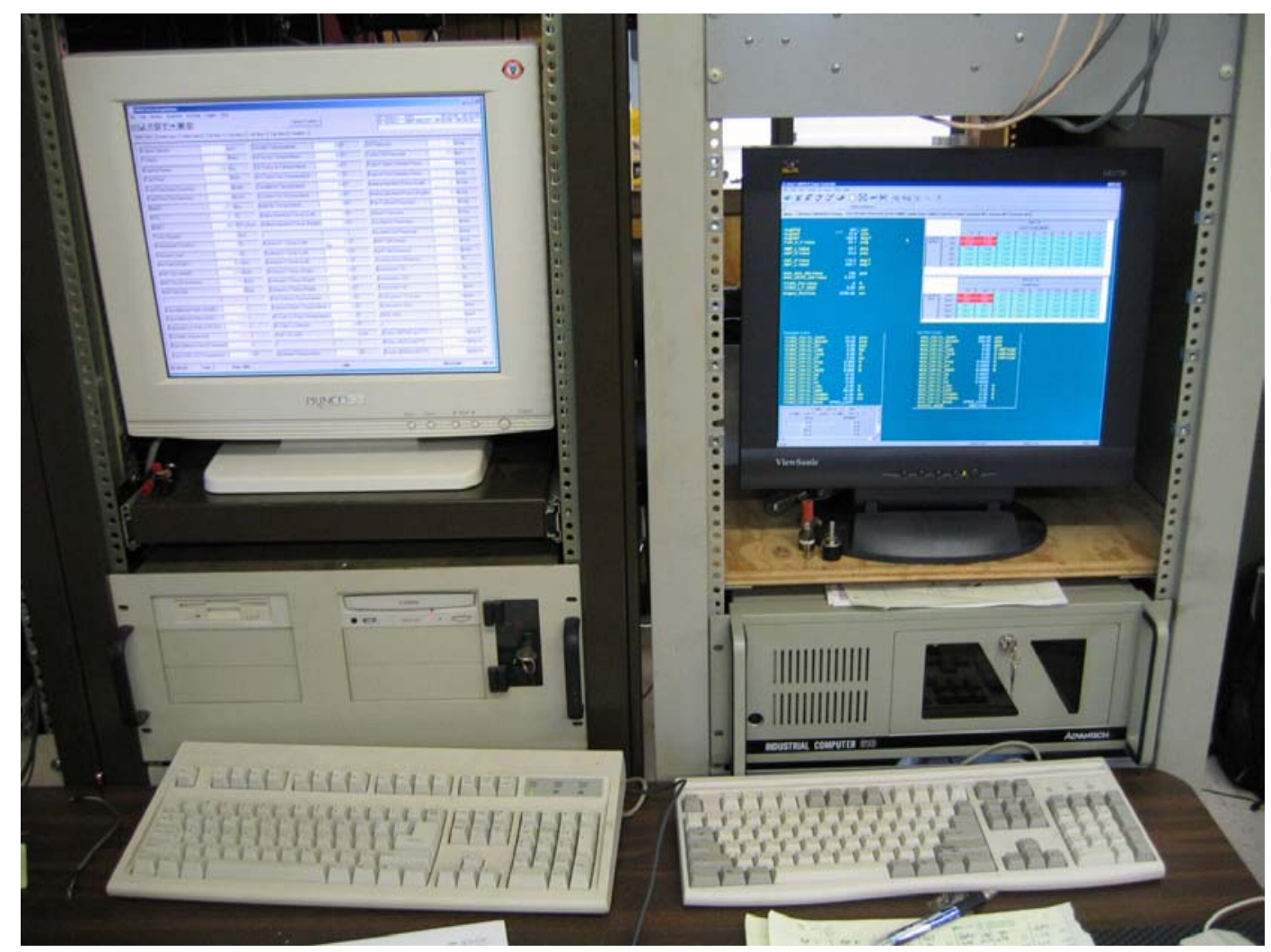

Figure 6.2. Photograph of RPECS and Data Acquisition System 


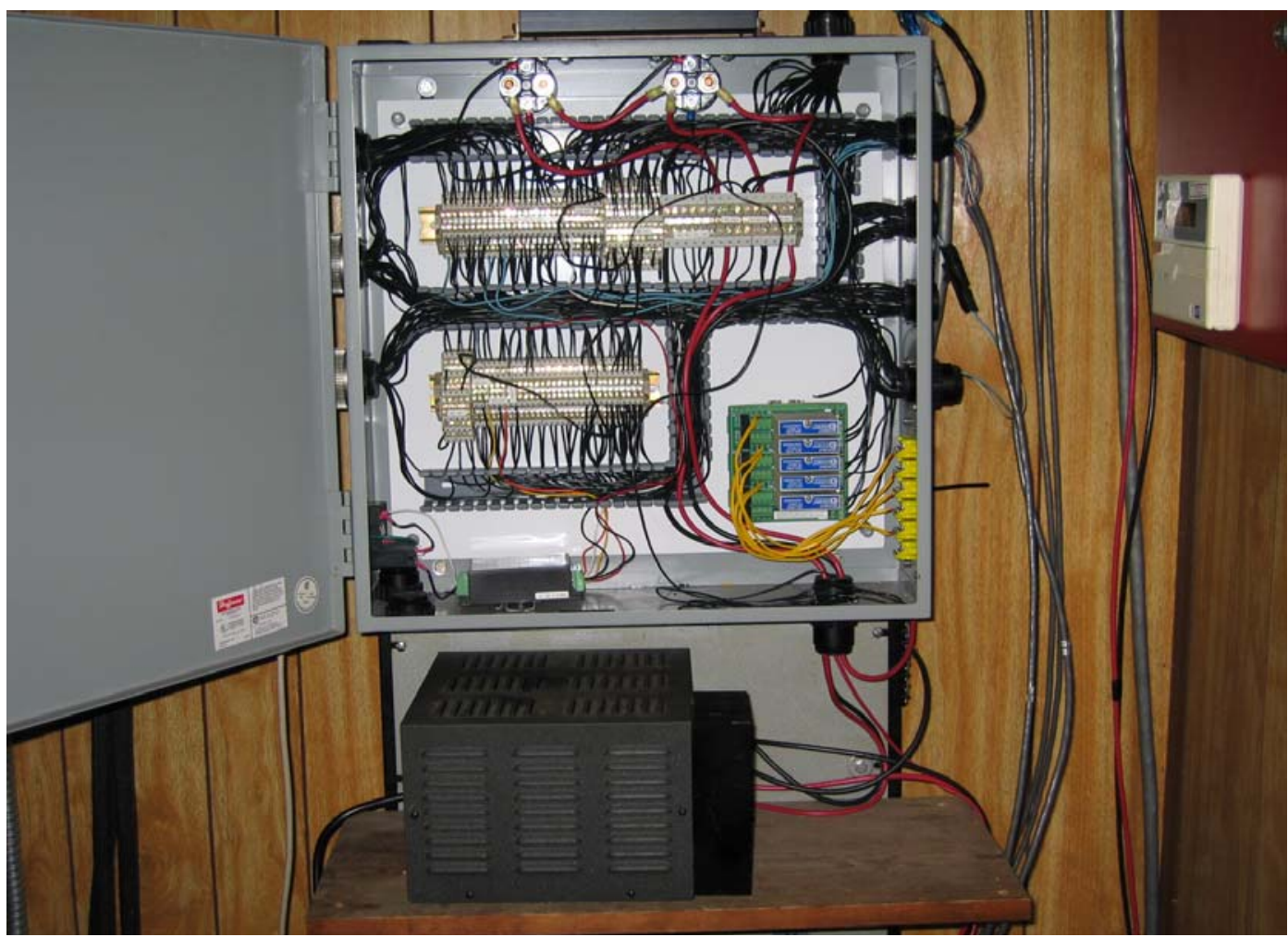

Figure 6.3. Photograph of Interior Controls Junction Box

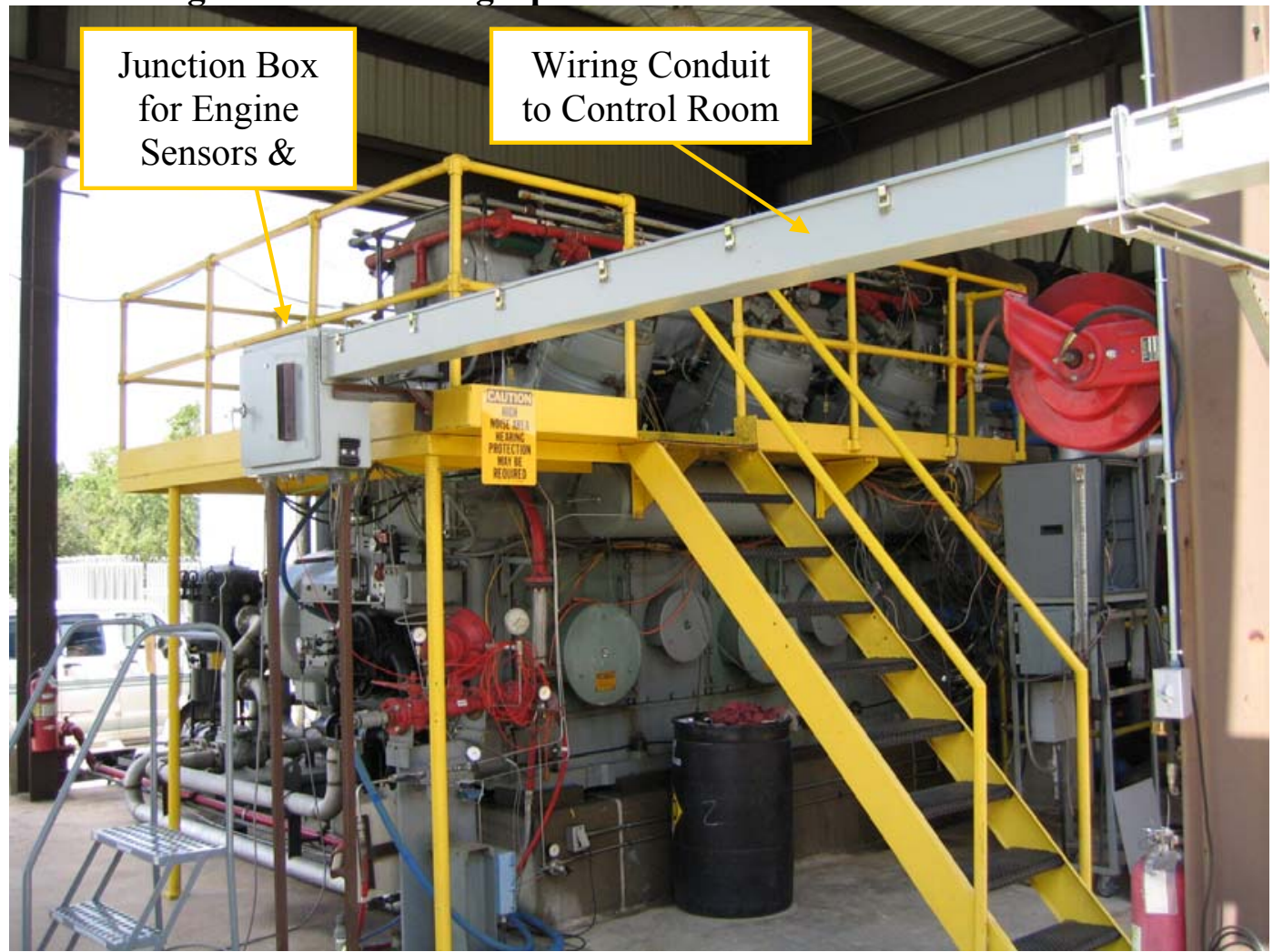

Figure 6.4. Photograph of Engine-Side Control Junction Box 


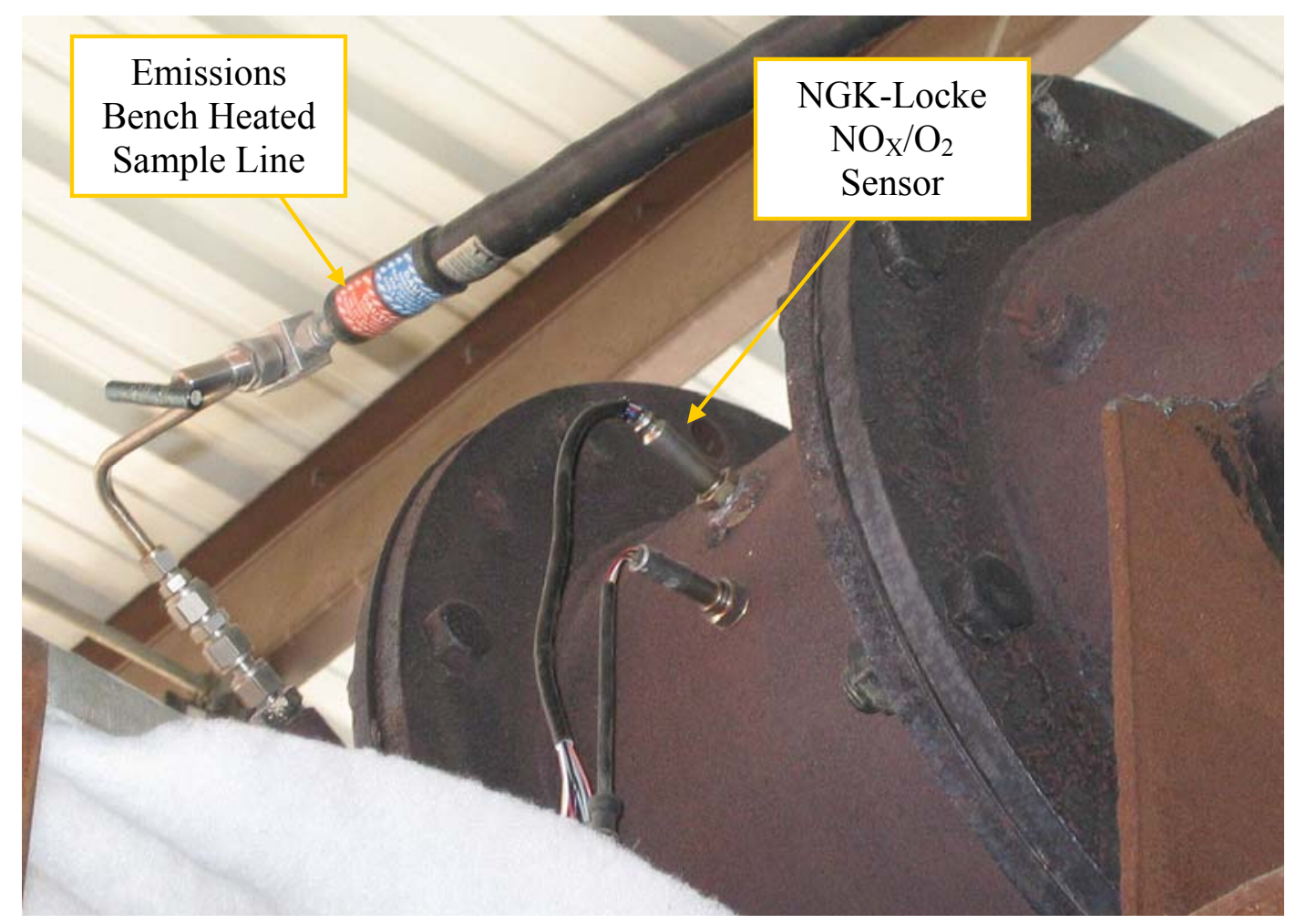

Figure 6.5. Photograph of NGK-Locke $\mathrm{NO}_{\mathrm{X}}$ Sensor Installed In Exhaust

\subsection{NGK-Locke Combined $\mathrm{NO}_{\mathrm{X}} / \mathrm{O}_{2}$ Sensor}

The NGK-Locke sensor combines the UEGO function with direct measurement of exhaust $\mathrm{NO}_{\mathrm{X}}$ concentration. Therefore, one or both of these signals can be utilized as feedback to adjust or trim the fuel or air flow control signals. The sensor is a solid-state, thick film, amperometric, electrolyte type containing multiple diffusion cells and a temperature controlled sensing element $[24,25,26,27]$. The sensor has a stated accuracy of less than $\pm 10 \%$ of point, and is available with span ranges of 500, 1000, and 2000 parts per million (ppm). The output of this sensor is in the form of a 0-5 volt signal and compatible with present day engine control management (ECM) systems. The combined $\mathrm{NO}_{\mathrm{X}}$ range of this sensor can be as high as $0-2000 \mathrm{ppm}$ and has a published response time of $260 \mathrm{msec}$ for a 33 to 66 percent step change in $\mathrm{NO}_{\mathrm{X}}$ [27]. This sensor catalytically converts $\mathrm{NO}_{2}$ to $\mathrm{NO}$ to determine total $\mathrm{NO}_{\mathrm{X}}$ [24]. As an added application benefit, the sensor outputs a voltage that is proportional to the exhaust gas $\mathrm{O}_{2}$ level. Hence, both $\mathrm{NO}_{\mathrm{X}}$ and $\mathrm{O}_{2}$ can be determined from a single sensor. A photograph of the NGK-Locke sensor and electronic module is provided in Figure 6.6. 


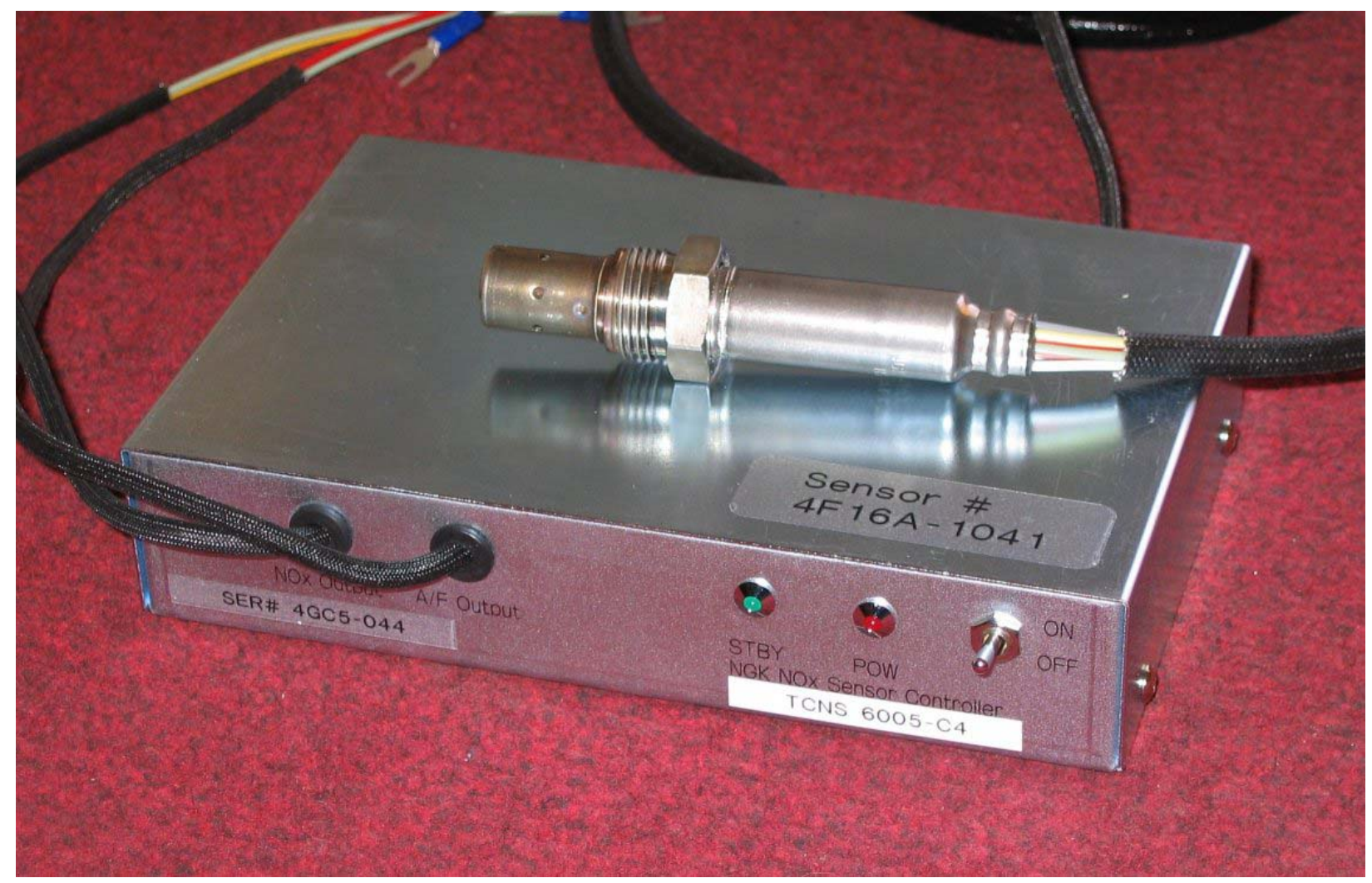

Figure 6.6. Photograph of NGK-Locke Combined $\mathrm{NO}_{\mathrm{X}} / \mathrm{O}_{2}$ Sensor

SwRI conducted a durability test of an early generation of this sensor in an on-highway diesel engine [28]. Since then, several of these sensors have been utilized by SwRI for both laboratory and field testing. Two sensors in ranges of 0-1000 and 0-2000ppm were purchased for this project. The $\mathrm{NO}_{\mathrm{X}}$ and $\mathrm{O}_{2}$ channels were calibrated versus emissions bench measurements over the range produced by the GMVH-6 engine. The $\mathrm{O}_{2}$ channel was also calibrated versus the exhaust (global) equivalence ratio derived from exhaust emissions, using equations in Appendix A. The 2000 range sensor was used for engine testing in open-chamber configuration and the 1000 range sensor was used for engine testing in the PCC configuration. Calibration data for these sensors is shown in Figures 6.7 and 6.8 for the $\mathrm{NO}_{\mathrm{X}}$ and $\mathrm{O}_{2}$ channels. The data in these figures were acquired over several weeks of testing. A third sensor used for field testing on a separate project was calibrated on the GMVH-6 engine, and a year later the calibration was retested. The data from these calibrations is shown in Figure 6.9. This data illustrates good accuracy and repeatability of these sensors. 


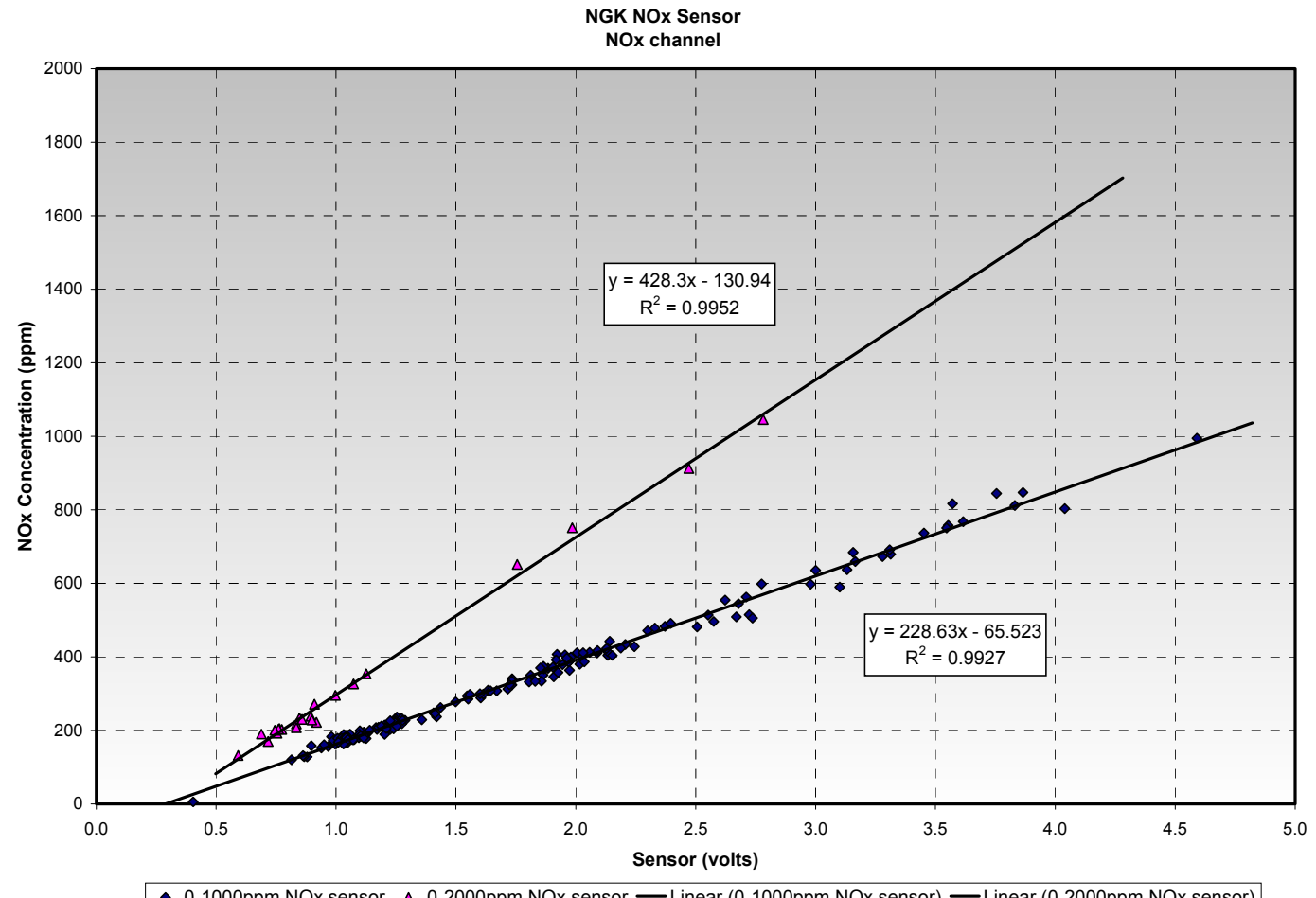

Figure 6.7. $\mathrm{NO}_{\mathrm{X}}$ Calibration Data for 0-1000 and 0-2000ppm NGK Sensors

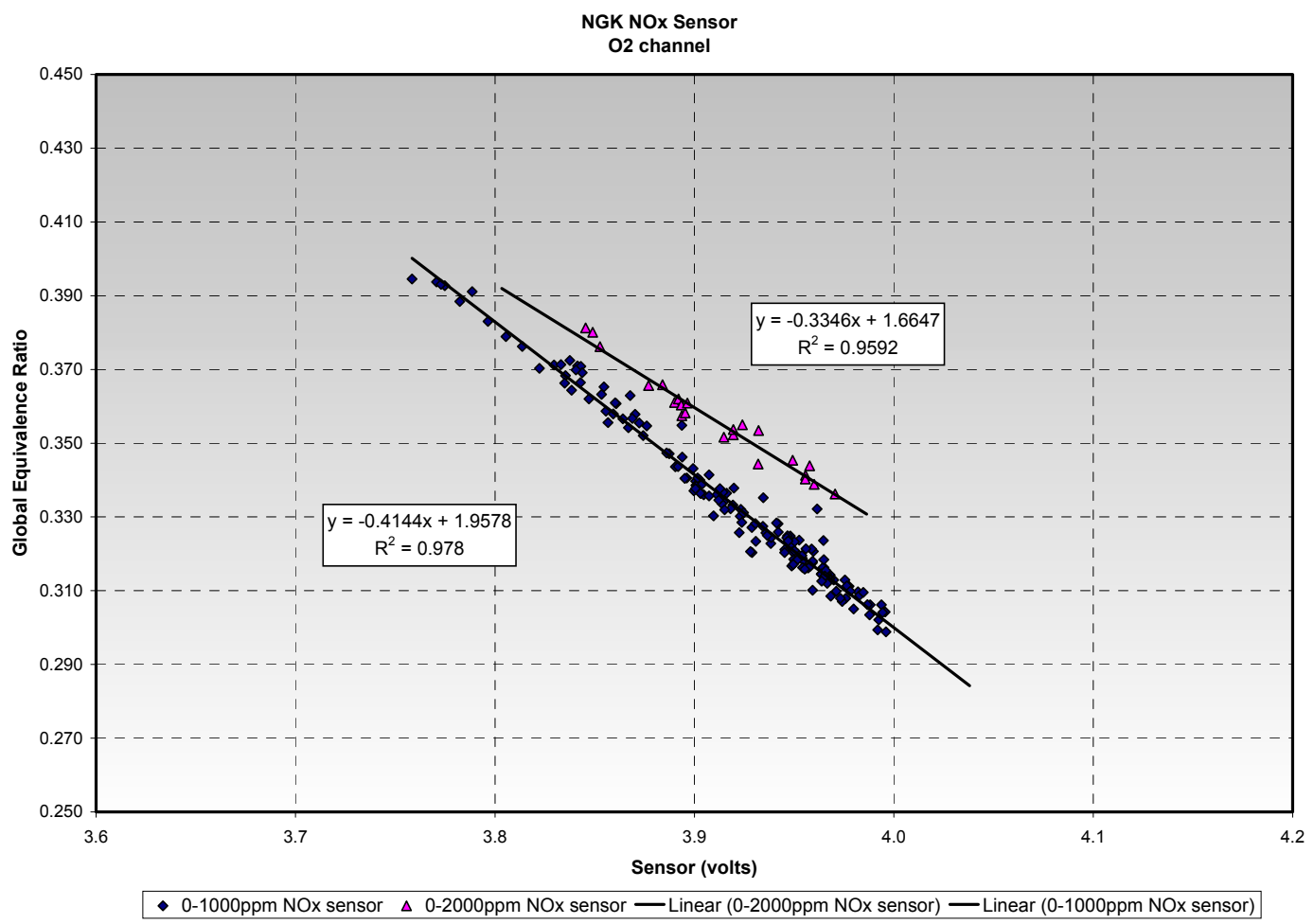

Figure 6.8. Global Equivalence Ratio Calibration of 0-1000 \& 0-2000ppm NGK Sensors 


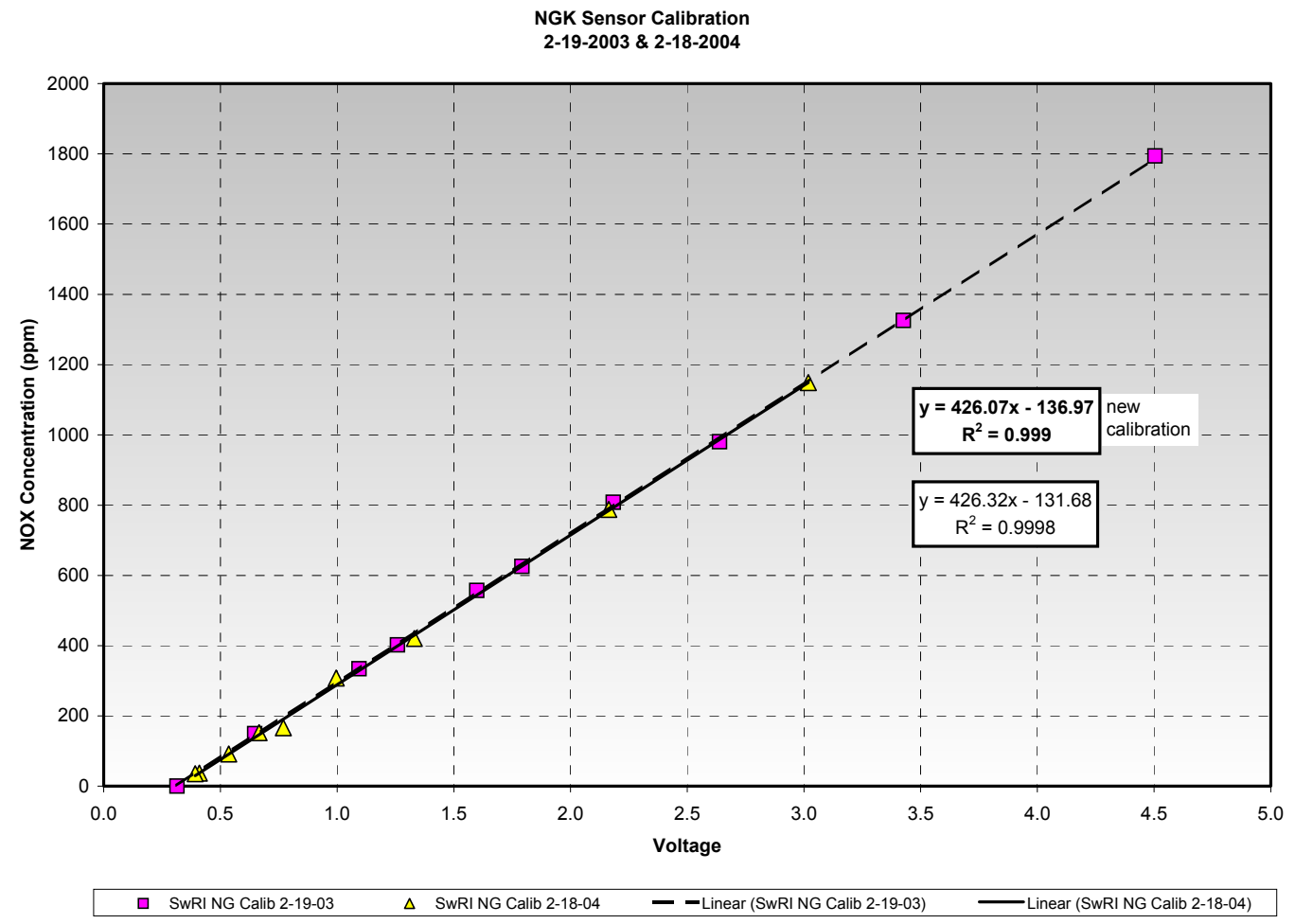

Figure 6.9. $\quad \mathrm{NO}_{\mathrm{X}}$ Calibration Data for 0-2000ppm NGK Sensor Over 1 Year Span

The data in Figures 6.7 to 6.9 represent 10-point averages at each condition. The response of the NGK-Locke sensor is very fast, and an example of the transient response and instantaneous comparison to the emissions bench analyzer is shown in Figure 6.10. The calibration from Figure 6.7 was used to convert the voltage signal to $\mathrm{NO}_{\mathrm{X}}$ concentration for the data in Figure 6.10. The acquisition rate was $0.5 \mathrm{~Hz}$ for this dynamic performance test. 


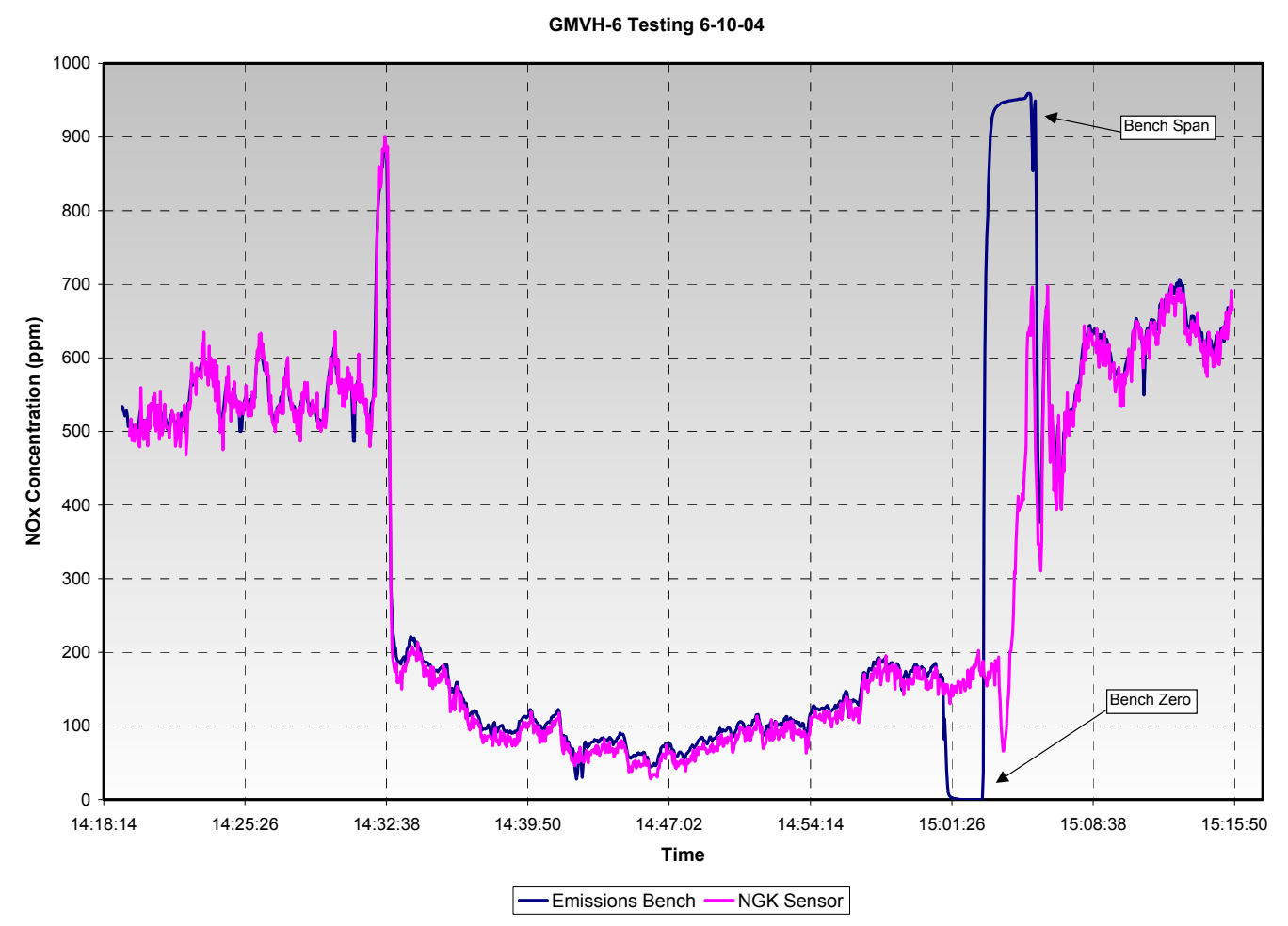

Figure 6.10. Comparison of NGK NO $\mathrm{X}_{\mathrm{X}}$ and Emissions Bench Analyzer Over Transient Operating Conditions

The data in Figures 6.7 to 6.10 shows the NGK-Locke $\mathrm{NO}_{\mathrm{X}}$ sensor to exhibit good accuracy, repeatability, and transient response. However, a long-term test in a typical compressor engine operating in the field has not yet been performed. This test is planned, and will involve installation of the sensor on a field engine that operates nearly continuously. Periodic measurements to check for sensor functionality will be performed during durability testing. A pre and post-calibration will be performed to determine the sensor degradation over an extended period.

\subsection{Hierarchy of Closed-Loop Control Strategies}

Closed-loop control utilizing the NGK-Locke sensor can range from simple to complex, and be incorporated into virtually all current strategies used on integrals gas engines. The output signal from this sensor can be used as direct feedback into the control algorithm or it can be used as a calibration tool to periodically adjust algorithm coefficients. Descriptions of several potential strategies are provided below.

\section{$\underline{\text { Simple Strategies }}$}

Simple strategies involve utilizing the sensor output as a diagnostic and alarm tool, comparable to oil pressure or coolant temperature sensors. For example, the $\mathrm{NO}_{\mathrm{X}}$ signal would only affect the engine control when a target level is reached or exceeded. When the target level is reached, a relay can be switched to prompt the engine controller to make a pre-determined change to a 
control device such as retard timing or to make a step-change (bias) to the air/fuel ratio. If the target level continues to be exceeded, additional step-changes can be initiated or a diagnostic fault or alarm can be set. Some time period must be programmed to hold the closed relay position before releasing. This strategy is only advisable to account for rare excursions in a situation where a large margin between operating $\mathrm{NO}_{\mathrm{X}}$ and the target $\mathrm{NO}_{\mathrm{X}}$ level normally exists. Otherwise, excessive relay switching would occur.

A more complicated approach would involve both a high and low threshold. This approach could act similar to a thermostat or like the inlet manifold temperature bias illustrated in Figure 5.4 for the fuel-air curve. When the high $\mathrm{NO}_{\mathrm{X}}$ threshold is reached, a bias to the fuel-air curve can be initiated to effectively lean the air/fuel ratio or retard timing. The bias will then remain in effect until the low $\mathrm{NO}_{\mathrm{X}}$ threshold is reached, at which time the bias would be removed. This can be accomplished with relays, or preferably with control logic that can incorporate diagnostics. Generic flowcharts of the previously described approaches are provided in Figure 6.11 .
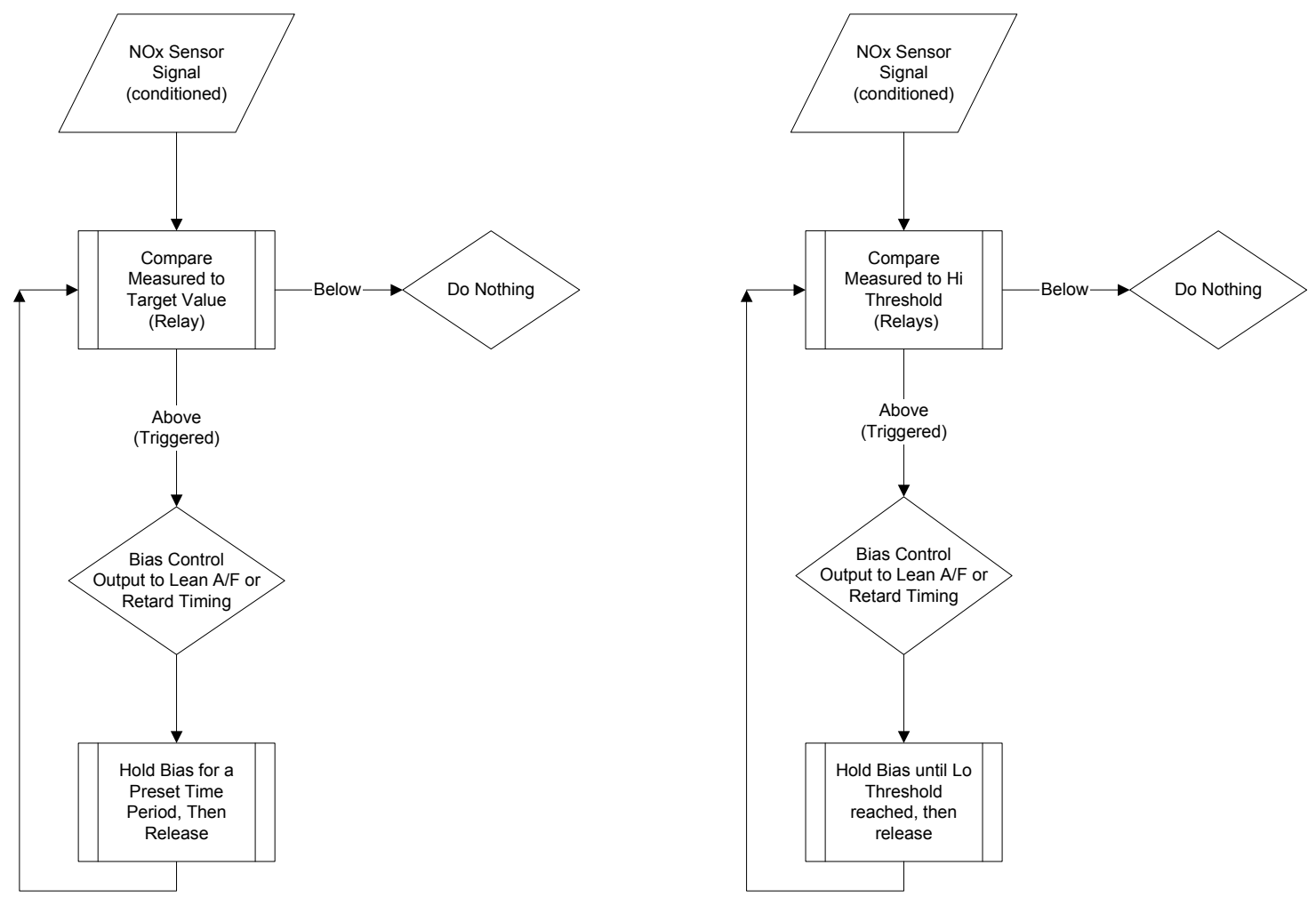

Figure 6.11. Flowcharts of Simple Strategies with NO $_{\mathbf{X}}$ Sensor Feedback 


\section{Moderately Complex Strategies}

The next level of complexity would involve using the sensor output as continuous closed-loop feedback, similar to the EGO sensor feedback in automotive systems. This level of complexity would require an electronic control system with sufficient capacity to continuously process the signals, calculate the closed-loop error, and adjust the open-loop control algorithm accordingly. The sensor feedback is an integral feature of this type control strategy. Unlike the simple strategies outlined previously, continuous closed-loop feedback offers the potential to improve engine efficiency by maintaining optimum control settings under varying conditions. The diagnostic and alarm functionality is retained as well.

The Modified Fuel-Air Curve strategy, developed under this project and described in Section 6.4, falls under this level of complexity. If the control logic is based on global equivalence ratio, the $\mathrm{O}_{2}$ channel can be utilized for direct feedback to adjust the open-loop fuel calculation/calibration, while the $\mathrm{NO}_{\mathrm{X}}$ signal can provide a limiting function. Other applications could use $\mathrm{NO}_{\mathrm{X}}$ feedback to continuously trim the calculated trapped equivalence ratio or AMP setpoints in systems described in Sections 5.5.2 and 5.5.4. A generic flowchart of a close-loop feedback control approach is provided in Figure 6.12.

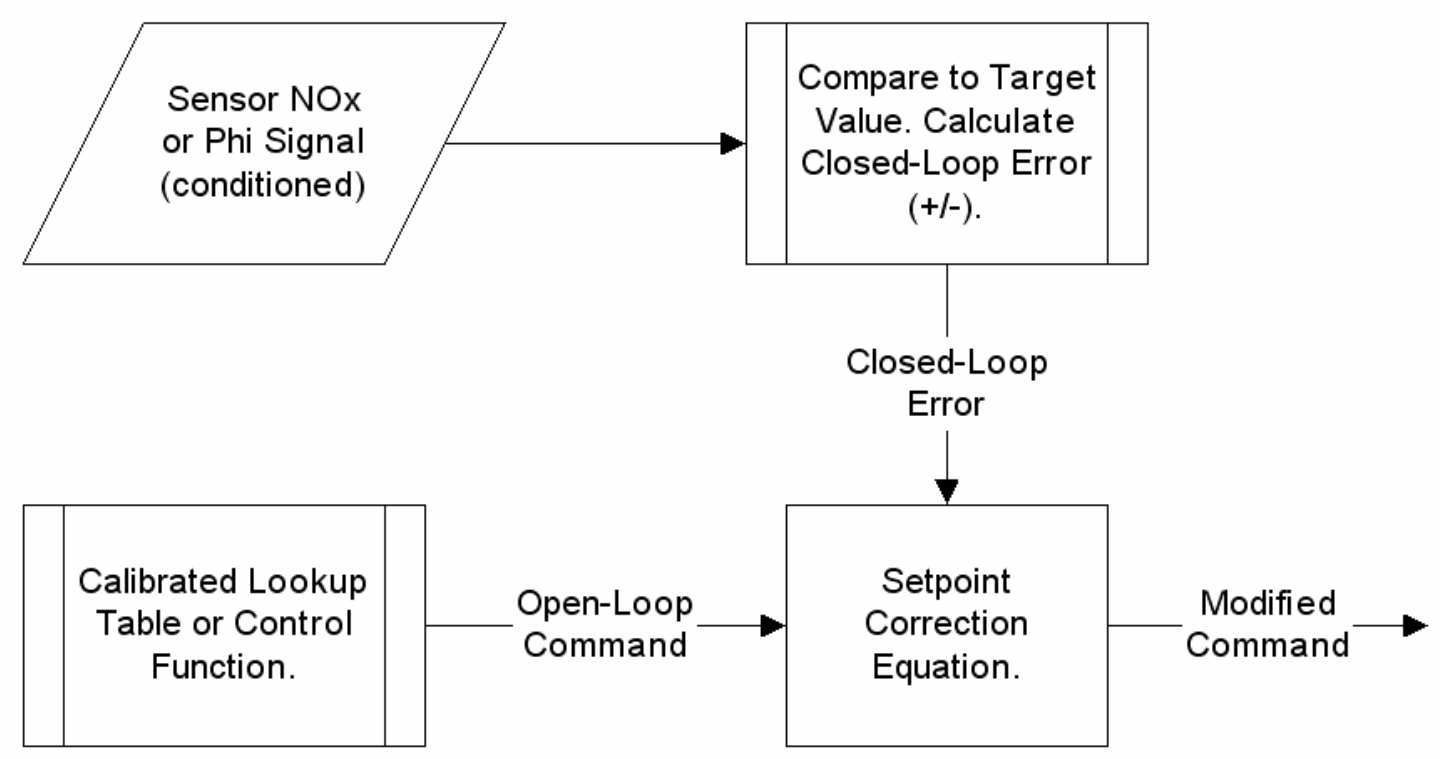

Figure 6.12. Flowchart of Basic Closed-Loop $\mathrm{NO}_{\mathrm{X}}$ or Equivalence Ratio Control

\section{Complex Strategies}

Complex strategies involve using the sensor feedback to continually adjust coefficients and trim setpoints in model-based control systems. The measured values of $\mathrm{NO}_{\mathrm{X}}$ and/or global equivalence ratio can be used in thermodynamic calculations or regression equations directly or indirectly as a comparator to trim coefficients. For a two-stroke engine, where trapped equivalence ratio is the focus, the global equivalence ratio feedback can be utilized to tune the trapped mass calculations for greater accuracy. If a $\mathrm{NO}_{\mathrm{X}}$ prediction algorithm is employed, the 
$\mathrm{NO}_{\mathrm{X}}$ signal can provide a direct feedback to tune the model. A model-based strategy involving the derivation of trapped equivalence ratio is described in Section 6.5 below. In this strategy, both channels of the NGK-Locke sensor are utilized. Other applications could be the use of $\mathrm{NO}_{\mathrm{X}}$ feedback as a closed-loop trim to a PEMS system as described in Section 5.5.4. A generic flowchart to utilize $\mathrm{NO}_{\mathrm{X}}$ feedback in a $\mathrm{NO}_{\mathrm{X}}$ prediction algorithm is provided in Figure 6.13.

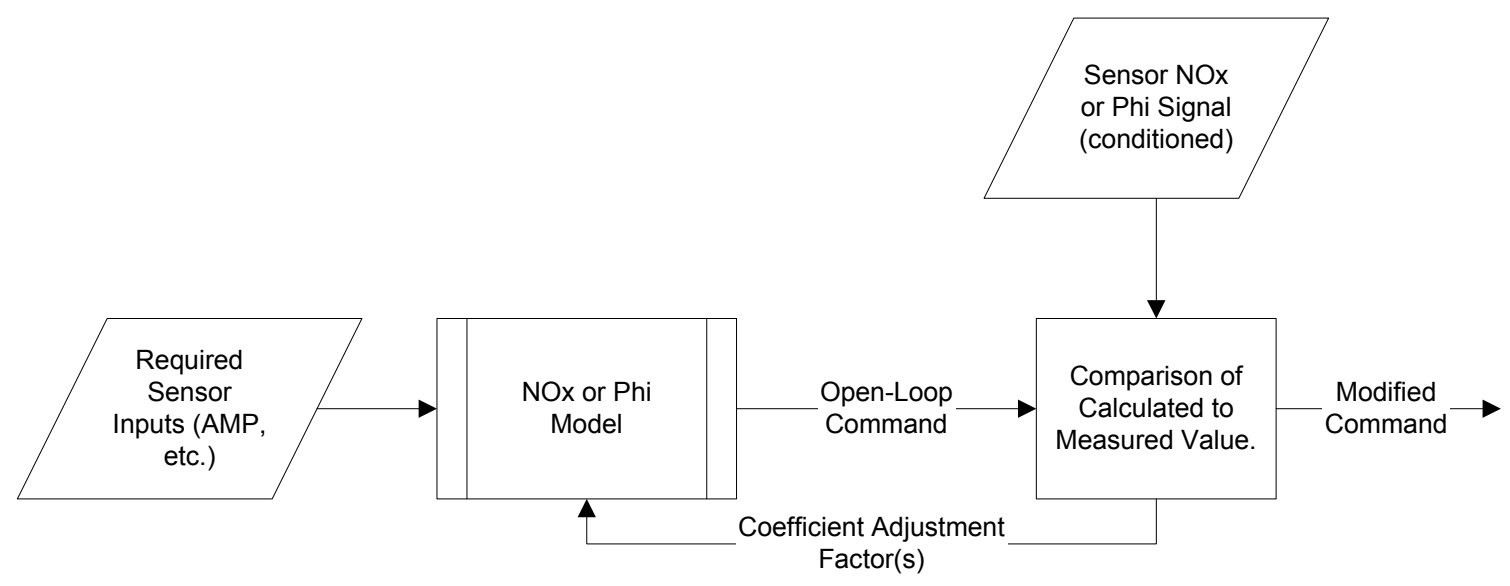

Figure 6.13. Flowchart of Basic $\mathrm{NO}_{\mathrm{X}}$ or Equivalence Ratio Trim of Model-Based Control

Alternative Uses

Alternative uses of a $\mathrm{NO}_{\mathrm{X}}$ sensor include calibration and model tuning on an initial or periodic basis. A calibrated sensor could be installed during commissioning with an automatic algorithm tuning process. When completed over a certain period of time, the sensor could be removed and possibly reinstalled at a later date for re-tuning. The automatic tuning process would involve operating the engine over the typical range. If a lookup table is being utilized, the table values can be modified based on sensor feedback as the engine is swept through the operating range. If a model-based control algorithm is being utilized, the sensor feedback can be used in a regression equation to modify model coefficients for improved prediction accuracy.

\section{$\underline{\text { Diagnostics }}$}

It is not advisable or recommended that a control system be solely dependent on a sensor feedback without redundancy (comparative parameter) or diagnostics incorporated. Sensor failure, calibration drift, or electrical interference can cause inaccurate feedback. If unchecked, a faulty or incorrect signal could cause the engine controller to adjust settings to a point where the engine could be damaged by detonation, or encounter lean misfire. Redundancy would require a secondary signal to compare with the primary to ensure accurate feedback. A properly tuned $\mathrm{NO}_{\mathrm{X}}$ prediction type algorithm could provide a diagnostic check by setting a maximum error band above which further adjustment would be limited.

A diagnostic strategy should be developed to determine if the sensor has failed or signal output has been compromised. Diagnostic strategies in on-highway engine control systems are the most 
advanced of all engine systems. Many of these strategies can be incorporated into a control system for integral compressor engines. The most basic diagnostics are to determine if the sensor is faulty. More robust strategies would determine either a sensor fault or a fault of the engine control devices. Like automotive systems, the diagnostic strategy can allow for the control system to fall back into an open-loop control mode under fault conditions to keep the engine running until repairs can be made. Potential fault strategies are as follows:

- High/Low Signal Fault - The sensor range should be selected where the engine $\mathrm{NO}_{\mathrm{X}}$ output or target falls between 20 and 80 percent of the sensor range during all operating conditions. A high fault can then be a condition where the sensor continuously outputs a signal in the upper portion ( $>80$ percent) of its range. A low fault can then be a condition where the sensor continuously outputs a signal in the lower portion $(<20$ percent $)$ of its range. This fault would detect either an open or shorted condition, as well as failure of the sensor or sensor control module.

- Closed-Loop Correction Error - Most applications of closed-loop feedback involve the calculation of a closed-loop error from which the open-loop setpoint is adjusted. A maximum limit of correction should be imposed ( $\sim 30$ percent) to prevent excessive adjustment. A fault can be set if the closed-loop error remains at the maximum limit for a preset period of time. This fault can detect a sensor signal calibration error or engine component fault. The sensor proportional output, or calibration, could shift due to contamination and give an inaccurate feedback that is still within the High/Low limits. An engine control device (i.e. wastegate or fuel injector) could fail and not respond correctly to control commands, leading to excessive correction.

- Model Comparison Error - If a prediction algorithm is employed, either as primary control or as a diagnostic function, the error between predicted and sensor values can be used for fault detection. A maximum error limit would need to be determined based on the accuracy of the predictive model. A fault can then be set if the maximum comparative error limit has been exceeded for a preset period of time.

More elaborate diagnostics can be employed to check the sensor response to expected behavior during warm-up or transients. The direction and rate of change of sensor output during these conditions could be evaluated for normal sensor operation. A database of recorded parameters can be assimilated over time, normalized or filtered, and sensor output can be compared to calibrated values at similar operating conditions for fault detection [29].

\subsection{Modified Fuel-Air Curve Strategy}

With the premise that having $\mathrm{NO}_{\mathrm{X}}$ feedback could lessen the complexity required in the control strategy and still prevent excursions above the $\mathrm{NO}_{\mathrm{X}}$ setpoint, a closed-loop strategy was developed for demonstration. This strategy, called the Modified Fuel/Air Curve, was developed from the original OEM fuel-air curve approach for turbocharged two-stroke integral engines described in Section 5.5.1. A relationship of AMP to FHP is retained, but was expanded in another dimension to include engine speed. The multiple curves were developed at constant $\mathrm{NO}_{\mathrm{X}}$ emissions output for various engine speeds with optimized spark timing at each speed. The 
feedback signal from the $\mathrm{NO}_{\mathrm{X}}$ sensor then provides an adjustment or trim to the calibration fuelair curves to compensate for deviations from the target value.

Initial mapping was conducted on the GMVH-6 test engine where the AMP was adjusted on the GMVH- 6 at several engine speeds, loads, and spark timings to achieve $2 \mathrm{~g} / \mathrm{bhp}-\mathrm{hr} \mathrm{NO}_{\mathrm{X}}$. The results of the mapping are illustrated in Figure 6.14. These lines represent a surface, of which a single function could be fit or a two-dimensional table could be built. Using a two-dimensional table, as is common in automotive control code, provided for non-linearity at extreme corners of the operating map (startup, shutdown, etc.) and could more easily allow an adaptive learn function to adjust the discreet points of the map. The initial surface programmed into a twodimensional table in the RPECS is shown in Figure 6.15. Spark timing was then programmed as a function of engine speed.

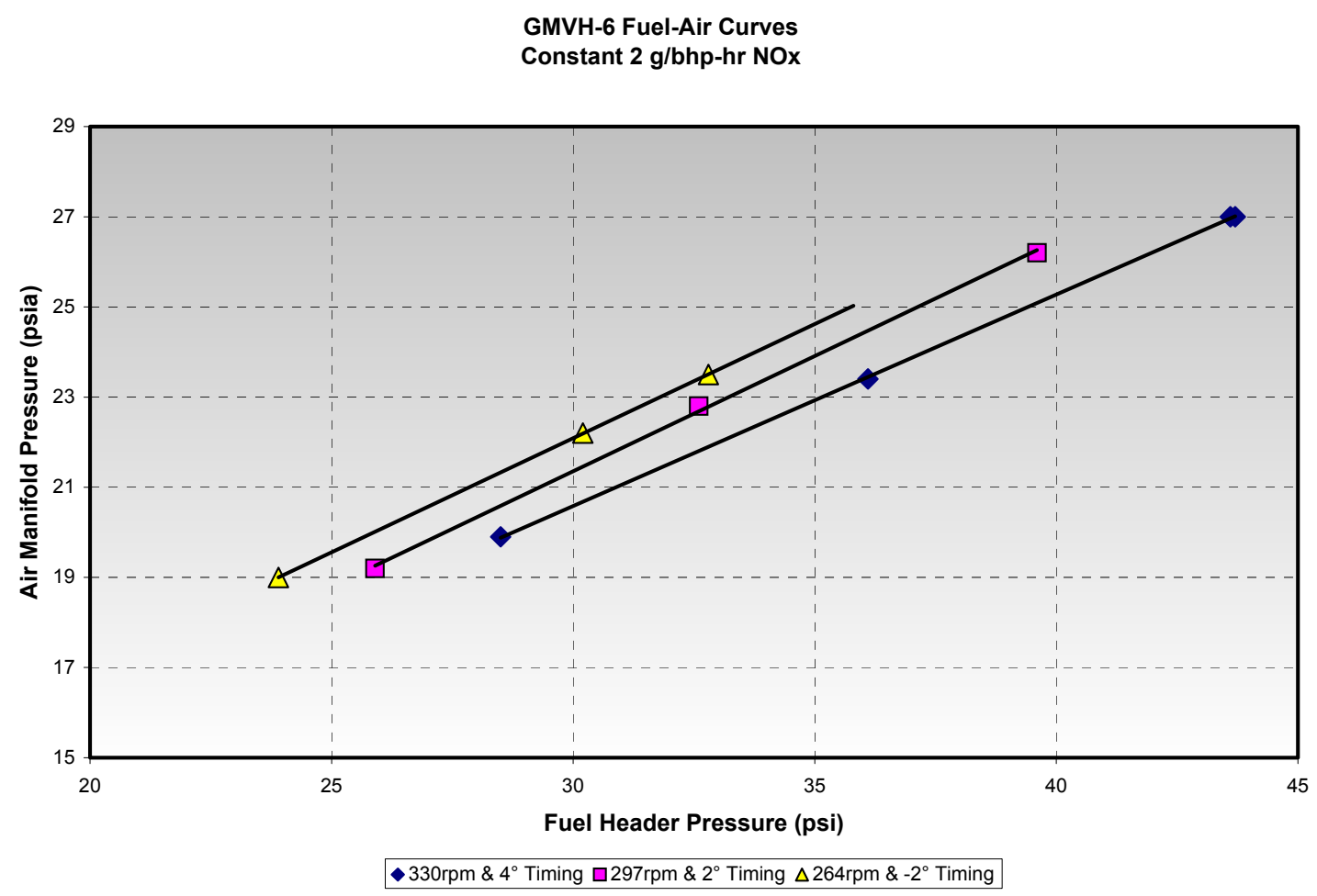

Figure 6.14. Multiple Fuel-Air Curves for Constant $\mathrm{NO}_{\mathrm{X}}$ and Different Speeds 


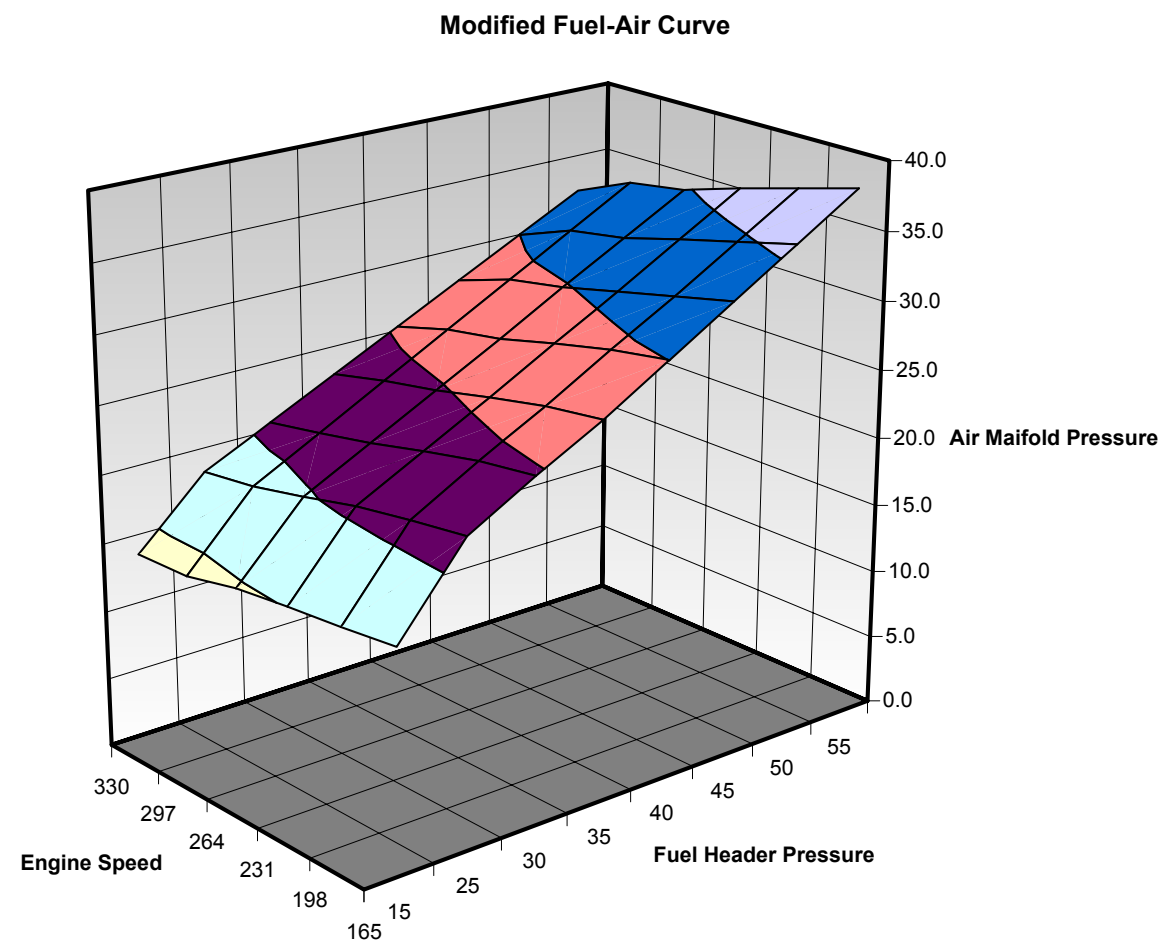

Figure 6.15. Surface Plot of Initial Modified Fuel-Air Curve RPECS Calibration

Changes in ambient humidity, fuel quality, and other factors were not addressed specifically in this approach, but are instead compensated for globally by the closed-loop correction. It was instead left to the closed-loop $\mathrm{NO}_{\mathrm{X}}$ function to adjust the wastegate and achieve the air/fuel ratio necessary to maintain the $\mathrm{NO}_{\mathrm{X}}$ setpoint. This approach also eliminated the need to estimate the trapped equivalence ratio, and the associated complexity and error involved. This also eliminated many of the additional sensor inputs required for a more complex model based control strategy.

One concern with this strategy surrounds a maximum boost condition, or closed wastegate, where insufficient air is available to lean the engine to the desired $\mathrm{NO}_{\mathrm{X}}$ setpoint. This condition could occur with a turbocharger of marginal capacity and a very hot day where the air density is low. This problem was addressed by a function that detected when this condition occurs and then slowly retards spark timing until wastegate control could resume. The function detects the maximum air condition through closed-loop error calculations and a continuous maximum command output, or with feedback from a wastegate position sensor. These factors are also used to detect when the maximum air condition has been alleviated and normal timing can resume.

After finalizing the design of this control strategy, shown schematically in Figure 6.16, the RPECS software was programmed with the initial calibration from Figure 6.15. A series of engine tests were initiated to check the control system response with and without the closed-loop $\mathrm{NO}_{\mathrm{X}}$ function enabled. 


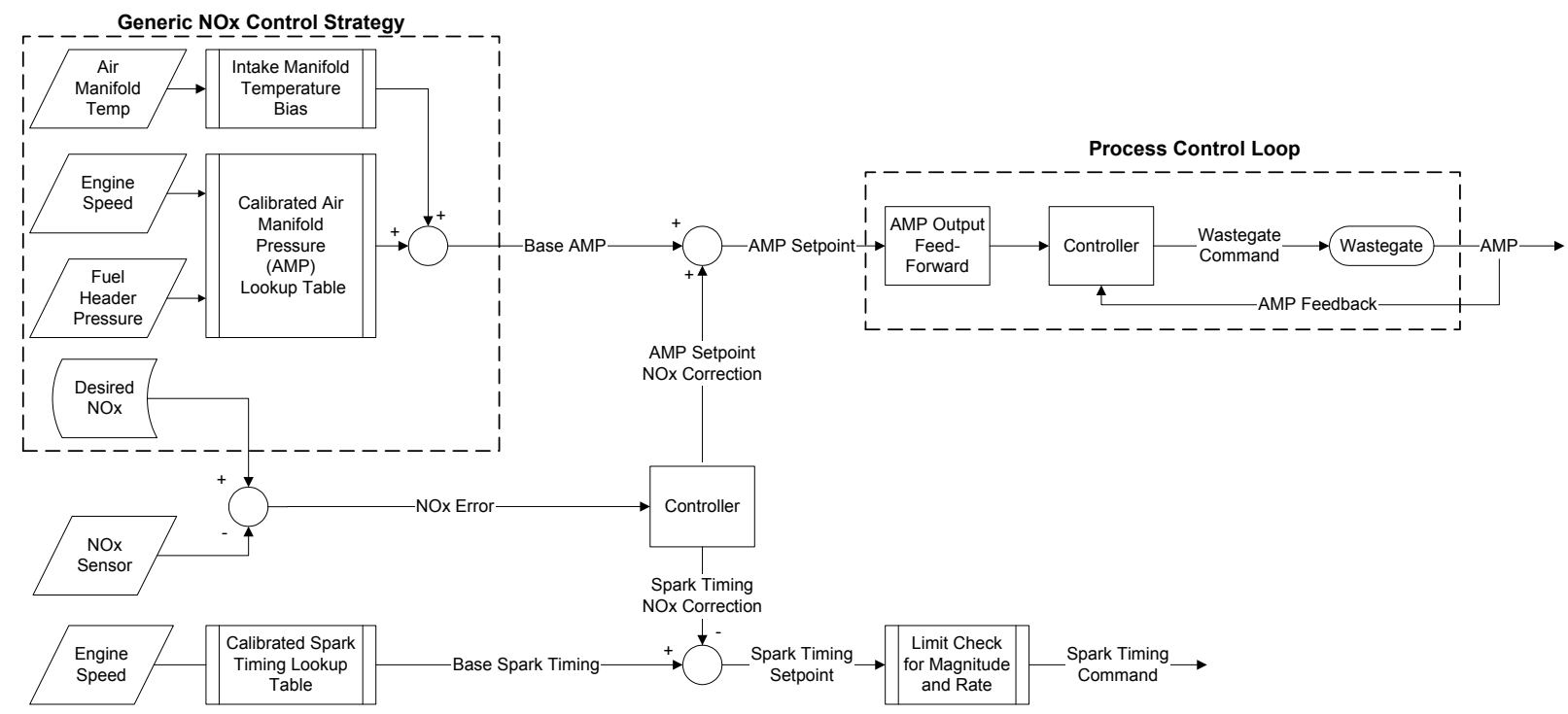

References:

ref. A: AMP_SP=AMP_base*(1+AMP_NOx_corr)

ref. B: Dependent on integrator limit and time at limit. Spark timing correction will only be to retard.

ref. C: Incorporated gain scheduling and deadband to improve control loop performance

ref. D: NOx control Strategy can include parametric and model based approches

\begin{tabular}{|l|l|l|l|}
\hline TITLE N NOx Control & \multicolumn{3}{|l|}{ DESCRIPTION } \\
& CL NOx Control Overview \\
\hline FILENAME & DATE & PAGE & DRAWN BY \\
\hline
\end{tabular}

Figure 6.16. Schematic of Modified Fuel-Air Curve Algorithm

The GMVH engine was first run through a series of speed and load transients to set the proportional and integral gains. The engine was then operated through a load-step matrix. The load-steps were 100-80-90-70-100-80 percent of rated load, with an hour of steady operation at each step. The test was first conducted without the closed-loop $\mathrm{NO}_{\mathrm{X}}$ functionality, and operated off the calibrated AMP setpoint table. The load step matrix was then performed several times with the closed-loop $\mathrm{NO}_{\mathrm{X}}$ functionality enabled. Initial tests were performed to calibrate the control parameters for transient response of the engine and turbocharger. A final test was then performed to determine the accuracy and ability to reduce $\mathrm{NO}_{\mathrm{X}}$ excursions when in closed-loop.

A strip chart of the open-loop testing under AMP control is shown in Figure 6.17. In this graph, the inlet air temperature, ambient relative humidity, fuel header pressure, and percent error of $\mathrm{NO}_{\mathrm{X}}$ from setpoint is plotted versus time. The load steps can be seen in the stepped fuel header pressure trace. Ambient humidity did not change much during this test, rising only a small amount late in the day. The percent error in $\mathrm{NO}_{\mathrm{X}}$ from the target is shown to swing from approximately +10 to -20 percent, with more of a tendency to swing to the rich side or high $\mathrm{NO}_{\mathrm{X}}$ side of the target (more negative error). This swing represents -0.2 to $+0.4 \mathrm{~g} / \mathrm{bhp}-\mathrm{hr} \mathrm{NO}_{\mathrm{X}}$ variations. A brief but fairly large excursion to higher $\mathrm{NO}_{\mathrm{X}}$ (rich mixture) was captured during the transient from 70 to 100 percent load. 


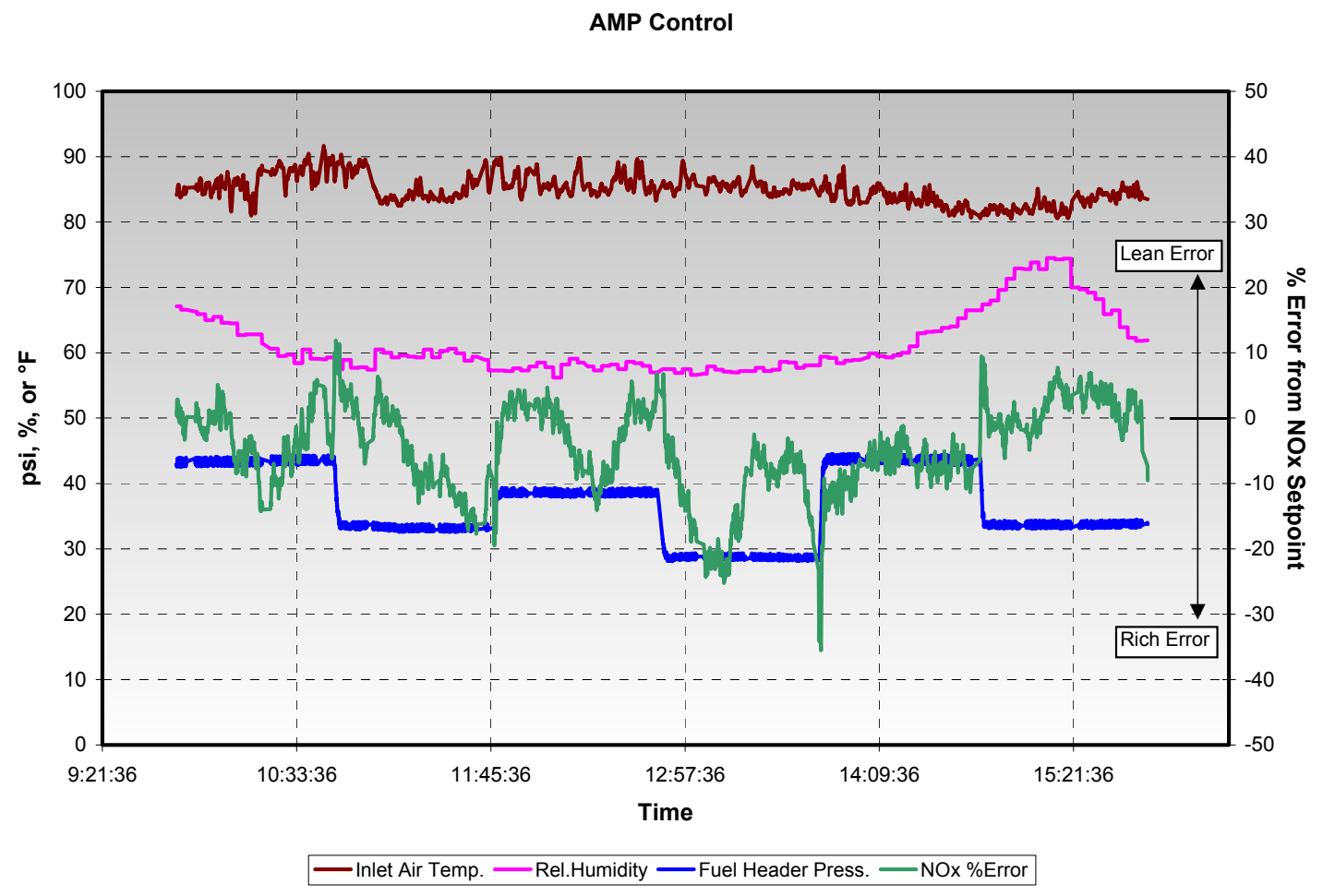

Figure 6.17. Engine Test Data Without Closed-Loop $\mathrm{NO}_{\mathrm{X}}$ Control

The same test was then repeated with closed-loop $\mathrm{NO}_{\mathrm{X}}$ control enabled. The results of the closed-loop test are shown in Figure 6.18. The same variables as in the previous graph are plotted in this second data set. The small drop in ambient humidity between tests can be seen in these graphs to be approximately 60 to 40 percent from one test to the next. The percent error in $\mathrm{NO}_{\mathrm{X}}$ can be seen in this second graph to be much more lower and consistent during the test with closed-loop control enabled. The majority of the data fell within a \pm 5 percent band, but there were larger excursions to the lean side during transients. This is likely due to the differences in the spool down/up of the turbocharger, which can be mitigated through a more precise feedforward calibration of the wastegate position setpoint. 


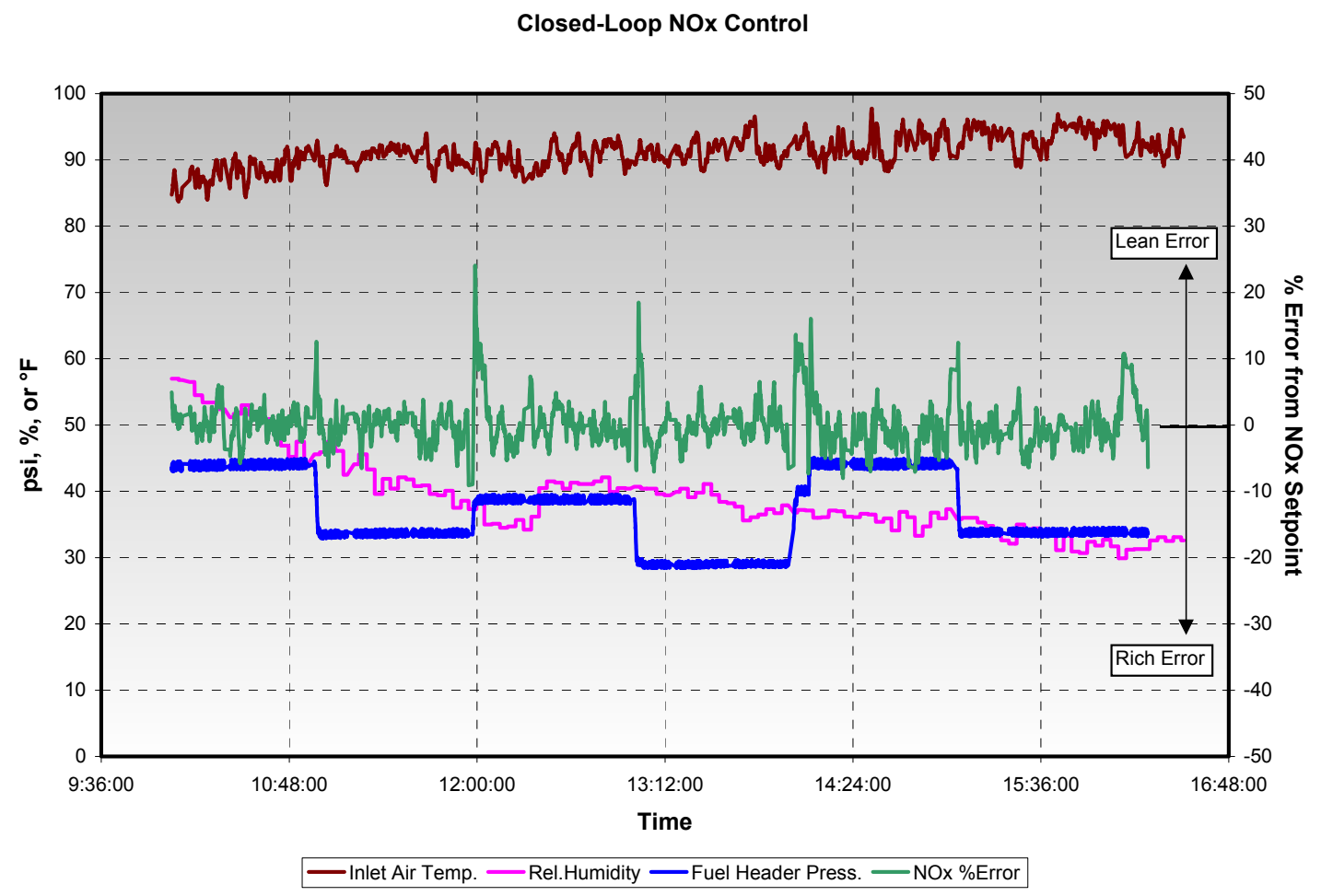

Figure 6.18. Engine Test Data With Closed-Loop $\mathrm{NO}_{\mathrm{X}}$ Control

The rich error plotted in Figure 6.17 for the open-loop test show that an open-loop $\mathrm{NO}_{\mathrm{X}}$ margin of approximately 30 percent would be required to prevent exceeding the target. This would require significant adjustment of the AMP table to lean the air/fuel ratio, which in-turn would lead to reduced fuel efficiency and increased combustion instability. The rich error plotted in Figure 6.18 for the closed-loop test show that the $\mathrm{NO}_{\mathrm{X}}$ margin can be reduced significantly to approximately 10 percent. Reducing the $\mathrm{NO}_{\mathrm{X}}$ margin by this magnitude would greatly increase the efficiency and combustion stability.

To better quantify the benefit of a reduced $\mathrm{NO}_{\mathrm{X}}$ margin, the brake specific $\mathrm{NO}_{\mathrm{X}}\left(\mathrm{BSNO}_{\mathrm{X}}\right)$ versus brake specific fuel consumption (BSFC) for this GMVH-6 engine was plotted. Figure 6.19 shows this $\mathrm{BSNO}_{\mathrm{X}}$ versus BSFC trade-off over several operating conditions of engine speed, load, ignition timing, and air/fuel ratio. It can be seen in this data that on the lower end of the $\mathrm{BSNO}_{\mathrm{X}}$ range, around $2 \mathrm{~g} / \mathrm{hp}-\mathrm{hr}$, a small reduction in $\mathrm{NO}_{\mathrm{X}}$ translates to a large increase in specific fuel consumption. 


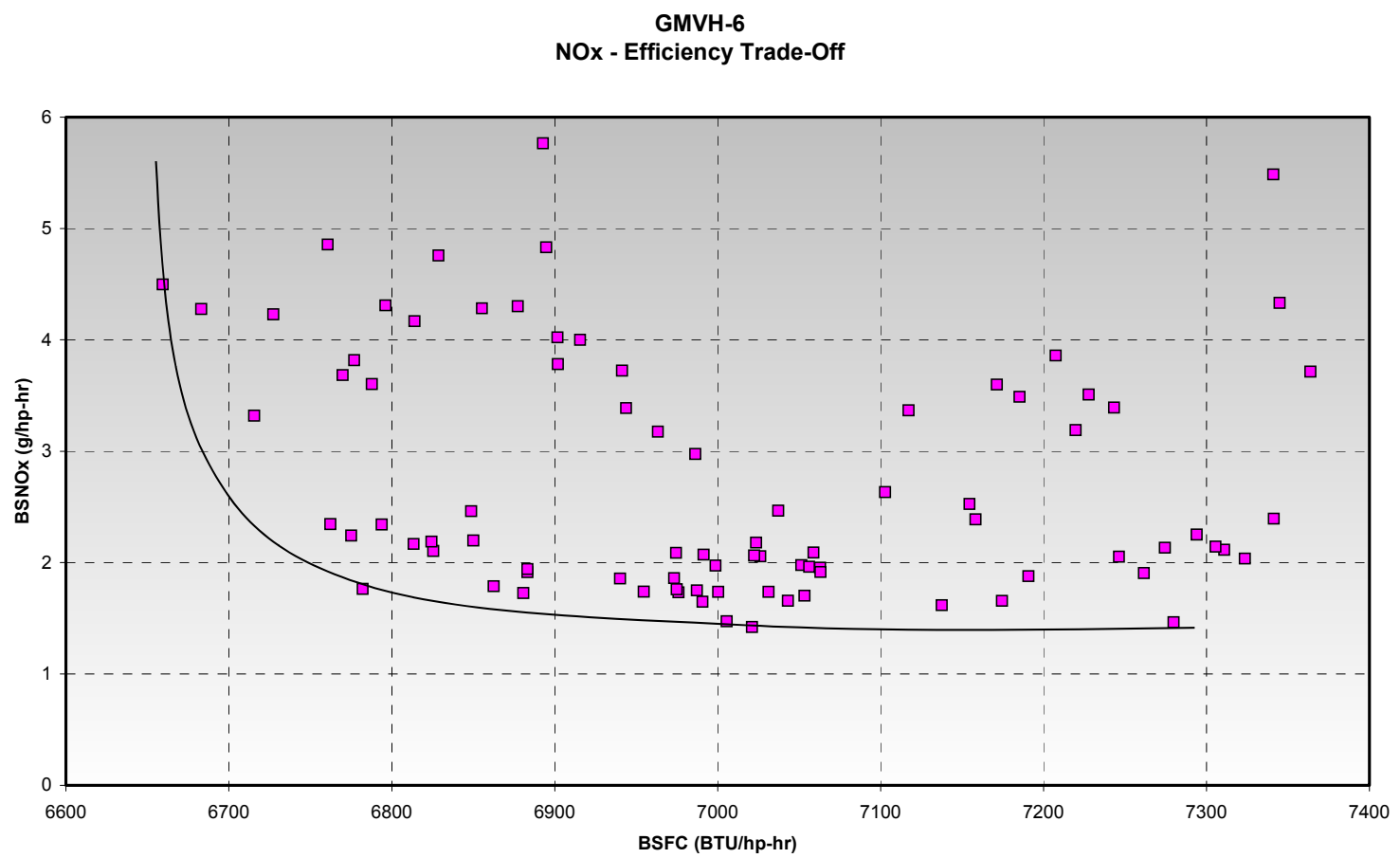

Figure 6.19. GMVH Engine Brake Specific NO $_{\mathbf{X}}$ versus Brake Specific Fuel Consumption

The BSFC at $2 \mathrm{~g} / \mathrm{hp}-\mathrm{hr} \mathrm{NO}_{\mathrm{X}}$ for the GMVH-6 integral engine is approximately $6,750 \mathrm{BTU} / \mathrm{hp}-\mathrm{hr}$, based on data in Figure 6.19. The BSFC for a 10 percent and 30 percent margin below this level are approximately 6,790 and 7,040 BTU/hp-hr, respectively. These efficiency values can be used in a simple analysis to determine approximate annual fuel cost savings by reducing the margin for $\mathrm{NO}_{\mathrm{X}}$ emissions as follows:

Assumptions:

$\begin{array}{rcl}\text { LHV } & 20400 & \mathrm{BTU} / \mathrm{lb} \\ \text { Rated Power } & 1350 & \mathrm{hp} \\ \text { Fuel Cost } & 7.32 & \$ / \mathrm{Mcf} \\ \text { Utilization* }^{*} & 80 & \%\end{array}$

Benefit Calculations:

\begin{tabular}{cccc} 
& BSNOx & \multicolumn{2}{c}{ BSFC } \\
\% margin & g/hp-hr & BTU/hp-hr & lb/hp-hr \\
& 2 & 6750 & 0.331 \\
10 & 1.8 & 6790 & 0.333 \\
30 & 1.4 & 7040 & 0.345
\end{tabular}

Fuel

\begin{tabular}{cccc}
\multicolumn{2}{c}{ Consumption } & \multicolumn{2}{c}{ Fuel Cost } \\
$\mathrm{lb} / \mathrm{hr}$ & Ib/day* & $\$ /$ day $^{*}$ & $\$ /$ year* \\
446.7 & 8576 & $\$ 1,372$ & $\$ 500,866$ \\
449.3 & 8627 & $\$ 1,380$ & $\$ 503,834$ \\
465.9 & 8945 & $\$ 1,431$ & $\$ 522,385$
\end{tabular}

Annual savings by reduced NOx margin with closed-loop control - per engine $=\$ 18,551$ Annual savings by reduced NOx margin with closed-loop control - per 100 engines $=\$ 1,855,059$

This analysis shows that a significant fuel cost savings should be realized with closed-loop $\mathrm{NO}_{\mathrm{X}}$ control and the reduced the $\mathrm{NO}_{\mathrm{X}}$ operating margin. This analysis shows an approximate $\$ 1.8 \mathrm{M}$ can be saved annually for 100 six-cylinder engines operating at an 80 percent utilization if fuel cost is $\$ 7.32$ per Mcf. This equates to an approximate $4 \%$ fuel economy improvement. For 
larger number of cylinders per engine, which is realistic for the current fleet of integral engines, the cost savings would be greater.

Another important point to consider is that for many of the older integral engines, the $\mathrm{NO}_{\mathrm{X}}$ limit may be so low that the engine cannot be operated at a 30 percent margin. A 30 percent margin may require such lean air/fuel ratios that lean misfire occurs and the engine simply cannot run at this level. Expensive retrofit hardware (i.e. turbocharging, combustion technology, etc.) would then be required for the engine to operate at such levels. There may be, however, a situation where a closed-loop $\mathrm{NO}_{\mathrm{X}}$ control system, with reduced margin, would allow a particular engine to operate without the expensive retrofit technology. In this situation the cost benefit would be significantly greater than that based on fuel consumption alone.

\subsection{Trapped Equivalence Ratio Strategy}

Another control strategy was developed on this project that utilizes a calculated trapped equivalence ratio calibrated to $\mathrm{NO}_{\mathrm{X}}$ emissions. The modeled mass air flow and calculated trapped equivalence ratio make up the open-loop control function and feedback from the NGKLocke sensor provides the closed-loop feedback. The trapped equivalence ratio is derived from scavenging and trapping efficiency calculations, using Equations 5.11, 5.12, and 5.14. The assumption of complete mixing is used in this strategy for the scavenging efficiency derivation. Although the assumption of complete mixing may not be completely accurate, especially over a broad speed range, the addition of closed-loop feedback lessens the absolute accuracy needed for good engine control. This strategy differs from the systems discussed in Section 5.5.3 due to the use of scavenging/trapping efficiency calculations and a limited data set for calibration, rather than a detailed regression model.

Both channels of the NGK-Locke sensor are utilized in this strategy. The $\mathrm{NO}_{\mathrm{X}}$ channel is calibrated for $\mathrm{NO}_{\mathrm{X}}$ concentration as shown in Figure 6.7. The $\mathrm{O}_{2}$ channel is calibrated for global equivalence ratio as shown in Figure 6.8. The fuel flow measurement is combined with the global equivalence ratio to determine the total mass air flow using the following equation:

$$
\dot{m}_{\text {Air }}=\dot{m}_{\text {Fuel }}\left[\frac{(A / F) \text { stoich }}{\Phi_{\text {Global }}}\right]
$$

The sensor derived total mass air flow is used as a comparative value to a modeled total mass air flow using Equation 5.15. This is done to prevent a sole dependence on the sensor feedback so that an open-loop function can operate in the event of a sensor fault. To utilize this approach, a flow coefficient for the subject engine must be known or determined. The flow coefficient for the GMVH-6 engine was derived in the laboratory by using measured mass air flow and rearranging Equation 5.15. The derived flow coefficient was then fit to easily measured parameters though a regression analysis. The derived and regressed flow coefficients versus cylinder pressure ratio are depicted in Figure 6.20. This trend compares favorably with trends presented by Taylor [4]. In an application on a field engine where measured mass air flow is not available, the mass air flow can be derived from emissions based equivalence ratio or from the sensor based equivalence ratio as shown above in Equation 6.1. With either method, the purpose 
is to establish a flow coefficient representative of the particular engine for use in an open-loop control algorithm.

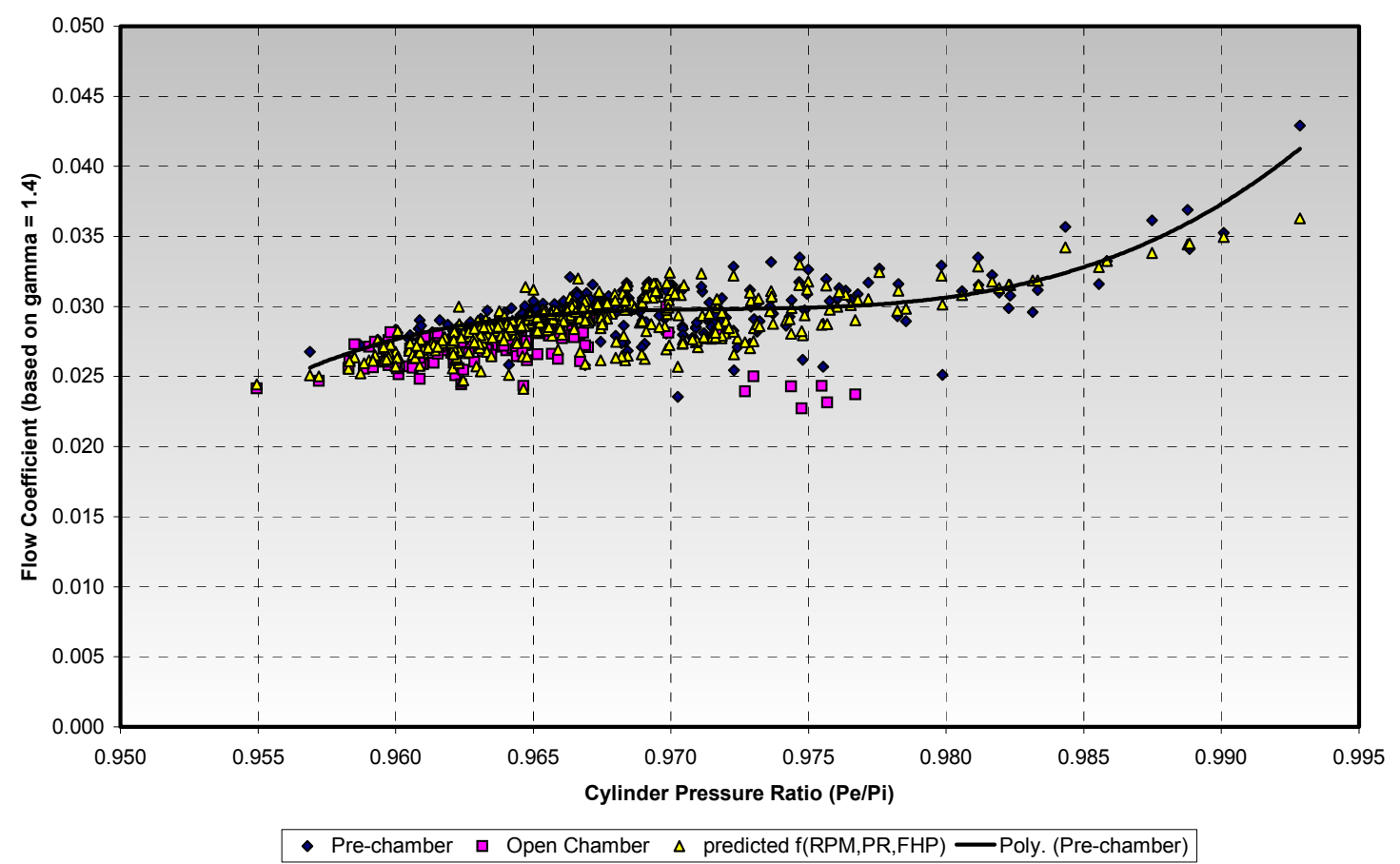

Figure 6.20. Comparison of Flow Coefficient Derived from Measured Air flow and Predicted from Regression Model

As a check, the modeled mass air flow was compared to emissions based mass air flow over approximately three hundred test runs. This comparison is provided in Figure 6.21. The correlation shows that the modeled values fall within an error band of \pm 5 percent over most of the operating range. With a tuned model of the total mass air flow, the trapped equivalence ratio can be calculated using Equations 5.11, 5.12, and 5.14. This procedure was performed on the same test run data used in Figures 6.14 and 6.15 for calibration of the Modified Fuel-Air Curve strategy. This data was acquired over a broad speed/load range with optimal ignition timing versus engine speed and a constant $\mathrm{NO}_{\mathrm{X}}$ level of $2 \mathrm{~g} / \mathrm{bhp}-\mathrm{hr}$. The resulting trapped equivalence ratio versus engine speed is shown in Figure 6.22, where a fairly constant trend is depicted and the average value is 0.538 .

While the data shown in Figure 6.22 indicates that a constant value for trapped equivalence ratio would allow for fairly constant $\mathrm{NO}_{\mathrm{X}}$ emissions, it was felt a two-dimensional lookup table for multiple trapped equivalence ratios would be more desirable. The two-dimensional lookup table allows programming of trapped equivalence ratio setpoints versus engine speed and AMP. This feature can compensate for varying setpoint requirements for startup, warmup (unloaded), and other off peak operating conditions to maximize engine integrity and efficiency. This feature also provides for an adaptive learn function that modifies a mirror table based on the long-term trim, similar to that described in Section 5.2.2, to achieve a more accurate open-loop control and compensate for changing conditions or device response. 


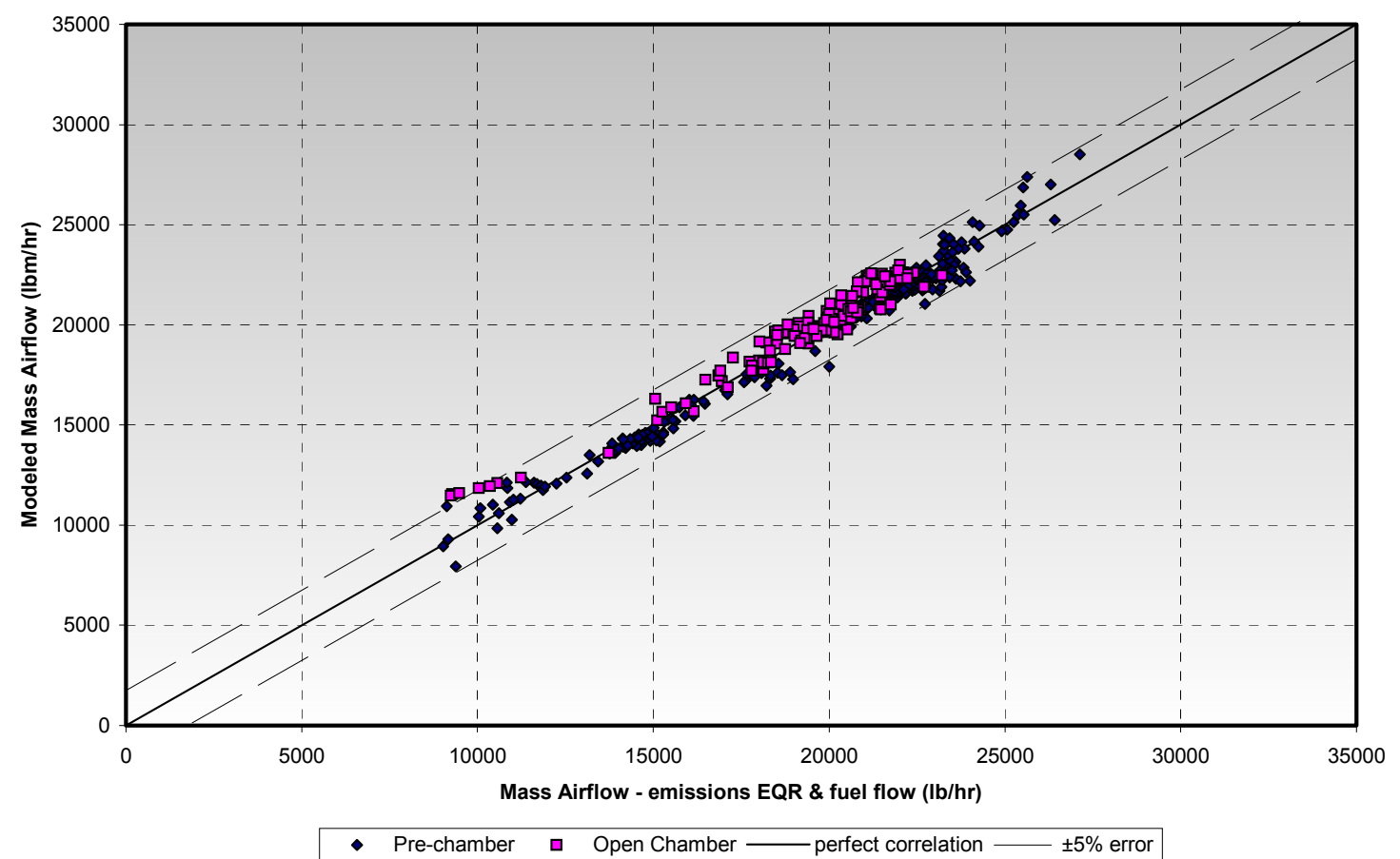

Figure 6.21. Comparison of Dry Total Mass Air flow and Modeled Total Mass Air flow

\section{GMVH-6 Trapped Equivalence Ratio \\ $2 \pm 0.2 \mathrm{~g} / \mathrm{bhp}$-hr NOx, Varying Speed \& Load}

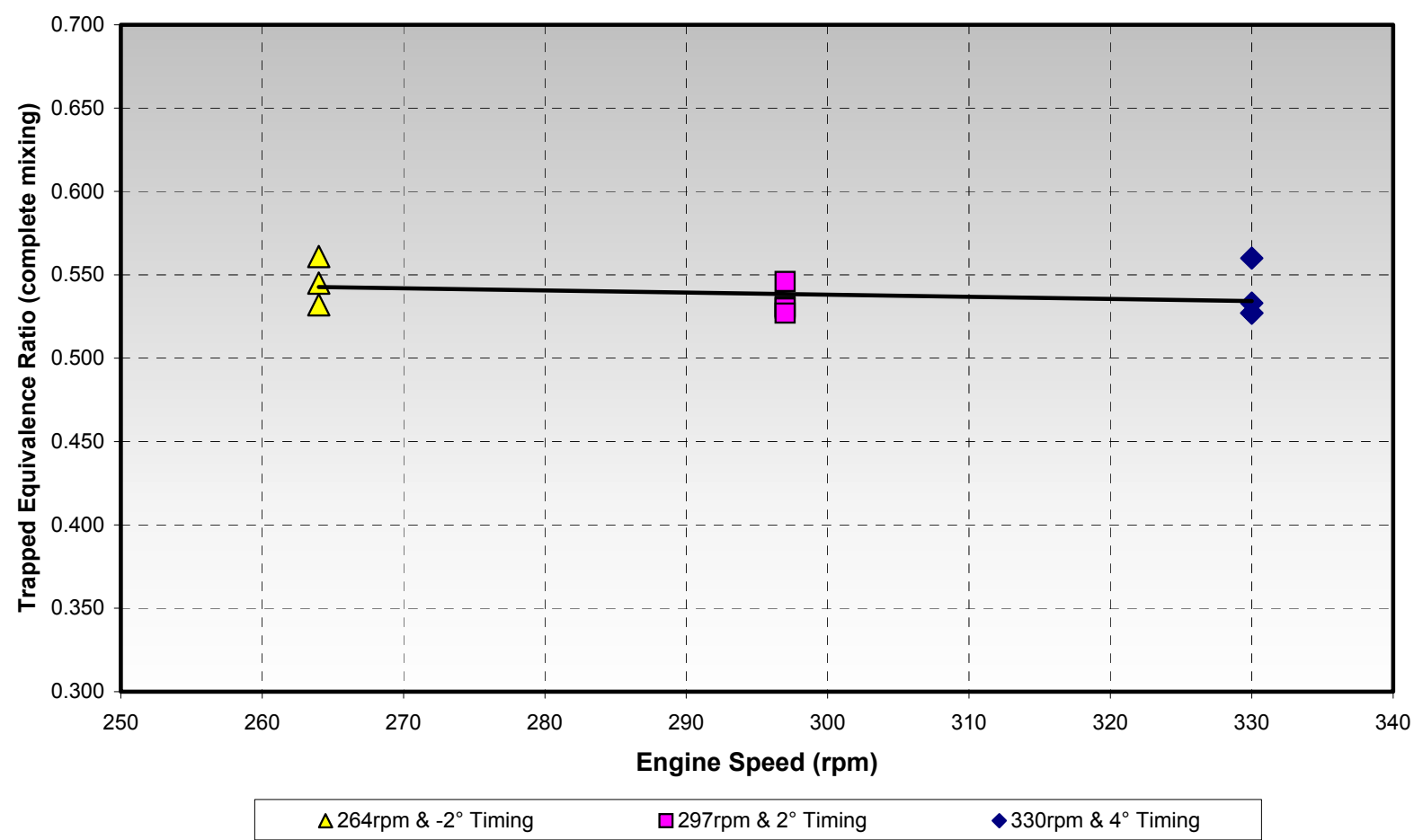

Figure 6.22. Calculated Trapped Equivalence Ratio versus Engine Speed 
The closed-loop feature of this strategy is two-fold. The sensor $\mathrm{O}_{2}$ channel is used as discussed above to provide a total mass air flow feedback to the model based trapped equivalence ratio algorithm. This feedback allows for continuous adjustment of the flow coefficient within bounds of a correction limit. The sensor $\mathrm{NO}_{\mathrm{X}}$ channel is used for feedback to trim the trapped equivalence ratio setpoint, similar to the adjustment of the AMP setpoint in the Modified FuelAir Curve strategy. The trapped equivalence ratio adjustment is also bound by a close-loop correction limit, and is based on an error calculation from the measured to programmed target $\mathrm{NO}_{\mathrm{X}}$. A schematic of the Trapped Equivalence Ratio strategy is depicted in Figure 6.23.

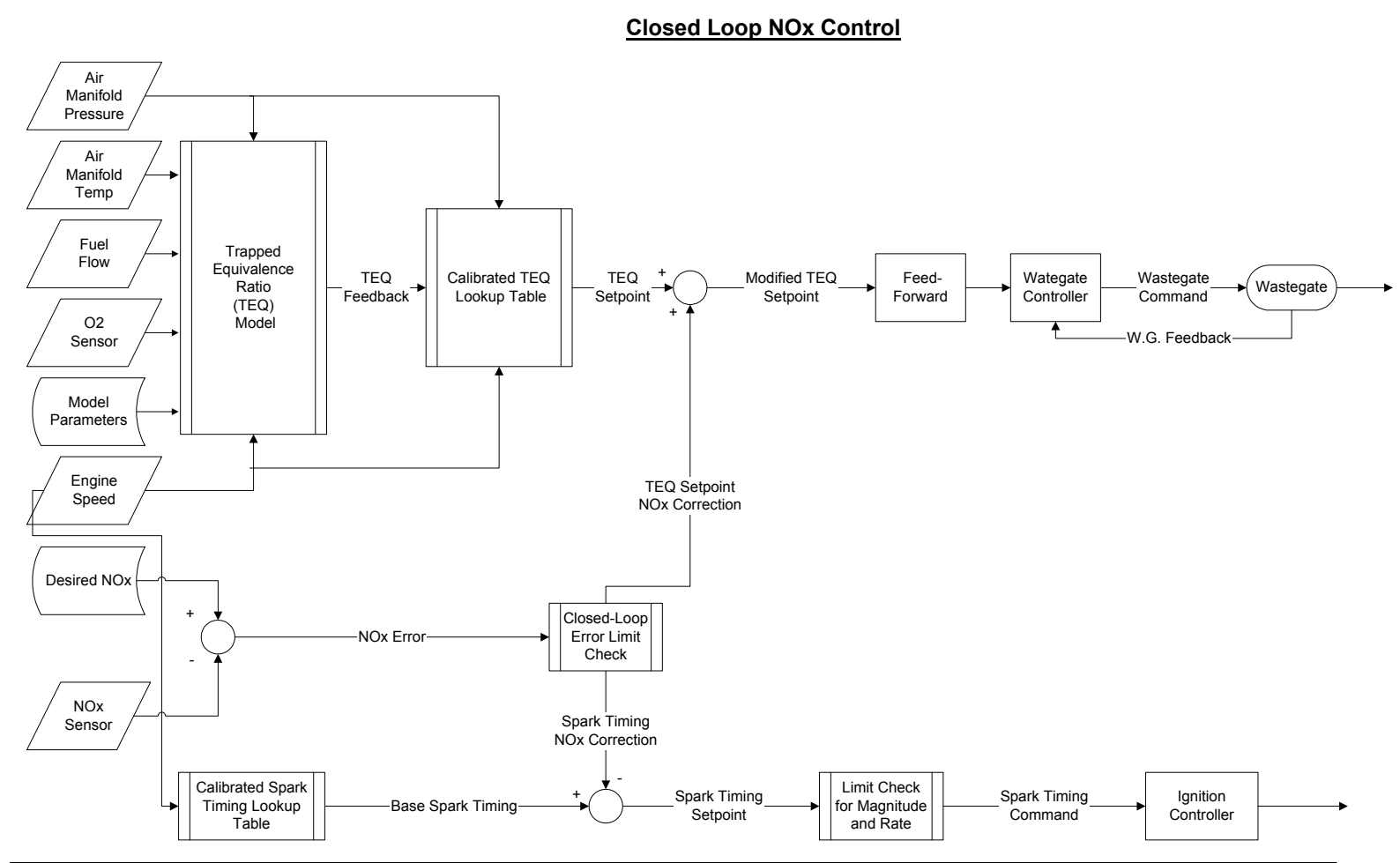

Figure 6.23. Schematic of Trapped Equivalence Ratio Algorithm

Testing of the Trapped Equivalence Ratio strategy was not conducted due to the GMVH-6 engine being out of operation.

\subsection{CONCLUSIONS}

A literature review of integral compressor engine control technology showed that significant advancements are being made. These advancements include control algorithms and control devices. However, field test experiences and communications with personnel in the gas transmission industry have indicated that a relatively small portion of the current engine fleet is currently utilizing this advanced technology. Many engines still have simple pneumatic control systems and the majority have simple open-loop control systems installed. The engines receiving the newer control technology are those in regions with strict emissions regulations. 
To address the wide variance in control technology employment, a hierarchy of strategies for using the NGK-Locke combined $\mathrm{O}_{2} / \mathrm{NO}_{\mathrm{X}}$ sensor was outlined. For engines that can normally operate under less stringent compliance limits, the $\mathrm{NO}_{\mathrm{X}}$ sensor can be used more as a monitoring sensor and make a step-change adjustment when a rare excursion occurs. A second level of complexity involves utilizing the $\mathrm{NO}_{\mathrm{X}}$ sensor for real-time closed-loop feedback to continuously maintain tight control for stricter compliance levels. A more advanced level of control incorporates closed-loop feedback of both channels from the NGK-Locke sensor with additional sensor signals to control to a precise air/fuel ratio and ignition timing.

The NGK-Locke combined $\mathrm{O}_{2} / \mathrm{NO}_{\mathrm{X}}$ sensor has shown within the confines of this project to be a consistent and repeatable sensor for use in emissions control strategies. The use of the NGKLocke sensor for closed-loop feedback signals can apply to virtually all open-loop controls strategies being used and developed for integral compressor engines today. The ease of implementing the sensor into an existing strategy for tighter emission control has been demonstrated. The advantage of a $\mathrm{NO}_{\mathrm{X}}$ sensor in a closed-loop function includes:

- Less historical data required to develop a base calibration

- Accounts for changes in engine performance over time

- Adjust for changing conditions such as ambient or fuel quality

- Control flexibility allows distribution to a wider variety of applications

- Can assist self-tuning for predictive emission models where the sensor may only be used during commissioning

The closed-loop $\mathrm{NO}_{\mathrm{X}}$ strategies and sensor technology appears feasible to become an integral component in future control strategies. This integration is already happening in the on-highway engine control arena.

A closed-loop control strategy was developed and demonstrated on this project. This strategy is called the Modified Fuel-Air Curve and stems from the original OEM control strategy. Testing of the Modified Fuel-Air Curve strategy showed good control of $\mathrm{NO}_{\mathrm{X}}$ over constant speed loadstep testing. The excursion in $\mathrm{NO}_{\mathrm{X}}$ above the target setting was less than 10 percent under closed-loop control, compared to 30 percent with closed-loop disabled. Analysis of the $\mathrm{NO}_{\mathrm{X}^{-}}$ efficiency trade-off for the GMVH-6 engine showed that reducing the $\mathrm{NO}_{\mathrm{X}}$ margin from 30 to 10 percent would give a 4 percent improvement in specific fuel consumption. This fuel consumption improvement equates to approximate annual savings of $\$ 1.8 \mathrm{M}$ for 100 six-cylinder engines (assumed equivalent to the laboratory engine) operating at an 80 percent utilization if fuel cost is $\$ 7.32$ per Mcf. For larger number of cylinders per engine, which is realistic for the current fleet of integral engines, the dollar amount would be higher.

A patent application for the Modified Fuel-Air Curve control strategy was filed in September 2004, SwRI ID No. 3111-02. A technical paper was written and presented on the Modified FuelAir Curve control strategy at the 2004 Gas Machinery Conference in October 2004 [30].

A second closed-loop control strategy was developed on this project, and involved feedback of both channels of the NGK-Locke sensor. This strategy called the Trapped Equivalence Ratio uses model based calculations of scavenging and trapping efficiencies and derivation of the 
trapped equivalence ratio. $\mathrm{NO}_{\mathrm{X}}$ emissions were shown to correlate well with trapped equivalence ratio. The $\mathrm{O}_{2}$ channel was calibrated to global (engine-out) equivalence ratio, from which the total mass air flow was derived. The total mass air flow derivation is compared to the modeled mass air flow, and the deviation was used to trim the model coefficients. The $\mathrm{NO}_{\mathrm{X}}$ channel feedback was used to determine a closed-loop error from target $\mathrm{NO}_{\mathrm{X}}$ output, which was then used to trim the trapped equivalence ratio command. Testing of this system was not performed due to the laboratory engine being disassembled and unavailable for testing.

A long-term durability test of the NGK-Locke sensor is planned on a separate project. This test is vital to document and quantify the long-term reliability of the sensor under more continuous operation. There are also plans to implement the Modified Fuel Air Curve strategy in a field engine.

\section{REFERENCES}

1. Palm, William, Modeling, Analysis, and Control of Dynamic Systems, John Wiley \& Sons, 2000. Page 449.

2. Heywood, John, Internal Combustion Engine Fundamentals, McGraw-Hill Publishing Company, 1988.

3. Society of Automotive Engineers, Recommended Practice, J1829, 2002.

4. Taylor, C.F., The Internal Combustion Engine in Theory and Practice, Vol. $1,2^{\text {nd }}$ ED., MIT Press, 1985.

5. "Enhanced Monitoring Protocol Guidelines for IC Engine Parameter Based Compliance Monitoring Systems,” PRCI Final Report, Contract No. PR-239-9439, 1997.

6. Stone, Richard, Introduction to Internal Combustion Engines, Society of Automotive Engineers, 1999.

7. Wood, C.D., et al, "Evaluation of Emissions Control Technology for Reciprocating Integral Engine-Compressor Units," SwRI Final Report for Tenneco Gas Environmental and Technology Department, 1995.

8. Kubesh, J. and Liss, W., "Simple $\mathrm{NO}_{\mathrm{X}}$ Model for Predictive Emissions Monitoring," ASME Paper ICE-Vol. 21, 1994.

9. Beshouri, G.M., "Combustion Pressure Based Emissions Monitoring and Control for Large Bore IC Engines - An Alternative Parametric Emissions Model (PEM) Methodology," ASME Paper, 1998.

10. Fuel-Air Curve for GMV Engine provided by Cooper Compression, 2004. 
11. Malicke, D. and Mathews, H., "Equivalence Ratio Based Air/Fuel Ratio Control Strategies," Gas Machinery Conference, October, 6, 2003.

12. Beshouri, G. and Matthews, H., "Designing Engine Retrofits for Emissions Reduction," Gas Machinery Conference, October, 2002.

13. Brooks, M., "Enginuity Technologies Complete First Ever Low-Emissions Combustion Retrofit of Ingersoll-Rand KVG Engine-Compressor," Compressor Tech Magazine, November-December, 1999.

14. Smith, J., "Integration Of Engine And Compressor Controls", SwRI Report to Gas Machinery Research Council, May, 2002.

15. Bourn, G., "Identification of Compressor Load-Step on $\mathrm{NO}_{\mathrm{X}}$ Emissions and Efficiency," SwRI Internal Research Final Report, 2002.

16. Brooks, M., et al, "Revitalization of the GMW Engine Family Part 2 - Complete Station Upgrade," Gas Machinery Conference, October, 2001.

17. Huntley, D. and Mathews, H., "User Experience with an All Electronic High-Pressure Fuel Injection System on a Large Bore, Two-Stroke, Integral Compressor Engine," Gas Machinery Conference, October 2001.

18. Elliot, J., "Supersonic Fuel Injection Nozzle Designed to Solve Gas Engine $\mathrm{NO}_{\mathrm{X}}$ Problems," Compressor Tech Two, January-February 2001.

19. Hubbard, J.W., "Clean Burn Technology for Increased Efficiency and Reduced Emissions on Non-Turbocharged Engines,” ASME Paper, 1986.

20. Elliot, J., "Precombustion Chamber for Large Bore 2 and 4 Cycle Engines," Compressor Tech Two, November-December 2002.

21. Bourn, G., "Testing/Evaluation of the Adrenaline Research Ignition System on the Caterpillar 3501 Gas Engine," SwRI Final Report to Woodward Governor Company, July 2001.

22. Tozzi, L., "Combustion Monitoring of Lean Burn Gas Engines with Ion Feedback," ASME Paper ICEF2004-914, October 2004.

23. Smalley, A., Harris, R., and Bourn, G., "Technologies to Enhance Operation of the Existing Natural Gas Compression Infrastructure - Quarterly Technical Progress Report 4/1/04 to 6/30/04," SwRI Report to U.S. Department of Energy, July 2004.

24. Kato, N., Nakagaki, K., and Ina, N., “Thick Film ZrO2 NOX Sensor, SAE Paper No. 960334, February 1996. 
25. Kato, N., Hamada, Y., and Kurachi, H., "Performance of Thick Film $\mathrm{NO}_{\mathrm{X}}$ Sensor on Diesel and Gasoline engines, SAE Paper No. 970858, February 1997.

26. Kato, N., Kurachi, H., and Hamada, Y., "Thick Film ZrOx $\mathrm{NO}_{\mathrm{X}}$ Sensor for the Measurement of Low NOx Concentration”, SAE Paper No. 980170, February 1998.

27. Kato, N., Kokune, N., Lemire, B. and Walde, T., "Long Term Stable $\mathrm{NO}_{\mathrm{X}}$ Sensor with Integrated In-Connector Control Electronics", SAE Paper No. 199-01-0202, March 1999.

28. Smith, J. A., "Demonstration of a Fast Response On-Board $\mathrm{NO}_{\mathrm{X}}$ Sensor for Heavy-Duty Diesel Vehicles," SwRI Final Report on Project No. 03-02256 for CARB \& SCAQMD, July 2000.

29. Smalley, A., McKee, B., and Bourn, G., "Engine/Compressor Performance Data Normalization," SwRI Final Report to GRI, December 2002.

30. Bourn, G., Smith, J., Gingrich, J., and Lawler, W., "Closed-Loop Control of $\mathrm{NO}_{\mathrm{X}}$ Emissions in a Two-Stroke Integral Compressor Engine - Part I," Gas Machinery Conference, October 2004. 
APPENDIX A

Equivalence Ratio from Emissions

Final Report

Page A

(Reporting Period 09/22/03 - 12/31/04)

DOE Award No. DE-FC26-03NT41859 - SwRI Project 03.10198

March 2005 


\section{Equivalence Ratio from Emissions}

An accurate determination of fuel/air equivalence ratio can be derived from measurements of exhaust gas constituents. This method is ideal for laboratory engine testing and development, but is not practical for field engines and control due to the expensive and high maintenance analyzers required. However, this method is often utilized to calibrate engine performance, calculate equivalence ratio, and calibrate UEGO sensors for either engine development or tuning. A technique published by Heywood outlines the equivalence ratio determination from measurements of exhaust $\mathrm{CO}_{2}, \mathrm{CO}, \mathrm{O}_{2}, \mathrm{HC}$, and $\mathrm{NO}_{\mathrm{X}}$. The $\mathrm{HC}$ is assumed to be unburned fuel of the same properties as the supplied fuel. Any nitrogen in the fuel is typically very small, as shown in Table 5.1 above for natural gas, and therefore neglected. The modified chemical equation for incomplete combustion utilizing equivalence ratio and exhaust constituents is as follows [2]:

$$
\begin{aligned}
& \mathrm{C}_{n} \mathrm{H}_{m} \mathrm{O}_{r}+\frac{n_{\mathrm{O} 2}}{\Phi}\left(\mathrm{O}_{2}+3.773 \mathrm{~N}_{2}\right) \Rightarrow n_{P}\left(\widetilde{x}_{\mathrm{CnHm}} \mathrm{C}_{n} \mathrm{H}_{m}+\tilde{x}_{\mathrm{CO}} \mathrm{CO}+\widetilde{x}_{\mathrm{CO} 2} \mathrm{CO}_{2}\right. \\
& \left.+\tilde{x}_{\mathrm{O}_{2}} \mathrm{O}_{2}+\tilde{x}_{\mathrm{NO}} \mathrm{NO}+\tilde{x}_{\mathrm{NO} 2} \mathrm{NO}_{2}+\tilde{x}_{\mathrm{H} 2 \mathrm{O}}+\tilde{x}_{\mathrm{N}_{2}} \mathrm{~N}_{2}+\tilde{x}_{\mathrm{H} 2} \mathrm{H}_{2}\right)
\end{aligned}
$$

where:

$$
\begin{aligned}
& n_{O 2}=\left(n+\frac{m}{4}-\frac{r}{2}\right) \\
& n_{P}=\text { Total Moles of Exhaust } \\
& \tilde{x}_{i}=\text { Mole Faction of ith Constituent }
\end{aligned}
$$

In many circumstances the measurements of $\mathrm{CO}_{2}, \mathrm{CO}, \mathrm{O}_{2}$, and $\mathrm{NO}_{\mathrm{X}}$ are performed from a dried exhaust sample by utilizing ice bath chillers. The HC measurement is typically from a fully wet sample with a flame ionization detector (FID). Given these types of wet/dry measurements, the calculation for equivalence ratio is as follows [2]:

$$
\Phi=\frac{2 n_{O 2}}{n_{P} \widetilde{x}_{H 2 O}+n_{P}\left(1-\tilde{x}_{H 2 O}\right)\left(\tilde{x}_{C O}^{\prime}+2 \widetilde{x}_{C O 2}^{\prime}+2 \tilde{x}_{O 2}^{\prime}+\tilde{x}_{N O}^{\prime}+2 \tilde{x}_{N O 2}^{\prime}\right)-r}
$$

where:

$$
\begin{aligned}
& \tilde{x}_{i}^{\prime}(d r y)=\frac{\tilde{x}_{i}(\text { wet })}{\left(1-\tilde{x}_{H 2 O}\right)}=d r y \text { to wet relationship } \\
& \tilde{x}_{H 2 O}=\frac{m}{2 n}\left(\frac{\tilde{x}_{C O}^{\prime}+\widetilde{x}_{C O 2}^{\prime}}{1+\left(\tilde{x}_{C O}^{\prime} / K \widetilde{x}_{C O 2}^{\prime}\right)+(m / 2 n)\left(\tilde{x}_{C O}^{\prime}+\tilde{x}_{C O 2}^{\prime}\right)}\right) \quad K \approx 3.5 \\
& n_{P}=\frac{n}{\tilde{x}_{H C}+\left(1-\tilde{x}_{H 2 O}\right)\left(\tilde{x}_{C O}^{\prime}+\tilde{x}_{C O 2}^{\prime}\right)}
\end{aligned}
$$




$$
\begin{aligned}
& \tilde{x}_{H 2}=\frac{\tilde{x}_{H 2 O} \tilde{x}_{C O}^{\prime}}{K \widetilde{x}_{C O 2}^{\prime}} \\
& \tilde{x}_{N 2}=\frac{3.773 n_{O 2}}{\Phi n_{P}}-\left(1-\widetilde{x}_{H 2 O}\right) \frac{\left(\widetilde{x}_{N O}^{\prime}+\widetilde{x}_{N O 2}^{\prime}\right)}{2}
\end{aligned}
$$


APPENDIX B

Nitric Oxide Formation 
Nitric Oxide (NO) is formed during combustion by three mechanisms: thermal, prompt, and nitrous oxide [6]. The extended Zeldovich mechanism provides the basis for the thermal mechanism. The rate equation and the three reaction equations are given below. Rate coefficients from two sources for each reaction are given in Table B.1.

$$
k_{i}=A_{i} \times T^{\beta_{i}} \times \exp \left(-\left(\frac{E}{R_{O}}\right)_{i} T\right)
$$

where:

$$
\begin{array}{ll}
k_{i}=\quad \text { reaction rate coefficient } \\
T=\quad \text { temperature }\left({ }^{\circ} \mathrm{K}\right) & \\
\mathrm{O}+\mathrm{N}_{2} \Leftrightarrow \mathrm{NO}+\mathrm{N} & \text { (Reaction 1) } \\
\mathrm{N}+\mathrm{O}_{2} \Leftrightarrow \mathrm{NO}+\mathrm{O} & \text { (Reaction 2) } \\
\mathrm{N}+\mathrm{OH} \Leftrightarrow \mathrm{NO}+\mathrm{H} & \text { (Reaction 3) }
\end{array}
$$

Table B1. Rate Coefficients for the Thermal NO Mechanism

\begin{tabular}{|l|c|c|c|c|c|c|c|c|c|}
\hline \multirow{2}{*}{ Source } & \multicolumn{3}{|c|}{ Reaction 1 } & \multicolumn{3}{c|}{ Reaction 2 } & \multicolumn{3}{c|}{ Reaction 3 } \\
\cline { 2 - 10 } & $\boldsymbol{A}$ & $\boldsymbol{\beta}$ & $\boldsymbol{E} / \boldsymbol{R}_{\boldsymbol{\theta}}$ & $\boldsymbol{A}$ & $\boldsymbol{\beta}$ & $\boldsymbol{E} / \boldsymbol{R}_{\boldsymbol{\theta}}$ & $\boldsymbol{A}$ & $\boldsymbol{\beta}$ & $\boldsymbol{E} / \boldsymbol{R}_{\boldsymbol{\theta}}$ \\
\hline Heywood [hey] & $1.6 \mathrm{E}+13$ & 0.0 & 0.0 & $6.4 \mathrm{E}+9$ & 1.0 & 3150 & $4.1 \mathrm{E}+13$ & 0.0 & 0.0 \\
\hline $\begin{array}{l}\text { Miller \& } \\
\text { Bowman [m\&b] }\end{array}$ & $3.3 \mathrm{E}+12$ & 0.3 & 0.0 & $6.4 \mathrm{E}+9$ & 1.0 & 3160 & $3.8 \mathrm{E}+13$ & 0.0 & 0.0 \\
\hline
\end{tabular}

The thermal mechanism rate constants are very slow compared to those for combustion. Therefore, the thermal NO mechanism is significant only when there is high enough flame temperature and sufficient time at temperature for formation. Measurements of NO concentration in the burnt gases do not extrapolate to zero at the flame, implying NO is formed in the flame by the prompt mechanism [6]. The prompt NO mechanism is significant when flame temperature is low enough to make the thermal mechanism negligible, or when there is fuel-bound nitrogen. The prompt mechanism is described by the following governing equation [6]:

$$
\mathrm{CH}+\mathrm{N}_{2} \Rightarrow \mathrm{HCN}+\mathrm{N}
$$

The nitrous oxide mechanism is also only important at low temperature, and is governed by the following equation:

$$
\mathrm{N}_{2}+\mathrm{O}+\mathrm{M} \Rightarrow \mathrm{N}_{2} \mathrm{O}+\mathrm{M}
$$

The nitrous oxide will decompose to NO, and this mechanism is significant with lean pre-mixed laminar flames [6]. 
In fuels for spark-ignition engines, the fuel-bound nitrogen is small and can be considered negligible for $\mathrm{NO}$ formation. The combustion temperature in internal combustion engines is high and the flame reaction zone thin with short residence time. Thus, the thermal mechanism is dominant. Therefore, NO (or $\mathrm{NO}_{\mathrm{X}}$ ) predictions are usually based on the extended Zeldovich mechanism. Combining the reaction equations above and rearranging results in the NO rate of formation equation below [2]:

$$
\frac{d[N O]}{d t}=\frac{2 R_{1}\left\{1-\left([N O] /[N O]_{e}\right)^{2}\right\}}{1+\left([N O] /[N O]_{e}\right) R_{1} /\left(R_{2}+R_{3}\right)}
$$

where:

$$
\begin{aligned}
& R_{1}=k_{1}^{+}[O]_{e}\left[N_{2}\right]_{e}=k_{1}^{-}[N O]_{e}[N]_{e} \\
& R_{2}=k_{2}^{+}[N]_{e}\left[O_{2}\right]_{e}=k_{2}^{-}[N O]_{e}[O]_{e} \\
& R_{3}=k_{3}^{+}[N]_{e}[O H]_{e}=k_{3}^{-}[N O]_{e}[H]_{e} \\
& {[]_{e}=\text { equilibrium concentration }}
\end{aligned}
$$

The equation above is for use in complex chemical kinetic models. 